Farbige organische Molekülverbindungen; von Paul Pfeiffer.

(Experimentell bearbeitet von W. Jowleff, Ph. Fischer, P. Monti und H. Mully.)

[Mitteilung aus dem chemischen Institut der Universität Zürich.]

(Eingelaufen am 1. März 1916.)

In der Arbeit über die Konstitution der Chinhydrone ${ }^{1}$ ) habe ich darauf hingewiesen, dab die drei wichtigsten Groppen farbiger organischer Molekülverbindungen: die Chinhydrone, die Kohlenwasserstoff-, Phenol- und Amin-Verbindungen der Nitrokörper und die Halochromieverbindungen der Ketone, Aldehyde und Säuren so nahe miteinander verwandt sind, dab sie sich alle unter einen einheitlichen Gesichtspunkt bringen lassen. Einen einfachen Ausdruck dieses Zusammenhangs geben uns die folgenden Konstitutionsformeln der einzelnen Additionsprodukte, die in der vorliegenden Mitteilung an Hand einer eingehenden experimentellen Untersuchung noch weiter gestützt werden sollen.

1. Chinhydrone.

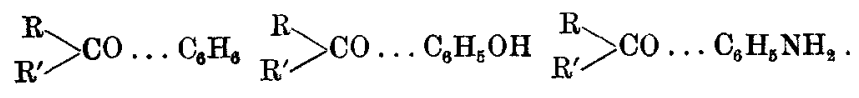

2. Molekülverbindungen der Nitrokörper. $\mathrm{R}-\mathrm{NO}_{2} \ldots \mathrm{C}_{6} \mathrm{H}_{6} \quad \mathrm{R}-\mathrm{NO}_{2} \ldots \mathrm{C}_{6} \mathrm{H}_{5} \mathrm{OH} \quad \mathrm{R}-\mathrm{NO}_{2} \ldots \mathrm{C}_{6} \mathrm{H}_{6} \mathrm{NH}_{2}$.

3. Halochromieverbindungen der Ketone usw.

$$
\stackrel{\mathrm{R}_{\mathrm{R}}}{\mathrm{R}^{\prime}}>\mathrm{CO} \ldots \mathrm{HX} \quad \begin{aligned}
& \mathrm{R} \\
& \mathrm{R}^{\prime}
\end{aligned}>\mathrm{CO} \ldots \mathrm{MeX}_{\mathrm{n}} .
$$

Wie man aus dieser Zusammenstellung ersieht, fehlten von den möglichen Verbindungstypen, die sich aus Nitrokörpern and Ketonen einerseits und aromatischen Kohlenwasserstoffen bzw. deren Derivaten und

1) Diese Annalen 404, 1 (1914).

Annalen der Chemie 412. Band. 
Metallsalzen und Säuren andererseits aufbauen, bisher noch Vereinigungen von Nitrokörpern mit Metallsalzen und Säuren.

Anch diese sind existenzfähig. Wir fanden, daß die Lösungen zah]reicher Nitrokörper in starken Säuren und metallsalzhaltigen Flüssigkeiten erhebliche Farbvertiefungen zeigen; auch gelang es uns in einzelnen Fällen feste Halochromieverbindungen der Nitrokörper zu iso-, lieren. Daß diese Molekülverbindungen bisher übersehen worden sind, hat seinen Grund im wesentlichen darin, daß die einfacheren aromatischen Nitrokörper, wie Trinitrobenzol, Trinitrotoluol usw. zwar gut charakterisierte Verbindungen mit Phenolen und Aminen geben, aber keine nennenswerten Halochromieerscheinungen zeigen. Diese treten erst bei ungesättigten Nitrokörpern, bei Nitrostilbenen und Nitrostyrolen auf, von denen sich natürlich auch farbige Phenol- und Aminverbindungen ableiten. Von den Molekülverbindungen der Ketone sind gerade umgekehrt die Halochromieverbindungen allgemein verbreitet, während sich hier die Chinhydrone, also die Kohlenwasserstoff-, Phenol- und Aminverbindungen, als eng umgrenzte Gruppe herausheben.

Die Konstitutionsformeln der Halochromieverbindungen der Nitrokörper werden wir in Analogie mit der Formulierung der Halochromieverbindungen der Ketone folgendermaßen schreiben:

$$
\mathrm{R}-\mathrm{NO}_{2} \ldots \mathrm{HX} \quad \mathrm{R} . \mathrm{NO}_{2} \ldots \mathrm{MeX}_{\mathrm{n}} \text {. }
$$

Diesen gut untersuchten Klassen organischer Molekülverbindungen schließen sich noch Verbindungen ungesättigter (auch aromatischer) Kohlenwasserstoffe mit Metallsalzen, Verbindungen der Ketimine und der Triphenylmethylhalogenide mit Metallsalzen und Säuren an. Dann gehören hierher noch zahlreiche Additionsprodukte der Azokörper, Tetrarylhydrazine usw. Es stellt sich immer mehr heraus, daß die ungesättigten organischen Verbindungen, vor allem die sogenannten Lückenver- 
bindungen, ganz allgemein durch gegenseitige lockere Verknüpfang oder durch Vereinigung mit Metallsalzen und Säuren Molekülverbindungen geben. Von diesen zeichnen sich namentlich die oben erwähnten dadurch aus, $\mathrm{da} B$ sie tieferfarbig als ihre Komponenten sind. $\mathrm{Da} B$ aber bei der Bildung organischer Molekülverbindnngen auch Farberhöhung eintreten kann, sehen wir am schönsten am Beispiel der aromatischen Nitrosokörper, die in monomolekularen Zustand grün, im bimolekularen Zustand, als lockere Vereinigungen je zweier Moleküle, aber farblos sind.

Wie können wir uns nun die so häufige Farbvertiefung bei der Bildung von Molekülverbindungen erklären? Jie Konstitutionsformeln der Halochromieverbindungen der Ketone und Nitrokörper

$$
\begin{array}{ll}
\mathrm{R}_{2} \mathrm{C}=0 \ldots \mathrm{HX} & \mathrm{R}_{3} \mathrm{C}=0 \ldots \mathrm{MeX}_{\mathrm{n}} \\
\mathrm{RN} \ll_{0}^{0 \ldots H X} & \mathrm{R} . \mathrm{N} \ll_{0}^{0} \ldots \mathrm{MeX}_{\mathrm{n}}
\end{array}
$$

zeigen uns, daß die $\mathrm{C}=0$ - bzw. $\mathrm{N}=0$-Lücken durch die Säure- und Metallsalzmoleküle nur einseitig abgesättigt werden. Ebenso ist eine nur einseitige Absättigung dieser Lücken bei den Verbindungen der Ketone und Nitrokörper mit ungesättigten (aromatischen) Kohlenwasserstoffen und ihren Derivaten anzunehmen, entsprechend folgenden Symbolen, in welchen $\mathrm{C}=\mathrm{C}$ als $\mathrm{Ab}$ kürzung für den ungesättigten Kohlenwasserstoff zu gelten hat, der, wie schon früher betont ${ }^{1}$ ), im allgemeinen koordinativ einwertig wirkt:

$$
\mathrm{R}_{2} \mathrm{C}=0 \ldots \mathrm{C}=\mathrm{C} \quad \mathrm{RN} \ll_{0}^{0} \ldots \mathrm{C}=\mathrm{C} .
$$

Auf diese einseitige Absättigung der Lücken führen wir zweckmäßig die Farbe der Molekülverbindungen zurück. ${ }^{2}$ )

Dadurch, daß bei der Bildung unserer Molekülverbindungen ein erheblicher 'Teil der Energie des Saner-

1) Siehe die Arbeit über Chinhydrone, a. a. 0 .

2) Siebe hierzu diese Annalen 383, 92 (1911). 
stoffatoms der $\mathrm{C}=\mathrm{O}-\mathrm{bzw} . \mathrm{N}=\mathrm{O}$-Lücke zur Bindung des Addenden verbraucht wird, kann dieses Atom die Affinität des C- bzw. N-Atoms nicht mehr so volIständig wie ursprünglich absättigen, so daß letztere einen relativ stark ungesättigten, also chromophoren Charakter annehmen müssen. Das können wir symbolisch folgendermaßen ausdrücken, indem wir den Addenden mit A bezeichnen:

$$
\underset{\downarrow}{\mathrm{R}_{2} \mathrm{C}=\mathrm{C}}=\mathrm{OA} \quad \underset{\downarrow}{\mathrm{RNO}_{2} \ldots \mathrm{A} .}
$$

Natürlich findet auch bei der zweiten Komponente unserer Molekülverbindungen, dem sogenannten Addenden, eine einseitige Affinitätsabsättigung statt. Das scheint farbchemisch bei den Verbindungen mit Metallsalzen und Säuren keine große Rolle zu spielen. Es ist aber sehr gut denkbar, daß dieser Umstand zur Erklärung der Farbenerscheinungen bei den Chinhydronen und den entsprechenden Verbindungen der Nitrokörper mit herangezogen werden muß.

Wir kommen so für diese Verbindungen zu den Formeln:

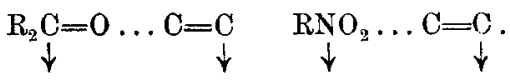

Nur eine genaue spektrochemische Untersuchung wird uns Aufschluß darüber geben können, in welcher Art und Weise die einzelnen "chromophoren" Atome bei der Entstehung der Farbe der Molekülverbindungen zusammenwirken. Dabei ist noch zu berücksichtigen, daß sich die nach unserer Theorie durch die Additionsreaktion entstehenden ungesättigten Atome und die in den Komponenten von vornherein schon vorhandenen chromophoren Gruppen (Äthylenlücken usw.) stark gegenseitig beeinflussen müssen. Vielleicht geschieht das derart, daß sich die chromophoren Zustände der einzelnen ungesättigten Atome auf einigen wenigen Atomen anhäufen. Es hat aber keinen Zweck, auf diese Dinge schon heute näher einzugehen.

Im folgenden sollen nun die Chinhydrone, die 
Kohlenwasserstoff-, Phenol- und Aminverbindungen der Nitrokörper, die Halochromieverbindungen der Nitrokörper und die Halochromieverbindungen der Ketone der Reihe nach besprochen werden.

\section{Die Chinhydrone.}

Wie ich vor kurzem zeigen konnte ${ }^{1}$ ), sind die Chinhydrone als Hydroxyl- bzw. Aminoderivate von Kohlenwasserstoffverbindungen der Chinone, der sogenannten "Kohlenwasserstoffchinhydrone", aufzufassen. Die Konstitution der letzteren ist so zu denken, daß je eine Nebenvalenz der Carbonylsauerstoffatome der chinoiden Komponente durch je eine Nebenvalenz eines ungesättigten Kohlenstoffatoms der benzoiden Komponente abgesättigt wird. Dementsprechend gelten für die Kohlenwasserstoffchinhydrone die folgenden Konstitutionssymbole:

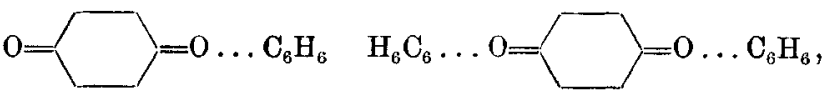

aus denen sich für die eigentlichen Chinhydrone die Formeln:

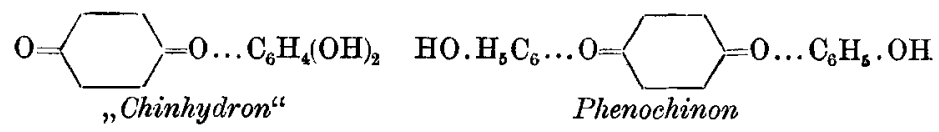

usw. ergeben.

Die experimentellen Grundlagen für die neue Formulierung der Chinhydrone sind inzwischen wesentlich vervollständigt worden, so daB an dieser Stelle noch einmal anf die Konstitutionsbestimmung dieser Verbindungen eingegangen werden muß.

Die neuen Konstitutionsformeln der Chinhydrone stützen sich vor allem auf die Tatsache, daß farbige Verbindungen der Chinone mit aromatischen Kohlenwasserstoffen existieren, die in ihrem ganzen Verhalten, vor allem in dem leichten Zerfall in die Komponenten, so sehr den Verbindungen der Chinone mit Phenolen

3) a. a. 0 . 
und Aminen, den Chinhydronen im engeren Sinne, glechen daß bei letzteren weder die Hydroxyl- noch die Aminogruppe an der Bindung der Komponenten beteiligt sein kann. Zu den in der letzten Mitteilung schon beschriebenen Durolverbindungen des Chloranils and Bromanils:

$$
\begin{aligned}
& \mathrm{C}_{6} \mathrm{Cl}_{4} \mathrm{O}_{2}, 2 \mathrm{O}_{6} \mathrm{H}_{2}\left(\mathrm{CH}_{3}\right)_{4} \\
& \text { leuchtend rote Blättchen } \\
& \begin{array}{c}
\mathrm{C}_{6} \mathrm{Br}_{4} \mathrm{O}_{2}, \mathrm{C}_{6} \mathrm{H}_{2}\left(\mathrm{CH}_{3}\right)_{4} \\
\text { rote Nadeln }
\end{array}
\end{aligned}
$$

können wir noch die Dichlorchinonverbindung:

hinzufügen.

$$
\begin{gathered}
\mathrm{C}_{13} \mathrm{H}_{2} \mathrm{Cl}_{2} \mathrm{O}_{2}, 2 \mathrm{C}_{6} \mathrm{H}_{2}\left(\mathrm{CH}_{3}\right)_{4} \\
\text { orangegelbe Tafeln }
\end{gathered}
$$

Daß ebensowenig wie die Hydroxyl- und Aminogruppen, die aromatisch gebundenen Wasserstoffatome der benzoiden Komponente für die Chinhydronbildung in Betracht kommen, zeigen sehr schön die folgenden 4 Verbindungen des Hexamethylbenzols:

$$
\begin{array}{cc}
\mathrm{C}_{6} \mathrm{Cl}_{4} \mathrm{O}_{2}, \mathrm{C}_{6}\left(\mathrm{CH}_{3}\right)_{6} & \mathrm{C}_{6} \mathrm{Br}_{4} \mathrm{O}_{2}, \mathrm{C}_{6}\left(\mathrm{CH}_{3}\right)_{6} \\
\text { violettbraune Nadeln } & \text { violettbraune Nadeln } \\
\mathrm{C}_{6} \mathrm{H}_{2} \mathrm{Cl}_{2} \mathrm{O}_{2}, \mathrm{C}_{6}\left(\mathrm{CH}_{3}\right)_{6} & \mathrm{C}_{6} \mathrm{H}_{3} \mathrm{ClO}_{2}, \mathrm{C}_{6}\left(\mathrm{CH}_{3}\right)_{6} \\
\text { hellrote Krystalle } & \text { orangefarbene Nadeln }
\end{array},
$$

die sich in Farbe und Eigenschaften vollständig den entsprechenden Verbindungen des Durols anschließen.

Nach alledem bleibt keine andere Wahl als anzunehmen, daß sich die benzoiden Moleküle vermittelst ihrer ungesättigten Kohlenstoffatome ${ }^{1}$ ) an die chinoide Komponente binden. Mit dieser Auffassung stimmt sehr gut überein, daß Hexahydrodurol, im Gegensatz zum Verhalten des Durols, keine Farbenreaktionen mit Chinonen gibt. So löst sich Chloranil in Durol blutrot, in Hexahydrodurol aber nur grünstichig gelb; Bromanil gibt mit Durol eine undurchsichtig blutrote, mit Hexahydrodurol eine gelbe Lösung usw. Daß sich Chinone in Terpenen, wie Limonen usw., und in aliphatischen ungesättigten Koblen-

1) Bei den Additionsprodukten der Stilbene können natürlich die ungesättigten Kohlenstoffatome der Äthylenbrücke als Bindestellen in Betracht kornmen. 


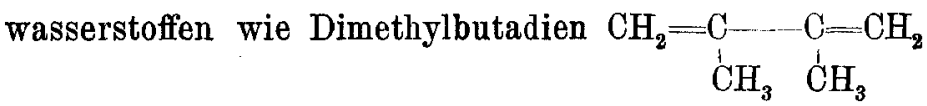
mehr oder weniger tieffarbig lösen ${ }^{1}$ ), ist nun auch verständlich.

In der chinoiden Komponente der Chinhydrone sind, in Übereinstimmung mit der Annahme Willstätters ${ }^{2}$ ), jedenfalls die Carbonylsauerstoffatome als Bindestellen anzusprechen, zumal ja die Untersuchungen der letzten Jahre über die Halochromieerscheinungen gezeigt haben, daB die Sauerstoffatome der Ketone einen ausgesprochen ungesättigten Charakter besitzen. ${ }^{3}$ )

Berücksichtigen wir nun, dab in den Chinhydronen fast ausnahmslos auf $1 \mathrm{Mol}$. eines Chinons 1 oder $2 \mathrm{Mol}$. einer benzoiden Komponente kommen, so werden wir die Formeln ihrer (hypothetischen) Grundverbindungen, unter Vermeidung der Anwendung überflüssiger Striche, am einfachsten folgendermaßen schreiben:

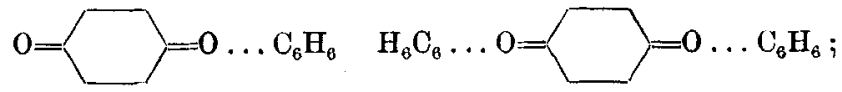

auf diese Symbole lassen sich ohne jede Schwierigkeit fast sämtliche bisher bekannten Kohlenwasserstoff-, Phenol- und Aminchinhydrone beziehen.

Auf die eigenartige Tatsache, daß die benzoide Komponente der Chinhydrone trotz des Vorhandenseins zahlreicher ungesättigter Kohlenstoffatome nur eine einzige Nebenvalenz betätigt, habe ich schon früher hingewiesen. ${ }^{4}$ )

An dieser Stelle mögen noch einige Spezialfragen der Chinhydronchemie besprochen werden.

Uns interessierte $\mathrm{zu}$ wissen, $\mathrm{ob}$ außer den $\mathrm{p}$-Chinonen auch die 0 -Chinone Kohlenwasserstoffverbindungen geben. Das ist in der Tat der Fall.

1) Die heißen Lösungen von Chloranil in Limonen und Dimethylbutadien sind orange gefärbt.

2) Ber. d. d. chem. Ges. 41, 1458 (1908).

s) Siehe z. B. P. Pfeiffer, diese Annalen 383, 92 (1911).

4) Diese Annalen 404, 9 (1914). 
So existiert eine orangefarbene Verbindung von Phenanthrenchinon mit Hexamethylbenzol von der Formel:

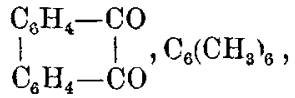

deren Farbe allerdings von der des Phenanthrenchinons selbst nur unwesentlich abweicht.

Weitere Kohlenwasserstoffverbindungen der o-Reihe leiten sich vom Tetrachlor-0-chinon, dem o-Chloranil ab. In der Literatur sind bereits zwei derartige Verbindungen, die Benzolverbindung $\left.{ }^{1}\right) \mathrm{C}_{6} \mathrm{Cl}_{4} \mathrm{O}_{2}, 3 \mathrm{C}_{6} \mathrm{H}_{6}$ und die Toluolverbindung $\left.{ }^{2}\right) \mathrm{C}_{6} \mathrm{Cl}_{4} \mathrm{O}_{2}, \mathrm{C}_{6} \mathrm{H}_{5} . \mathrm{CH}_{3}$ beschrieben. Bei einer erneuten Darstellung dieser Verbindungen fanden wir die Angaben der Literatur bestätigt. Die Benzolverbindung - sie ist außerordentlich labil und hält sich in einer Benzolatmosphäre nur kurze Zeit - besitzt also in der Tat eine anomale Zusammensetzung; über die Bindung des dritten, „überschüssigen" Benzolmoleküls kann nichts mit Sicherheit ausgesagt werden.

Diesen beiden Additionsprodukten schließen sich als neue Kohlenwasserstoff-Chinhydrone die Verbindnngen mit p-Xylol und Hexamethylbenzol

$$
\mathrm{C}_{6} \mathrm{Cl}_{4} \mathrm{O}_{2}, \mathrm{C}_{6} \mathrm{H}_{4}\left(\mathrm{CH}_{3}\right)_{2} \text { und } \mathrm{C}_{6} \mathrm{Cl}_{4} \mathrm{O}_{2}, \mathrm{C}_{6}\left(\mathrm{CH}_{3}\right)_{6}
$$

an. Eine wesentliche Farbvertiefung konstatieren wir nur bei der Hexamethylbenzolverbindung, sie bildet grünschwarze, glänzende Nädelchen. Die Verbindungen mit Benzol, Toluol und Xylol besitzen die rote Farbe des freien Tetrachlor-o-chinons.

Die weiteren Versuche beschäftigen sich mit der Frage, in welcher Art und Weise die Farbe der Chinhydrone von der Natur und Verteilung der Substituenten abhängt. Als erste Farbregel sei folgende erwähnt.

Methylgruppen wirken in der benzoiden Komponente bathochrom, in der chinoiden Komponente hypsochrom.

Daß Methylgruppen im benzoiden Kern die Farbe

$\left.{ }^{1}\right)$ Cousin, Compt. rend. 129, 967 (1899).

2) Jackson und Mac Laurin, Am. chem. Journ. 38, 168 (1907). 
vertiefen, erkennt man deutlich an den Farbunterschieden zwischen den Durol- bzw. Xylolverbindungen einerseits und den Hexamethylbenzolverbindungen andererseits:

$$
\begin{array}{cc}
\mathrm{p}-\mathrm{C}_{6} \mathrm{Cl}_{4} \mathrm{O}_{2}, 2 \mathrm{C}_{6} \mathrm{H}_{2}\left(\mathrm{CH}_{3}\right)_{4} & \mathrm{p}-\mathrm{C}_{6} \mathrm{Cl}_{4} \mathrm{O}_{2}, \mathrm{C}_{6}\left(\mathrm{CH}_{3}\right)_{6} \\
\text { leuchtend rot } & \text { violettbraun } \\
\mathrm{p}-\mathrm{C}_{6} \mathrm{Br}_{4} \mathrm{O}_{2}, \mathrm{C}_{6} \mathrm{H}_{2}\left(\mathrm{CH}_{3}\right)_{4} & \mathrm{p}-\mathrm{C}_{6} \mathrm{Br}_{4} \mathrm{O}_{2}, \mathrm{C}_{6}\left(\mathrm{CH}_{3}\right)_{6} \\
\text { rot } & \text { dunkelviolettbraun } \\
\mathrm{p}-\mathrm{C}_{6} \mathrm{H}_{2} \mathrm{Cl}_{2} \mathrm{O}_{2}, \mathrm{C}_{6} \mathrm{H}_{2}\left(\mathrm{CH}_{3}\right)_{4} & \mathrm{p}-\mathrm{C}_{6} \mathrm{H}_{2} \mathrm{Cl}_{2} \mathrm{O}_{2}, \mathrm{C}_{6}\left(\mathrm{CH}_{3}\right)_{6} \\
\text { orangerot } & \text { hellrot } \\
0-\mathrm{C}_{6} \mathrm{Cl}_{4} \mathrm{O}_{2}, \mathrm{C}_{6} \mathrm{H}_{4}\left(\mathrm{CH}_{9}\right)_{2} & \text { o- } \mathrm{C}_{6} \mathrm{Cl}_{4} \mathrm{O}_{2}, \mathrm{C}_{8}\left(\mathrm{CH}_{3}\right)_{6} \\
\text { rot } & \text { grüschwarz }
\end{array}
$$

Die Lösungsfarben der Chinone in aromatischen Kohlenwasserstoffen lassen diese Gesetzmäßigkeit ebenfalls deutlich erkennen. ${ }^{1}$ ) p-Chinon löst sich in Benzol und p-Xylol mit grünstichig gelber, in geschmolzenem Durol mit rein gelber, in geschmolzenem Hexamethylbenzol aber mit orangegelber Farbe. Beim Chloranil treten die Farbunterschiede noch schärfer hervor. Die Lösung von Chloranil in Benzol ist grünstichig gelb, in Xylol orangestichig gelb, in Jurol blutrot und in Hexamethylbenzol sogar violettrot gefärbt.

Die hypsochrome Wirkung der im chinoiden Kern befindlichen Methylgruppen zeigt uns ein Vergleich der Lösungsfarben von p-Chinon und Durochinon. Die Lösungsfarben der beiden Chinone in Benzol, p-Xylol und Durol sind zwar noch identisch ${ }^{2}$ ), doch treten mit Hexamethylbenzol, Phenol, Anilin und Dimethylanilin Unterschiede in dem Sinne auf, dab die Durochinonlösungen weniger tieffarbig als die Chinonlösungen sind. $0,05 \mathrm{~g}$ Chinon bzw. Durochinon auf $1 / 4 \mathrm{ccm}$ Lösungsmittel.

\begin{tabular}{c|c|c}
\hline & Chinon & Durochinon \\
\hline \hline Hexamethylbenzol & orangestichig gelb & rein gelb \\
Phenol & orange & dunkelgelb \\
Anilin & blutrot & hellorange \\
orangerot
\end{tabular}

1) Die Lösungsfarben beziehen sich auf $0,01 \mathrm{~g}$ Chinon und $1 / 4$ ecm Kohlenwasserstoff.

2) Bei direkter Beobachtung. 
Der Methylgruppe schließen sich in ihrer farbverändernden Wirkung weitgehend die Methoxyl- und die Hydroxylgruppe an. DaB die letztgenannten Gruppen in der benzoiden Komponente stark farbvertiefend wirken, ist ja bekannt. ${ }^{1}$ ) Befinden sie sich in der chinoiden Komponente, so ist ihr Einfluß, wie ein Vergleich der Lösungsfarben von Chinon, Methoxychinon und Oxychinon gezeigt hat, im allgemeinen sehr gering. Eine wesentliche Farbdifferenz, und zwar ganz im erwarteten Sinne, wurde nur bei den Lösungen der Chinone in Dimethylanilin beobachtet. Während sich Chinon $(0,01 \mathrm{~g})$ in Dimethylanilin $(0,5 \mathrm{ccm})$ mit tief rotvioletter Farbe löst, geben Methoxy- und Oxychinon mit diesem Reagens, bei gleicher Konzentration, tief braunorange Lösungen.

Der eigenartige Einfluß der Methyl-, Methoxy- und Oxygruppe auf die Farbe der Chinhydrone ist um so interessanter, als wir bei den Molekülverbindungen der Nitrokörper auf ganz analoge Gesetzmäßigkeiten stoßen, ein deutliches Zeichen der konstitutionellen Zusammengehörigkeit beider Körperklassen.

Gerade umgekehrt wie die Methylgruppen wirken die Halogenatome auf die Farberscheinungen ein; sie erzeugen im chinoiden Kern einen bathochromen, im benzoiden Kern einen hypsochromen Effekt.

Die bathochrome Wirkung der im chinoiden Kern befindlichen Halogenatome läßt sich sehr schön der folgenden Zusammenstellung krystallisierter Chinhydrone entnehmen:

$$
\begin{array}{ccc}
\begin{array}{c}
\mathrm{C}_{6} \mathrm{Cl}_{4} \mathrm{O}_{2}, \mathrm{C}_{6}\left(\mathrm{CH}_{3}\right)_{6} \\
\text { violettbraun }
\end{array} & \mathrm{C}_{6} \mathrm{Cl}_{2} \mathrm{H}_{2} \mathrm{O}_{2}, \mathrm{C}_{6}\left(\mathrm{CH}_{3}\right)_{6} & \begin{array}{c}
\mathrm{C}_{6} \mathrm{ClH}_{3} \mathrm{O}_{2}, \mathrm{C}_{6}\left(\mathrm{CH}_{3}\right)_{6} \\
\text { hellyat }
\end{array} \\
\begin{array}{ccc}
\mathrm{C}_{6} \mathrm{Cl}_{4} \mathrm{O}_{2}, 2 \mathrm{C}_{6} \mathrm{H}_{2}\left(\mathrm{CH}_{3}\right)_{4} \\
\text { leuchtend rot }
\end{array} & \mathrm{C}_{6} \mathrm{Cl}_{2} \mathrm{H}_{2} \mathrm{O}_{2}, 2 \mathrm{C}_{6} \mathrm{H}_{2}\left(\mathrm{CH}_{3}\right)_{4} ; \\
\text { orangegelb }
\end{array}
$$

auch folgt sie aus einer Gegenüberstellung der Lösungsfarben des Chinons and seiner Halogenderivate:

1) Siehe z. B. diese Annalen 404, 7 (1914), Anmerkung. 
$0,01 \mathrm{~g}$ chinoide Substanz auf etwa $1 / 4 \mathrm{ccm}$ Kohlenwasserstoff.

\begin{tabular}{|c|c|c|c|c|c|}
\hline & Durol & $\begin{array}{l}\text { Hexamethyl- } \\
\text { benzol }\end{array}$ & Stilben & $\begin{array}{c}\text { p, } \mathbf{p}^{\prime} \text {-Dimeth- } \\
\text { oxystilben }\end{array}$ & Anisol \\
\hline Chinon & reingelb & orangegelb & rotorange & gelbrot & $\begin{array}{c}\text { grrün- } \\
\text { stichig gelb }\end{array}$ \\
\hline $\begin{array}{l}\text { Monochlor- } \\
\text { chinon }\end{array}$ & $\mid \begin{array}{c}\text { orange- } \\
\text { stichig gelb }\end{array}$ & orangerot & orangerot & $\begin{array}{c}\text { undurchsichtig } \\
\text { violettrot }\end{array}$ & reingelb \\
\hline $\begin{array}{l}\text { Dichlor- } \\
\text { chinon }\end{array}$ & orange & $\begin{array}{l}\text { undurch- } \\
\text { sichtig blutrot }\end{array}$ & blutrot & rein violett & orangegelb \\
\hline $\begin{array}{c}\text { Tetrachlor- } \\
\text { ehinon }\end{array}$ & blutrot & violettrot & violettrot & blau & orangerot \\
\hline
\end{tabular}

Besonders stark sind die Farbunterschiede der Lösungen der einzelnen Chinone in geschmolzenem Dimethoxystilben.

Für die hypsochrome Wirkung der benzoid gebundenen Halogenatome gibt die folgende Tabelle ein gutes Bild:

$0,01 \mathrm{~g}$ ehinoide Substanz auf etwa $0,5 \mathrm{ecm}$ Anisol, Trichloranisol usw.

\begin{tabular}{|c|c|c|c|}
\hline & Anisol & Trichloranisol & Tribromanisol \\
\hline Chinon & gelb & grünstichig gelb & gelb \\
\hline $\begin{array}{l}\text { Monochlor- } \\
\text { chinon }\end{array}$ & $\begin{array}{l}\text { orangestichig } \\
\text { gelb }\end{array}$ & grünstichig gelb & $\begin{array}{l}\text { orangestichig } \\
\text { gelb }\end{array}$ \\
\hline Dichlorchinon & orange & grünstichig gelb & gelb \\
\hline $\begin{array}{c}\text { Tetrachlor- } \\
\text { chinon }\end{array}$ & orangerot & gelb & gelb \\
\hline
\end{tabular}

Besonders auffällig ist die Tatsache, dab sich die gleichen Substituenten ganz verschiedenartig verhalten, je nachdem ob sie sich im benzoiden oder chinoiden Teil des Moleküls befinden; auch ist der Gegensatz in der Wirkung der Methyl-, Methoxy- and Oxygruppe einerseits und der Halogenatome andererseits recht bemerkenswert.

2. Die Kohlenwasserstoff-, Phenol- und Aminverbindungen der Nitrokörper.

Die Konstitution der Kohlenwasserstoffverbindungen der Nitrokörper ist schon von Werner ${ }^{1}$ ) dahin auf-

1) Ber. d. d. chem. Ges. 42, 4328 (1909). 
geklärt worden, daß es sich hier um Absättigung von Nebenvalenzen zwischen Nitrogruppen und ungesättigten Kohlenstoffatomen handelt. Insbesondere lassen sich auf Grund der Wernerschen Arbeit die Verbindungen der aromatischen Nitrokörper mit aromatischen Kohlenwasserstoffen auf das einfache Schema ${ }^{1}$ ) R. $\mathrm{NO}_{2} \ldots \mathrm{C}_{6} \mathrm{H}_{6}$ zurückführen, welches ganz dem der Kohlenwasserstoffchinhydrone $\mathrm{R}_{2} \mathrm{CO} \ldots \mathrm{C}_{6} \mathrm{H}_{6}$ entspricht. Nimmt man nun an, dab nicht nur bei den Kohlenwasserstoffchinhydronen, sondern auch bei den Kohlenwasserstoffverbindungen der Nitrokörper die Nebenvalenzen der ungesättigten Kohlenstoffatome an den Sauerstoffatomen der zweiten Komponente angreifen, so wird die konstitutionelle Analogie beider Körperklassen noch vollständiger.

Eine solche Übereinstimmung im Aufbau zweier Reihen farbiger Verbindungen sollte sich vor allem darin äußern, daß bei beiden die gleichen Farbgesetze gelten. Das ist in der Tat der Fall.

Um die bei den Molekülverbindungen der Nitrokörper gültigen Farbgesetze kennen zu lernen, war es vor allem notwendig, krystallisierte, farbige Verbindungen von Nitrokohlenwasserstoffen mit aromatischen Kohlenwasserstoffen zu isolieren. ${ }^{2}$ ) Die bisher bekannten farbigen Molekülverbindungen der Nitrokörper enthalten als nitroide Komponente meist Pikrinsäure ${ }^{3}$ ), über deren Bindung an die benzoide Komponente a priori zwei verschiedenartige Ansichten möglich sind, indem außer den Nitrogruppen auch die Hydroxylgruppe für die Verknüpfung der Komponenten maßgebend sein könnte.

Es ist uns nun gelungen, die folgenden Kohlen-

1) Wie bei den Chinhydronen, wirken auch hier die Kohlenwasserstoffe im allgemeinen koordinativ einwertig.

2) Die Wernerschen Betrachtungen knüpfen an farbige Lösungen von Nitrokörpern an.

3) Man kennt auch einige farbige Verbindungen höherer aromatischer Kohlenwasserstoffe mit Pikrylchlorid und Pikramid. 
Farbige organische Molekülverbindungen.

wasserstoffverbindungen des s-Trinitrobenzols in gut krystallisierter Form za erhalten (die Benzolverbindung war schon bekannt):

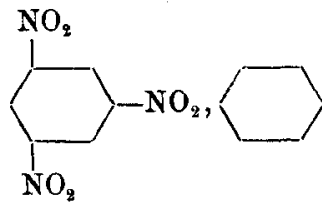

fast farblos

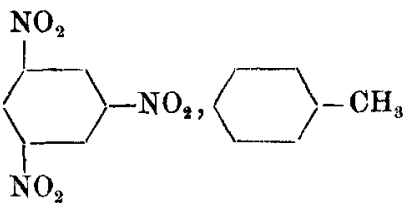

fast farblos<smiles>CC1CCC(CC(=O)N2CC([N+](=O)[O-])CC([N+](=O)[O-])C2)CC1</smiles>

gelbstichig

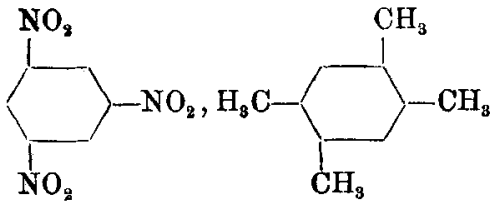

grünstichig gelb

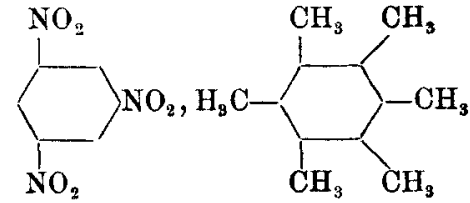

reingelb<smiles>O=[N+]([O-])C1CC([N+](=O)[O-])CC([N+](=O)[O-])C1</smiles>

reingelb<smiles>CC1CC(C=[N+]=O)C(C)CC1C=CC1CC([N+](=O)[O-])C(C)CC1C</smiles>

xinnoberrot

Wir entnehmen dieser Zusammenstellung, daß s-Trinitrobenzol schon mit relativ einfachen aromatischen Kohlenwasserstoffen farbige Molekülverbindungen gibt; diese gleichen in Zusammensetzung und Eigenschaften vollständig den entsprechenden Verbindungen der Pikrin- 
süure, so daß kein $Z$ weifel darüber bestehen kann, daß letztere, entsprechend der Formel: $\mathrm{HO} . \mathrm{C}_{6} \mathrm{H}_{2}\left(\mathrm{NO}_{2}\right)_{3} \ldots \mathrm{C}_{\mathrm{n}} \mathrm{H}_{\mathrm{m}}$, als Hydroxylderivate der Kohlenwasserstoffverbindungen des Trinitrobenzols aufzufassen sind; ihre Bezeichnung als "Pikrate" ist daher irrefïhrend. ${ }^{1}$ )

Vor allem aber zeigt unsere Tabelle, daß ebenso wie bei den Kohlenwasserstoffchinhydronen auch bei den Molekülverbindungen der Nitrokörper die Methylgruppe in der benzoiden Komponente ausgesprochen bathochrom wirkt. Beim Übergang von der Benzol- zur Hexamethylbenzolverbindung vertieft sich die Farbe systematisch von fast farblos zu rein gelb; der rein gelben Stilbenverbindung entspricht eine zinnoberrote Verbindung des Hexamethylstilbens.

Daß im Gegensatz hierzu, aber wiederum in Übereinstimmung mit den Verhältnissen bei den Chinhydronen, Methylgruppen im nitroiden Kern hypsochrom wirken, zeigt ein Vergleich der Lösungsfarben von p-Dinitrobenzol,

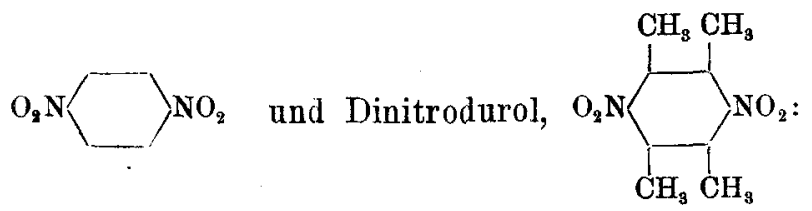

\begin{tabular}{|c|c|c|}
\hline $\begin{array}{c}\text { Lösungsmittel } \\
0,5 \mathrm{ccm}\end{array}$ & $\begin{array}{c}\text { Dinitrobensol } \\
0,01 \mathrm{~g}\end{array}$ & $\begin{array}{c}\text { Dinitrodurol } \\
0,01 \mathrm{~g} \\
\end{array}$ \\
\hline $\begin{array}{c}\text { Benzol } \\
\text { Durol }\end{array}$ & $\begin{array}{l}\text { hellgrünstichig gelb } \\
\text { grünstichig gelb }\end{array}$ & $\begin{array}{l}\text { farblos } \\
\text { fast farblos }\end{array}$ \\
\hline Hexamethylbenzol & rein gelb & fast farblos \\
\hline Phenol & rein gelb & fast farblos \\
\hline Hydrochinon & rotorange & hellgelb \\
\hline Anilin & tief orangerot & grünstichig gelb \\
\hline Dimethylanilin & braunrot & rein gelb \\
\hline
\end{tabular}

Durch diese Tatsachen ist unsere Annahme einer weitgehenden konstitutionellen Analogie der Kohlen-

1) Natürlich können auch Verbindungen der Pikrinsäure existieren, bei denen die Hydroxylgruppe die Verknüpfung der Komponenten bedingt. 
wasserstoff verbindungen der Nitrokörper und der Kohlenwasserstoffchinhydrone wohl genügend gestützt.

Weit zahlreicher noch als die Verbindungen der Nitrokörper mit Kohlenwasserstoffen sind ihre Verbindungen mit Phenolen und Aminen. Es liegt nun nahe, anzunehmen, daß diese als $0 x y-b z w$. Aminoderivate der Kohlenwasserstoffverbindungen, also als Analoga der eigentlichen Chinhydrone aufzufassen sind.

Für diese Ansicht spricht vor allem folgendes: Vergleichen wir die Verbindungen der Nitrokörper mit Kohlenwasserstoffen, Aminen, Phenolen und Phenoläthern untereinander in bezug auf ihre Farbe, so finden wir die uns geläufigen Gesetze auxochromer Gruppen wieder. Es zeigt sich nämlich, daß durch Eintritt von $\mathrm{NH}_{2}$ - bzw. OH-Gruppen in ein Additionsprodukt die Farbe wesentlich vertieft wird, daß Methylierung und Phenylierung der Aminogruppen in der gleichen Richtung wirken, daB Acetylierung der Amino- und Methylierung der Hydroxylgruppen im Gegensatz dazu die Farbe erhöhen. ${ }^{1}$ )

Diese Übereinstimmung in den Farbgesetzen von Molekülverbindungen und reinen Valenzverbindungen wird uns nur dann verständlich, wenn, ebenso wie in letzteren, auch in den Molekülverbindungen die stickstoff haltigen und sauerstoffhaltigen Reste frei als Substituenten vorhanden sind und nicht etwa die Bindung der Komponenten übernehmen. Denn wir wissen von der Chemie der Farbstoffe her, daß die auxochrome Wirkung einer $\mathrm{NH}_{2}$-Gruppe sofort verloren geht, wenn wir sie durch Überführung in eine Ammoniumsalzgruppe koordinativ absättigen.

Den Phenol- and Aminverbindungen kommen also die folgenden Konstitutionsformeln zu:

$$
\text { R. } \mathrm{NO}_{2} \ldots \mathrm{C}_{6} \mathrm{H}_{5} . \mathrm{OH} \quad \text { R. } . \mathrm{NO}_{2} \ldots \mathrm{C}_{6} \mathrm{H}_{5} . \mathrm{NH}_{2}
$$

1) S. hierzu auch Sudborough und Beard, Zentralbl. 1910, I, 2077 und W. Jowleff, Dissert. Zürich 1911. 
Pfeiffer,

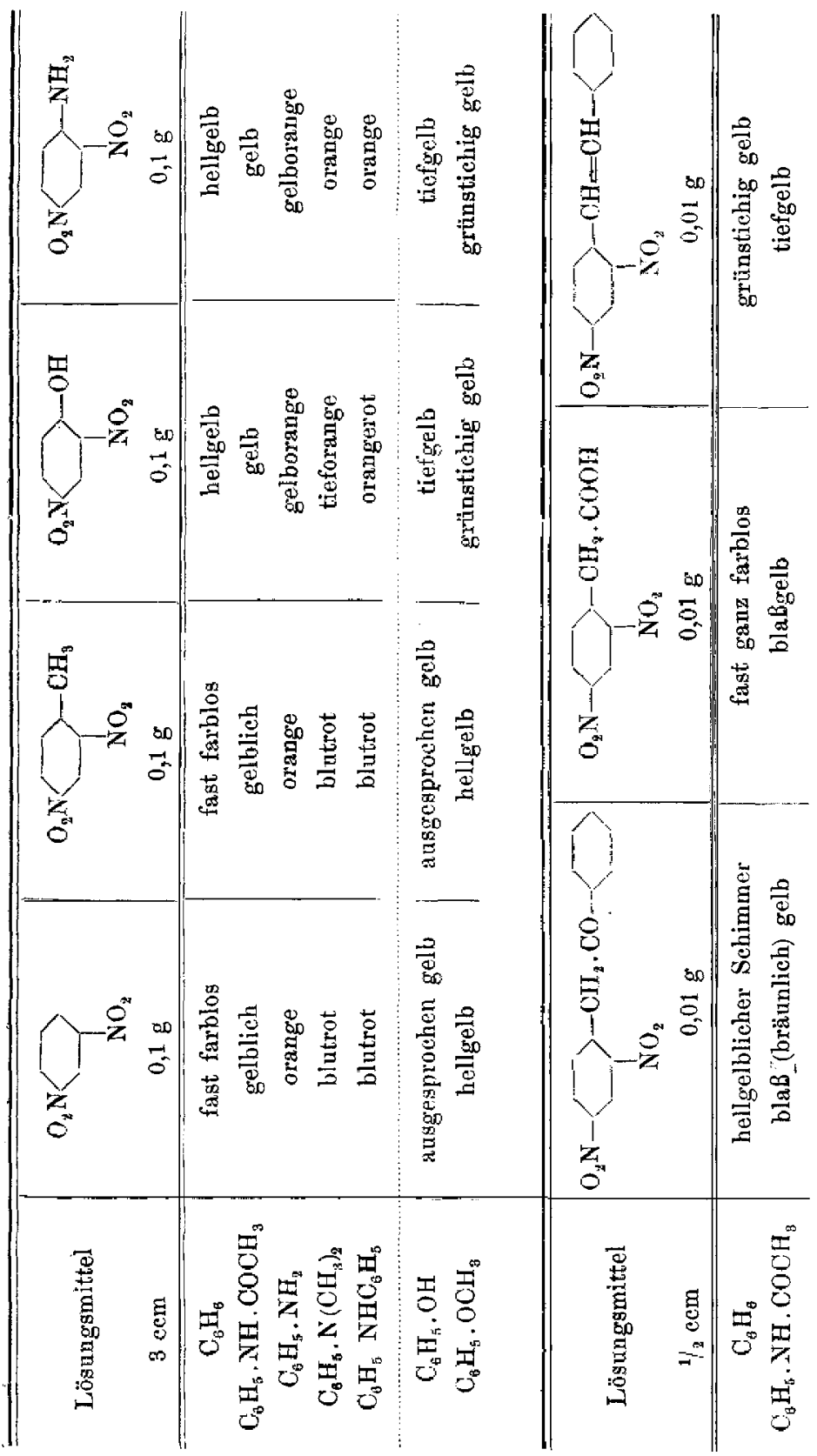


Farbige organische Molekülverbiudungen.

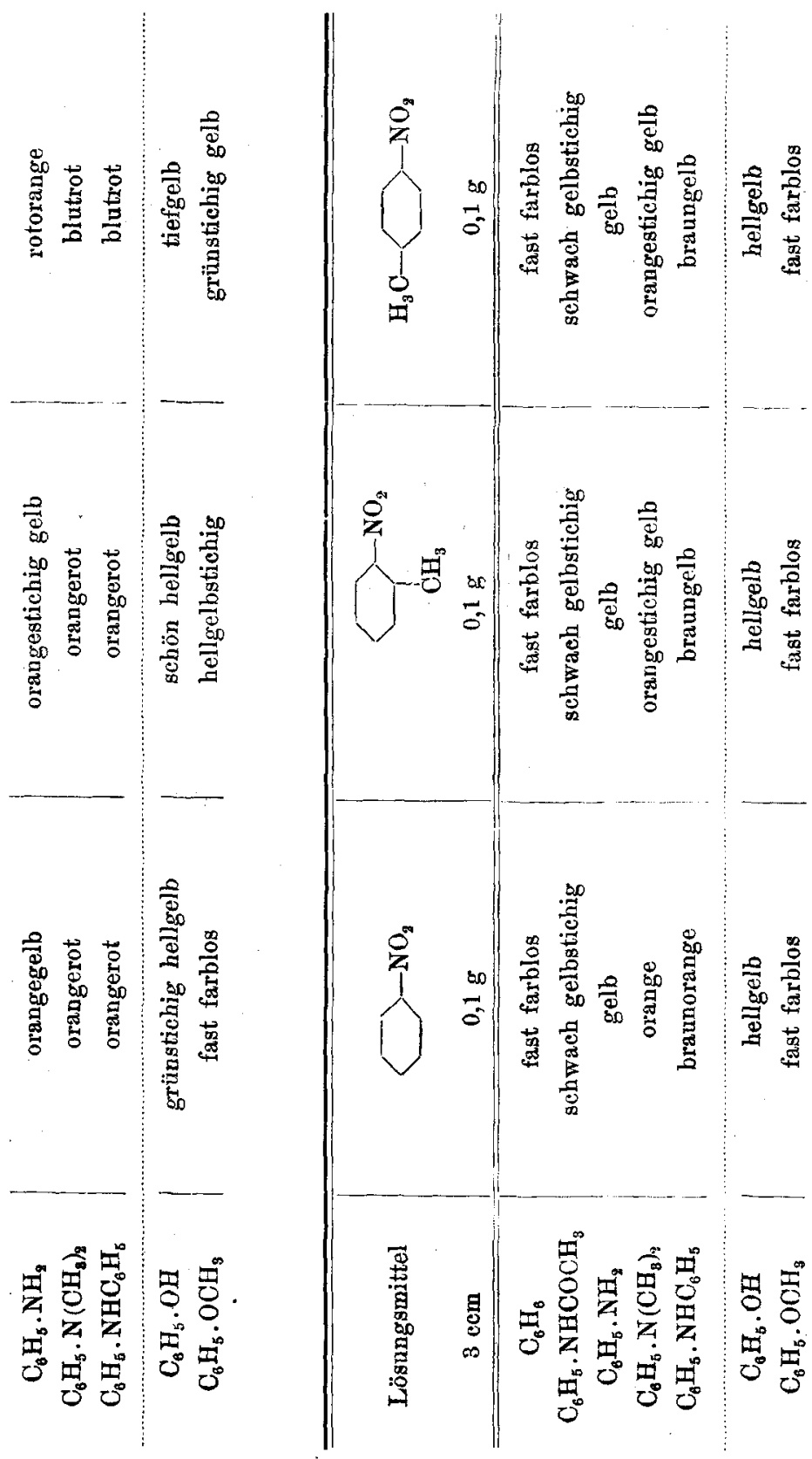

Annalen der Chemie 412. Band. 
die Kohlenwasserstoffverbindungen:

$$
\text { R. } \mathrm{NO}_{2} \ldots \mathrm{C}_{6} \mathrm{H}_{6}
$$

sind ihre Grundsubstanzen, von denen sie sich durch Finführung auxochromer Hydroxyl- und Aminogruppen ableiten.

Die Gültigkeit der Auxochromieregeln bei den Molekülverbindungen der Nitrokörper zeigen schon folgende der Literatur entnommene Beispiele:

$$
\begin{array}{r}
\mathrm{C}_{6} \mathrm{H}_{3}\left(\mathrm{NO}_{2}\right)_{3}+ \begin{cases}\mathrm{C}_{6} \mathrm{H}_{6} \cdot \mathrm{NH}_{2} & \text { orangerot } \\
\mathrm{C}_{6} \mathrm{H}_{5} \cdot \mathrm{NH} \cdot \mathrm{C}_{6} \mathrm{H}_{5} & \text { schwarz } \\
\mathrm{C}_{6} \mathrm{H}_{5} \cdot \mathrm{NH} \cdot \mathrm{COCH} & \text { schwefelgelb }\end{cases} \\
\mathrm{C}_{6} \mathrm{H}_{8}\left(\mathrm{NO}_{2}\right)_{3}+ \begin{cases}\mathrm{C}_{10} \mathrm{H}_{8} & \text { farblos } \\
\mathrm{C}_{10} \mathrm{H}_{7} \mathrm{OH}(\alpha) & \text { orangegelb } \\
\mathrm{C}_{10} \mathrm{H}_{7} \mathrm{OCH} \mathrm{CH}_{3}(\alpha) & \text { kanariengelb }\end{cases} \\
\mathrm{CH}_{3} \cdot \mathrm{C}_{6} \mathrm{H}_{2}\left(\mathrm{NO}_{2}\right)_{3}+ \begin{cases}\mathrm{C}_{6} \mathrm{H}_{5} \cdot \mathrm{NH}_{2} & \text { rot } \\
\mathrm{C}_{6} \mathrm{H}_{5} \cdot \mathrm{N}\left(\mathrm{CH}_{3}\right)_{2} & \text { dunkelviolett }\end{cases}
\end{array}
$$

Diesen schließen sich noch einige von uns dargestelite Verbindungen des s-Trinitrobenzols und 2,4,6-Trinitrostilbens an:

$$
\begin{aligned}
& 2 \mathrm{C}_{6} \mathrm{H}_{3}\left(\mathrm{NO}_{2}\right)_{9}+ \begin{cases}\mathrm{C}_{6} \mathrm{H}_{5} \cdot \mathrm{CH}==\mathrm{CH} \cdot \mathrm{C}_{6} \mathrm{H}_{5} & \text { goldgelb } \\
\mathrm{CH}_{3} \mathrm{O} \cdot \mathrm{C}_{6} \mathrm{H}_{4}, \mathrm{CH}=\mathrm{CH} \cdot \mathrm{C}_{8} \mathrm{H}_{4} \cdot \mathrm{OCH}_{3} & \text { rot }\end{cases} \\
& \mathrm{C}_{6} \mathrm{H}_{5} \cdot \mathrm{CH}=\mathrm{CH} . \mathrm{C}_{6} \mathrm{H}_{2}\left(\mathrm{NO}_{2}\right)_{3}+ \begin{cases}\mathrm{C}_{6} \mathrm{H}_{6} & \text { gelb } \\
\mathrm{C}_{6} \mathrm{H}_{5} \cdot \mathrm{NH}_{2} & \text { orange } \\
\mathrm{C}_{6} \mathrm{H}_{4}\left(\mathrm{CH}_{3}\right) \mathrm{NH}_{2} & \text { orange } \\
\mathrm{C}_{6} \mathrm{H}_{5} \mathrm{~N}\left(\mathrm{CH}_{8}\right)_{2} & \text { brawnoiolett }\end{cases}
\end{aligned}
$$

Daß die gleichen Gesetzmäßigkeiten auch für die Molekülverbindungen der Dinitro- und Mononitrokörper gelten, zeigen die vorstehenden Zusammenstellungen von Lösungsfarben ${ }^{1}$ ) (S. 268 u. 269).

Zum Schluß seien noch die Anilinverbindungen dreier Dinitrodesoxybenzoine angeführt; sie sind tiefgelb gefärbt und verwittern an der Luft allmählich zu den reinen, fast farblosen Ketonen. Diese Verbindungen bieten deshalb einiges Interesse, weil sie zu der bisher

1) Feste Molekülverbindungen der Mononitroreihe sind noch nicht dargestellt worden, wohl aber kennt man solehe der Dinitroreihe (s. W. Jowleff, Dissert. Zürich 1911 ). 
sehr kleinen Schaar fester Molekülverbindungen der Dinitroreihe gehören:

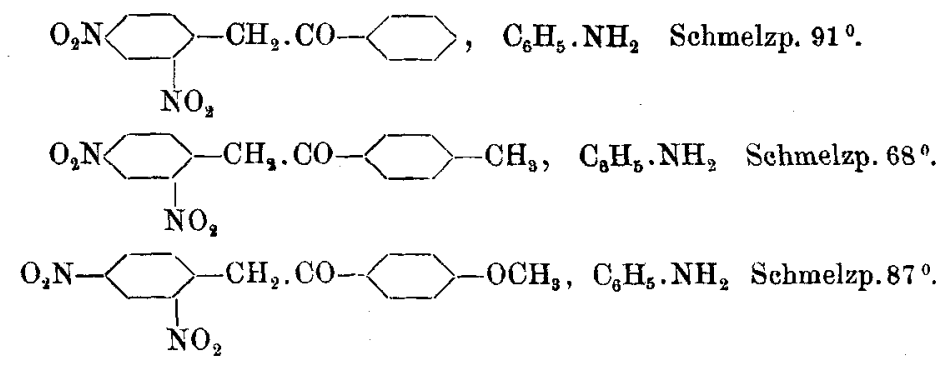

\section{Die Halochromieverbindungen der Nitrokörper.}

Ausgehend ron der Annahme einer weitgehenden Übereinstimmung im Aufbau der Molekülverbindungen der Ketone und Nitrokörper ließ sich die Existenz von Verbindungen der Nitrokörper mit Metallsalzen und Säuren, die den Halochromieverbindungen der Ketone an die Seite zu stellen wären, voraussehen. Solche existieren in der Tat. Dab sie bisher übersehen worden sind, hat seinen Grund in der Hauptsache darin, daß die Nitrokörper nur dann ausgesprochene Halochromieerscheinungen zeigen, wenn sie Äthylenlücken enthalten, während sich schon von den einfachsten aliphatischen und aromatischen Nitrokörpern farbige Verbindungen mit Phenolen und Aminen ableiten.

Die folgenden beiden Tabellen erläntern dies sehr schön. Wir sehen, daß Nitrobeuzol, m-Dinitrobenzol und s-Trinitrobenzol zwar farbige Verbindungen mit Anilin und Dimethylanilin, aber keine solchen mit Schwefelsäure, Überchlorsäure und Zinntetrachlorid geben. Ferner erkennen wir, daß sich die ungesättigten Nitrokörper, $\omega$-Nitrostyrol $\mathrm{O}_{2} \mathrm{~N} \cdot \mathrm{CH}=\mathrm{CH}-\longrightarrow$ und p-Methoxy$\omega$-nitrostyrol $\mathrm{O}_{2} \mathrm{~N} . \mathrm{CH}=\mathrm{CH}-\square-\mathrm{OCH}_{3}$ im Gegensatz dazu stark halochrom verhalten, wobei der bathochrome Einfluß der p-ständigen Methoxygruppe deutlich 
hervortritt, ähnlich wie bei den entsprechenden Ketonen R. $\mathrm{CO} . \mathrm{CH}=\mathrm{CH}-\longrightarrow-\mathrm{OCH}_{3}$.

\begin{tabular}{|c|c|c|c|c|c|c|}
\hline $\begin{array}{l}\text { Aufgelöste } \\
\text { Substanz } \\
\text { je } 0,01 \mathrm{~g}\end{array}$ & $\begin{array}{l}\text { Benzol } \\
1 \mathrm{ccm}\end{array}$ & $\begin{array}{l}\text { Anilin } \\
1 \mathrm{cem}\end{array}$ & $\begin{array}{c}\text { Dimethyl- } \\
\text { anilin } \\
1 \text { cem }\end{array}$ & $\begin{array}{r}1 \mathrm{cem} \\
\text { Benzol } \\
+\mathrm{SnCl}_{\mathbf{1}} \\
\end{array}$ & $\begin{array}{l}\mathrm{H}_{2} \mathrm{SO}_{4} \\
1 \mathrm{ccm}\end{array}$ & $\begin{array}{c}\mathrm{HClO}_{4} \\
(70 \text { Proz }) \\
1 \mathrm{ccm}\end{array}$ \\
\hline Nitrobenzol & farblos & gelb & $\begin{array}{l}\text { gelb- } \\
\text { orange }\end{array}$ & farblos & $\begin{array}{l}\text { gelb- } \\
\text { stichig } \\
\text { (unreine } \\
\text { Farbe) }\end{array}$ & $\begin{array}{l}\text { gelb- } \\
\text { stichig } \\
\text { (unreine } \\
\text { Farbe) }\end{array}$ \\
\hline Dinitrobenzol & farblos & $\begin{array}{l}\text { orange- } \\
\text { gelb }\end{array}$ & rotorange & farblos & farblos & $\begin{array}{c}\text { fast } \\
\text { farblos }\end{array}$ \\
\hline Trinitrobenzol & farblos & rotorange & $\begin{array}{l}\text { violett- } \\
\text { stichig } \\
\text { blutrot }\end{array}$ & farblos & farblos & $\begin{array}{c}\text { fast } \\
\text { farblos }\end{array}$ \\
\hline$\omega$-Nitrostyrol & $\begin{array}{l}\text { gelb- } \\
\text { stichig }\end{array}$ & $\begin{array}{l}\text { orange- } \\
\text { stichig } \\
\text { gelb }\end{array}$ & orange & $\begin{array}{l}\text { grïin- } \\
\text { stichig } \\
\text { gello }\end{array}$ & sattgelb & gelb \\
\hline $\begin{array}{c}\text { Methoxynitro- } \\
\text { styrol }\end{array}$ & $\begin{array}{l}\text { gelb- } \\
\text { stichig }\end{array}$ & $\begin{array}{l}\text { orange- } \\
\text { stichig } \\
\text { gelb }{ }^{1} \text { ) }\end{array}$ & orange ${ }^{1}$ ) & orange & $\begin{array}{l}\text { orange- } \\
\left.\text { rot }^{2}\right)\end{array}$ & orangerot \\
\hline
\end{tabular}

Den Nitrostyrolen schließen sich weitgehend die Nitrostilbene an. Zwar zeigen die einfachen Nitrostilbene nur verschwindend kleine Farbvertiefungen mit Säuren und Salzen; führt man aber in diese Nitrokörper Methylgruppen oder noch besser Methoxylgruppen ein, so entstehen Verbindungen mit ausgeprägten Halochromieeigenschaften. Dabei ist die Tatsache von besonderem Interesse, daß von den drei isomeren Nitromethoxystilbenen:

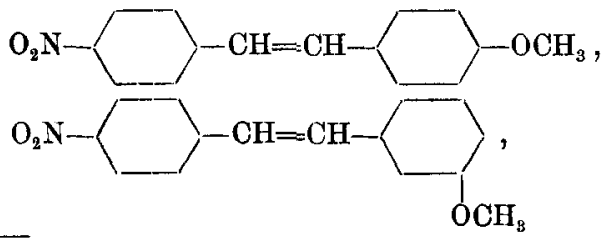

1) Diese Farben sind satter als die entsprechenden mit Nitrostyrol.

2) Aus der orangeroten, frischen $\mathrm{H}_{2} \mathrm{SO}_{4}$-Lösung läBt sich unverändertes Methoxynitrostyrol zurückgewinnen. 


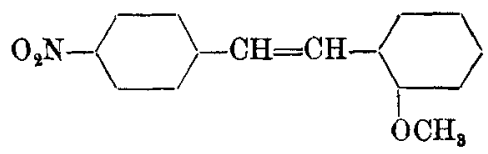

die $\mathrm{p}$-Verbindung die tiefsten, die $\mathrm{m}$-Verbindang die wenigst tiefen Farben erzeugt, während die o-Verbindung zwischen den beiden ersteren vermittelt, ganz in Übereinstimmung mit dem Verhalten der drei isomeren Methoxyketone:

R. $\mathrm{CO}-\mathrm{CH}=\mathrm{CH}-\longrightarrow-\mathrm{OCH}_{3}$,<smiles>CCC1CCCCC1C=COC(C)=O</smiles>

Da wir nun weiter oben gefunden haben, daß auch bei den Kohlenwasserstoff-, Phenol- und Aminverbindungen der Nitrokörper und Ketone übereinstimmende Farbgesetze herrschen, so erscheint die von uns gewählte analoge Formulierung all dieser Verbindungsklassen wohl begründet.

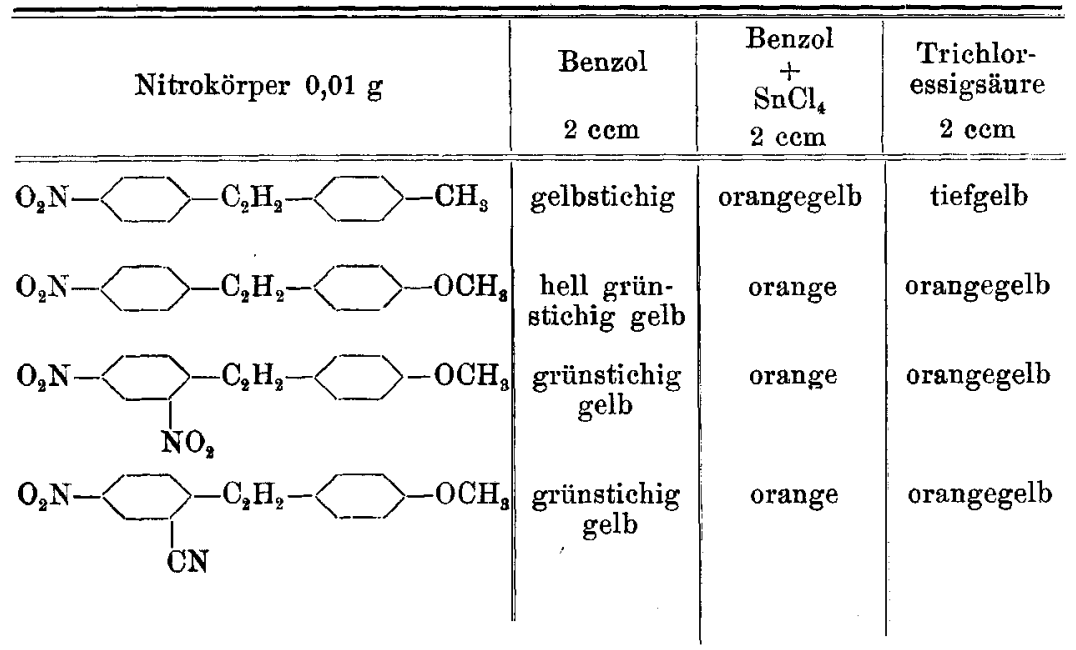




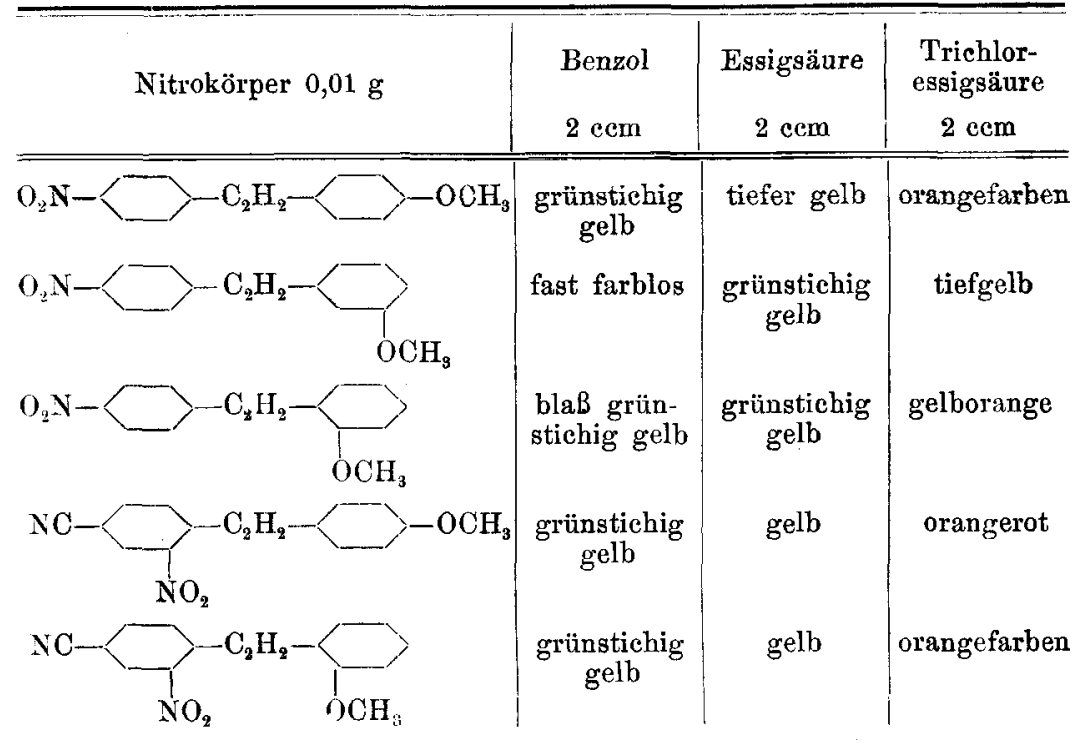

In fester Form haben wir bisher nur zwei Halochromieverbindungen der Nitrokörper erhalten, die Trichloressigsäureverbindung eines Benzoylaminonitromethoxystilbens:

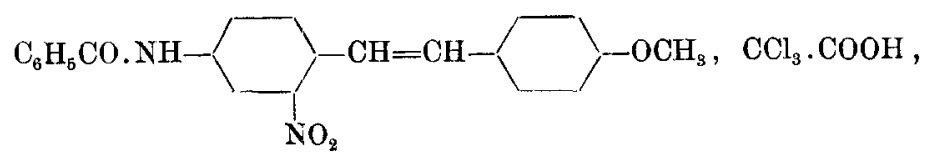

nnd die $\mathrm{SnCl}_{4}$-Verbindung des entsprechenden Cyannitromethoxystilbens :

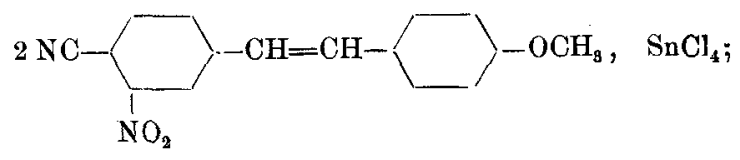

beide Additionsprodukte sind schön orangefarben und beide geben bei der Zersetzung gelbe Verwitterungsprodukte. Näheres über diese Verbindungen und den Farbendimorphismus der freien Nitromethoxystilbene s. Ber. d. d. chem. Ges. 48, 1777 (1915). 


\section{Die Halochromieverbindungen der Ketone.}

Von den Halochromieverbindungen der Ketone sind bisher am besten die Metallsalz-Additionsprodukte and von diesen wiederum die $\mathrm{SnCl}_{4}$-Verbindungen untersucht worden. ${ }^{1}$ ) Für die $\mathrm{SnCl}_{4}$-Verbindungen konnte die Konstitutionsformel:<smiles></smiles>

begründet werden; diese bringt sehr gut die Tatsache zum Ausdruck, daß Zinn die Koordinationszahl 6 besitzt und große Affinität zum Sauerstoff hat.

Entsprechend dieser Formulierung üben etwa vorhandene Methoxyle oder Äthylenlücken weder ihrer Zahl noch ihrer Stellnng nach irgend welchen Einfluß auf das Molekularverhältnis aus, in welchem die Komponenten zusammentreten. So fanden wir neuerdings, in Frgänzung des schon früher mitgeteilten Tatsachenmaterials, daß die $\mathrm{SnCl}_{4}$-Verbindungen von $0-, \mathrm{m}-, \mathrm{p}$ - und $\mathrm{p}^{\prime}$-Methoxychalkon ${ }^{2}$ ), 0-0'-, m-m'- und p-p'-Dimethoxydibenzalaceton, Benzalcinnamylidenaceton und Dicinnamylidenaceton ausnahmslos der allgemeinen Formel

$$
\mathrm{Cl}_{4} \mathrm{Sn}, 2 \mathrm{R}_{1} \mathrm{R}_{2} \mathrm{CO}
$$

entsprechen, obgleich sie an Zahl der Äthylenlücken und Methoxyle weitgehend voneinander differieren.

Neu sind die Ketone:

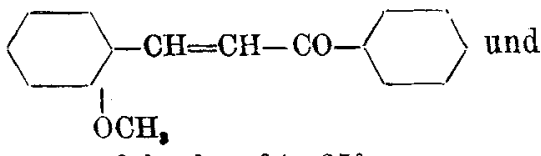

Schmelxp. 64-65

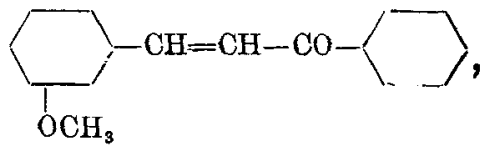

Schmelzp. $64^{\circ}$

über deren Darstellung und Eigenschaften sich genauere Angaben im experimentellen Teil der Arbeit finden.

1) P. Pfeiffex, diese Annalen 376, 285 (1910); 383, 92 (1911).

2) $\mathrm{p} \underset{\mathrm{m}}{\longrightarrow} \mathrm{CH}=\mathrm{CH}-\mathrm{CO}-\underset{\mathrm{o}^{\prime}}{\longrightarrow \mathrm{m}^{\prime}} \mathrm{p}^{\prime}$. 
Daß sich die übrigen Metallsalzverbindungen der Ketone unseren $\mathrm{SnCl}_{4}$-Verbindungen in der Konstitution anschließen, also die Formel

$$
\mathrm{X}_{\mathrm{n}} \mathrm{Me}\left(\ldots \mathrm{O}=\mathrm{C}<\mathrm{R}_{\mathbf{1}}^{\mathrm{R}_{1}}\right)_{\mathrm{m}}
$$

besitzen, ist ohne weiteres anzunehmen. Wie liegen aber die Konstitutionsverhältnisse bei den Säureverbindungen der Ketone?

Wenn es auch a priori wahrscheinlich ist, daß Metallsalz- und Säureverbindungen der Ketone konstitutionell eng zusammengehören, so war doch zur Entscheidung dieser Frage eine ernente Untersuchung der Säureverbindungen notwendig. Die bisher bekannten Verbindungen dieser Art sind nämlich so ungleichmäßig zusammengesetzt und besitzen in vielen Fällen eine so große Zahl von Säuremolekülen, daß die Ansicht nicht ganz von der Hand zu weisen war, daß außer den Carbonylgruppen auch die Äthylenlücken und Methoxyle für die Addition von Säuremolekülen in Betracht kommen könnten.

Einige charakteristische Verbindungen ron Ketonen mit Säuren seien hier angeführt: Dibenzalaceton addiert 1 und 2 Mol. Halogenwasserstoff, 1 und $3 \mathrm{Mol}$. Schwefelsäure und $1 \mathrm{Mol}$. Trichloressigsäure; Dianisalaceton verbindet sich mit 1 und $2 \mathrm{Mol}$. Dichloressigsäure, 1 und 2 Mol. Trichloressigsäure, 6 Mol. Monochloressigsäure und $2 \mathrm{Mol}$. Schwefelsäure. Ebenso mannigfache Molekularverhältnisse treffen wir bei den Säureverbindungen des Dicinnamylidenacetons an. Dieses Keton bindet 1 und 2 Mol. Chlorwasserstoff, 6 Mol. Monochloressigsäure, $2 \mathrm{Mol}$. Di- und 2 Mol. Trichloressigsäure.

Aus den Arbeiten von K. A. Hofman $n^{1}$ ) schien nun hervorzugehen, daß sich zu systematischen Untersuchungen über die Säureverbindungen der Ketone besonders gut die Überchlorsäure eignen müßte, einerseits weil sie

1) Ber. d. d. chem. Ges. 42, 4857 (1909); 43, 178 (1910). 
keine Neigung zur Bildung saurer Salze hat, dann aber auch, weil ihre Verbindungen im allgemeinen leicht krystallisieren. Unsere Vermutung hat sich bestätigt. Die „Perchlorate“ spielen unter den Säureverbindungen der Ketone eine ebenso wichtige Rolle, wie die $\mathrm{SnCl}_{4}$-Additionsprodukte unter den Metallsalzverbindungen.

Es seien hier zunächst alle diejenigen Ketone zusammengestellt, deren Überchlorsäureverbindungen von uns analysiert worden sind [bekannt waren nur die Perchlorate von Benzophenon und Dibenzalaceton $\left.{ }^{1}\right)$ ]:

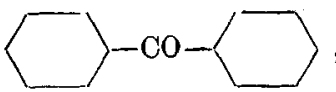

farblose Prismen, chmelzp. $48^{\circ}$

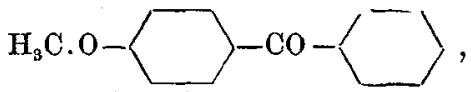

gelbstichige Prismen,

Schmelzp. $60-62^{0}$

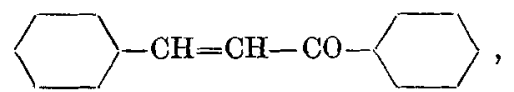

hellgelbe Prismen, Schmelzp. 57-58

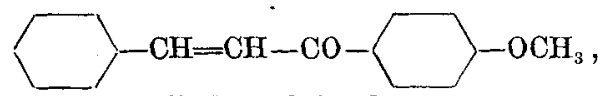

hellgelbe Nadeln, Schmelzp. 106-107

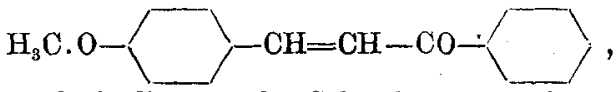

hellgelbe Nadeln, Schmelzp. 77-78

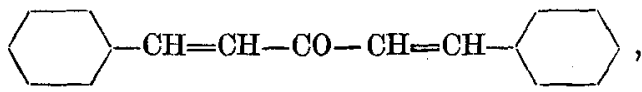

hellgelbe Blättchen, Schmelzp. $112^{\circ}$

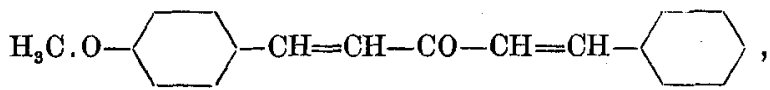

hellgelbe Nadeln, Schmelzp. $96^{\circ}$

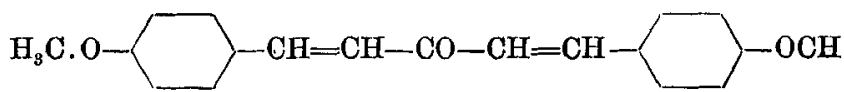

hellgraugelbe Blättchen, Schmelzp. 128-131

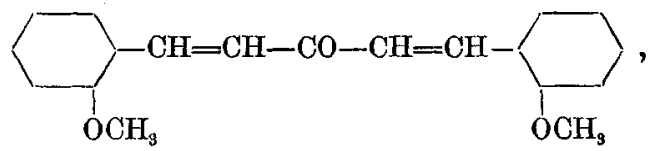

hellgrünstichig gelbe Blättchen, Schmelzp. $124^{\circ}$

1) K. A. Hofmann, a. a. O. 


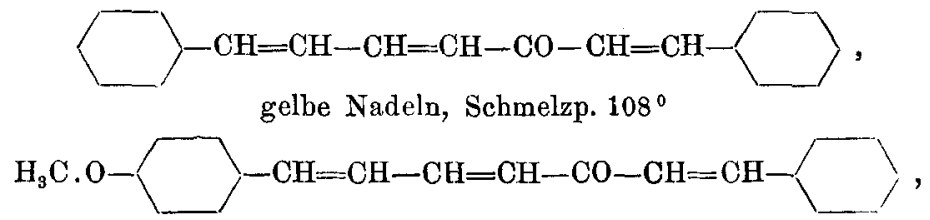

gelbe Nadeln, Schmelzp. 115-116
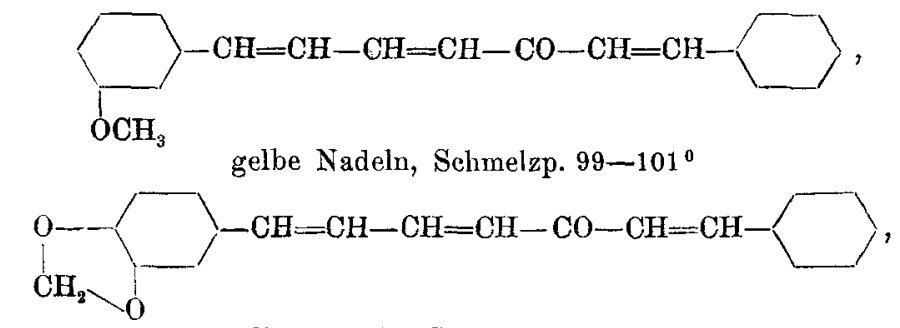

gelbe Nadeln, Schmelzp. 109-110

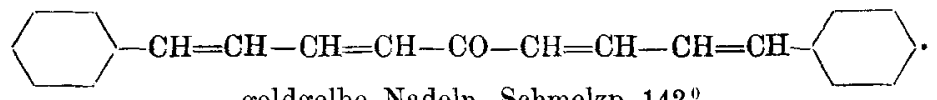

goldgelbe Nadeln, Schmelzp. 142"

Von diesen Ketonen sind m-Methoxycinnamylidenbenzalaceton, p-Methoxycinnamylidenbenzalaceton und Methylendioxycinnamylidenbenzalaceton neu. Sie wurden durch Kondensation von Benzalaceton mit den entsprechend substituierten Zimtaldehyden erhalten, welch letztere Kondensationsprodukte von m- bzw. p-Methoxybenzaldehyd und Piperonal mit Acetaldehyd sind. Die Darstellungsmethoden sind im experimentellen Teil der Arbeit genau beschrieben; dort befinden sich auch Angaben über die ebenfalls bisher noch unbekannten Ketone $p, p^{\prime}$-Dimethoxycinnamylidenbenzalaceton und $p, p^{\prime}$-Dimethoxydicinnamylidenaceton, deren Perchlorate zwar dargestellt, aber nicht analysiert wurden.

Nach der Analyse kommt nun allen Perchloraten der hier aufgezählten Ketone, ob diese keine oder eine bis vier Äthylenlücken, ob sie keine oder eine bis zwei Methoxygruppen oder etwa eine Nethylendioxygruppe enthalten, ein und dieselbe allgemeine Formel

$$
\mathrm{RR}^{\prime} \mathrm{CO}, \mathrm{HClO}_{4}
$$

zu, entsprechend einem Molekularverhältnis der Kompo- 
nenten gieich 1:1. Durch diese Tatsache werden wir aber zu der Annahme gedrängt, daß in den Perchloraten der Ketone das Säuremolekül $\mathrm{HClO}_{4}$ an die Carbonylgruppe und nicht etwa an eine Äthylenlücke oder eine Methoxygruppe gebanden ist.

Von den beiden noch möglichen Formulierungen

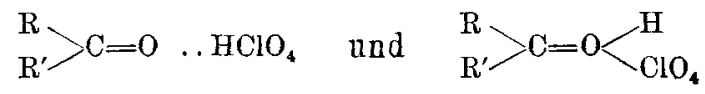

scheint nur die erstere annehmbar zu sein, indem nur sie die in den Farbenerscheinungen zutage tretende weitgehende Analogie zwischen den Perchloraten und den Zinntetrachloridadditionsprodukten auch in den Konstitutionsformeln scharf zum Ausdruck bringt.

Ein ähnliches Konstitutionsbild wie den Perchloraten kommt sicher auch den Verbindungen der Ketone mit den übrigen Säuren, wie Salzsäure, Salpetersäure, Schwefelsäure, Trichloressigsäure usw. zu, unabhängig davon, ob sie „überschüssige" Säuremoleküle enthalten oder nicht; denn die Farbenreaktionen der Ketone mit den verschiedenartigsten Säuren, so z. B. die Lösungsfarben der Ketone in Überchlorsäure und Schwefelsäure ${ }^{1}$ ), entsprechen einander so vollständig, daß sie vielfach mit blobem Auge nicht voneinander zu unterscheiden sind (vgl. hierzu die Angaben weiter unten). ${ }^{2}$ )

Wir müssen also den Säureverbindungen der Ketone die allgemeine Formel

$$
\mathrm{R}>\mathrm{C}=0 \ldots(\mathrm{HX})_{n}
$$

geben, indem wir annehmen, daß in solchen Fällen, in

1) Verbindungen mit ,überschüssigen" $\mathrm{H}_{2} \mathrm{SO}_{4}$-Molekülen sind z. B. $\left(\mathrm{C}_{6} \mathrm{H}_{5} \mathrm{C}_{2} \mathrm{H}_{2}\right)_{2} \mathrm{CO}, 3 \mathrm{H}_{2} \mathrm{SO}_{4}$ und $\left(\mathrm{CH}_{3} \mathrm{O} \cdot \mathrm{C}_{6} \mathrm{H}_{4} \cdot \mathrm{C}_{2} \mathrm{H}_{2}\right)_{2} \mathrm{CO}, 2 \mathrm{H}_{2} \mathrm{SO}_{4}$, Hoogewerff u. van Dorp, Zentralbl. 1903, II, S. 284.

2) Eine Anlagerung der überschüssigen "Säuremoleküle" an die Methoxyle ist schon deshalb nicht anzunehmen, weil eine solche Addition die bathochrome Natur dieser Gruppen vollständig aufheben würde (wie bei den Aminogruppen), so daß dann eine Farbenanalogie der Perchlorate und Sulfate ganz unmöglich wäre. 
denen ,überschüssige“ Säuremoleküle vorhanden sind, die Säuren im polymolekularen Zustand in Reaktion treten. Nach der Koordinationslehre ist diese Polymolekularität der Säuren so za verstehen, daß das Wasserstoffatom eines Säuremoleküls als Anlagerungszentrum für die übrigen Moleküle dient.

Nachdem es uns so gelungen ist, ein einheitliches Konstitutionsbild aller Metallsalz- und Säureverbindungen der Ketone $z u$ entwerfen, sollen im folgenden noch einige Farbgesetze der Halochromieverbindungen erörtert werden.

Die $\mathrm{SnCl}_{4}-\mathrm{Verbindungen}$ der Ketone werden am besten in krystallisiertem Zustand miteinander verglichen; die Halochromiefarben der Perchlorale lassen sich nur in Lösung erkennen, da die festen Produkte meist einen zu starken Oberflächenglanz besitzen, um einen Farbenvergleich zu gestatten. Die Sulfate wurden ebenfalls nur in Lösung untersucht.

Zunächst einige Daten über den Einfluß der Äthylenlücken auf die Farbe der Halochromieverbindungen:

$0,01 \mathrm{~g}$ Substanz, $2 \mathrm{cem}$ Eisessig, $1 / 2 \mathrm{ccm}$ konzentrierte $\mathrm{H}_{2} \mathrm{SO}_{4}$ bzw. $1 / 2 \mathrm{~cm} 70$ prozentige Überchlorsäure.

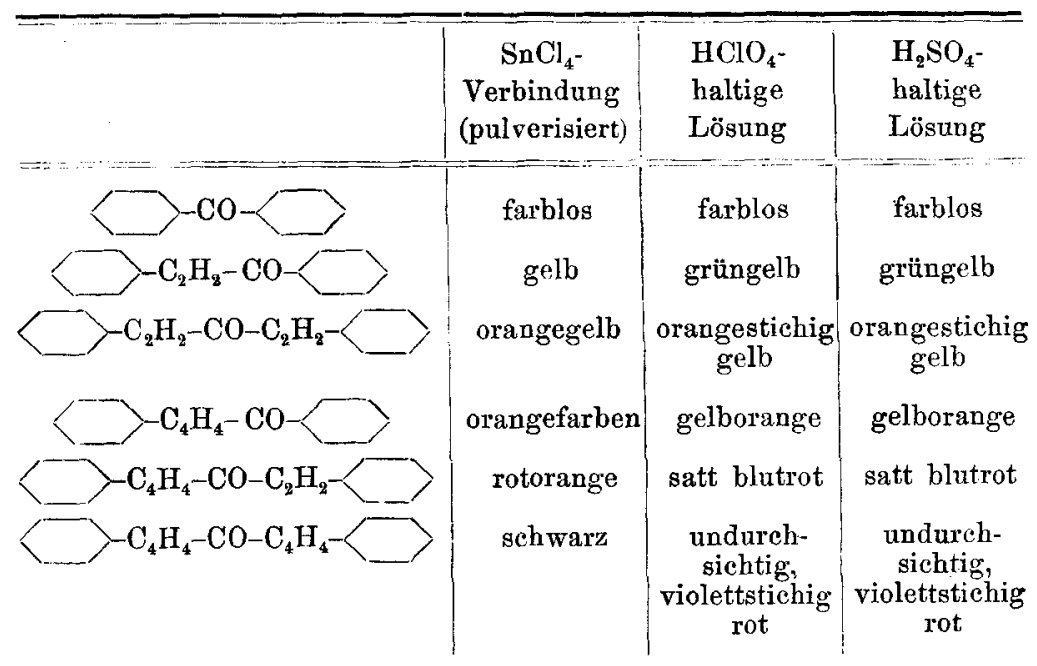


Wir entnehmen dieser Tabelle, daß, entsprechend unserer Theorie, die Halochromieverbindungen mit Metallsalzen und Säuren demselben Farbgesetz gehorchen; dasselbe lautet:

Treten in eine Halochromieverbindung zwischen Benzolkern und Carbonylgruppe Äthylenlücken ein, so findet eine systematische Vertiefung der Farbe statt. Hierbei wirken hintereinandergeschaltete Äthylenlücken stärker bathochrom als verteilte.

Zar Feststellung der Wirkung der Methoxyle wollen wir zunächst die Halochromieerscheinungen methoxylhaltiger gesättigter, dann die Halochromieerscheinungen methoxylhaltiger ungesättigter Aldehyde und Ketone besprechen.

Die Methoxybenzaldehyde und Methoxybenzophenone ergeben folgendes Bild:

\begin{tabular}{c|c}
\multicolumn{2}{c|}{ Methoxybenzaldehyde $\left.{ }^{2}\right)$} \\
\hline
\end{tabular}

\begin{tabular}{|c|c|}
\hline $0,03 \mathrm{~g}$ & $\begin{array}{c}\text { Lösung } \\
\text { in } 5 \text { cem konz. } \\
\mathrm{H}_{2} \mathrm{SO}_{4}\end{array}$ \\
\hline 0 & orange \\
\hline $\mathrm{m}$ & tiefgelb \\
\hline $\mathrm{p}$ & tiefgelb \\
\hline
\end{tabular}

Der Methoxylgruppe kommt also dann eine besonders starke bathochrome Wirkung zu, wenn sie in o-Stellung zum Carbonyl steht, in p-Stellung ist ihre Wirkung viel schwächer; die m-ständige $\mathrm{OCH}_{3}$-Gruppe schließt sich bald mehr der 0-, bald mehr der p-ständigen Gruppe an.

Interessant liegen die Verhältnisse bei den Methoxychalkonen:

1) Benzaldehyd selbst gibt eine farblose Verbindung mit $\mathrm{SnCl}_{4}$ und löst sich mit grünstichig gelber Farbe in konz. $\mathrm{H}_{2} \mathrm{SO}_{4}$.

$\left.{ }^{2}\right)$ Die Lösung von Benzophenon in konz. $\mathrm{H}_{8} \mathrm{SO}_{4}$ ist nahezu farblos. 


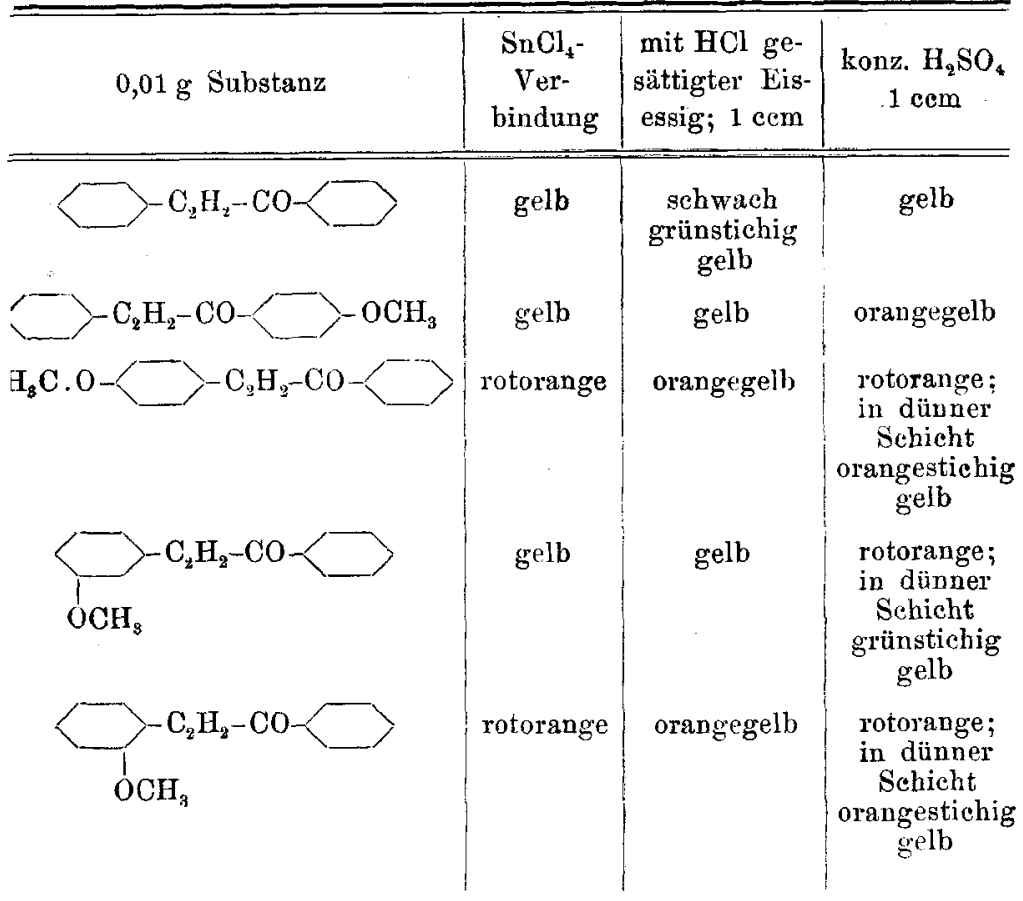

In Übereinstimmung mit dem Befund bei den Methoxybenzaldehyden und Methoxybenzophenonen konstatieren wir hier dann einen geringfügigen Einfluß des p-ständigen Methoxyls auf die Halochromiefarbe, wenn der substituierte Benzolkern in direkter Bindung mit dem Carbonyl steht. Ist aber zwischen das Carbonyl und den substituierten Benzolkern eine Äthylenlücke eingeschaltet, so ist die Wirkung des p-ständigen Methoxyls eine ganz erhebliche; das p-ständige Methoxyl stellt sich dann vollständig der 0-ständigen Gruppe an die Seite, während die $m$-ständige Gruppe in ihrer Wirkung hinter die 0 - und p-ständige zurücktritt.

Diese Verschiebung in der Bedeutung der verschiedenen Stellungen des Methoxyls für die Halochromiefarben findet ihren Abschluß bei den Methoxydibenzalacetonen. 
Farbige organische Molehülverbindungen.

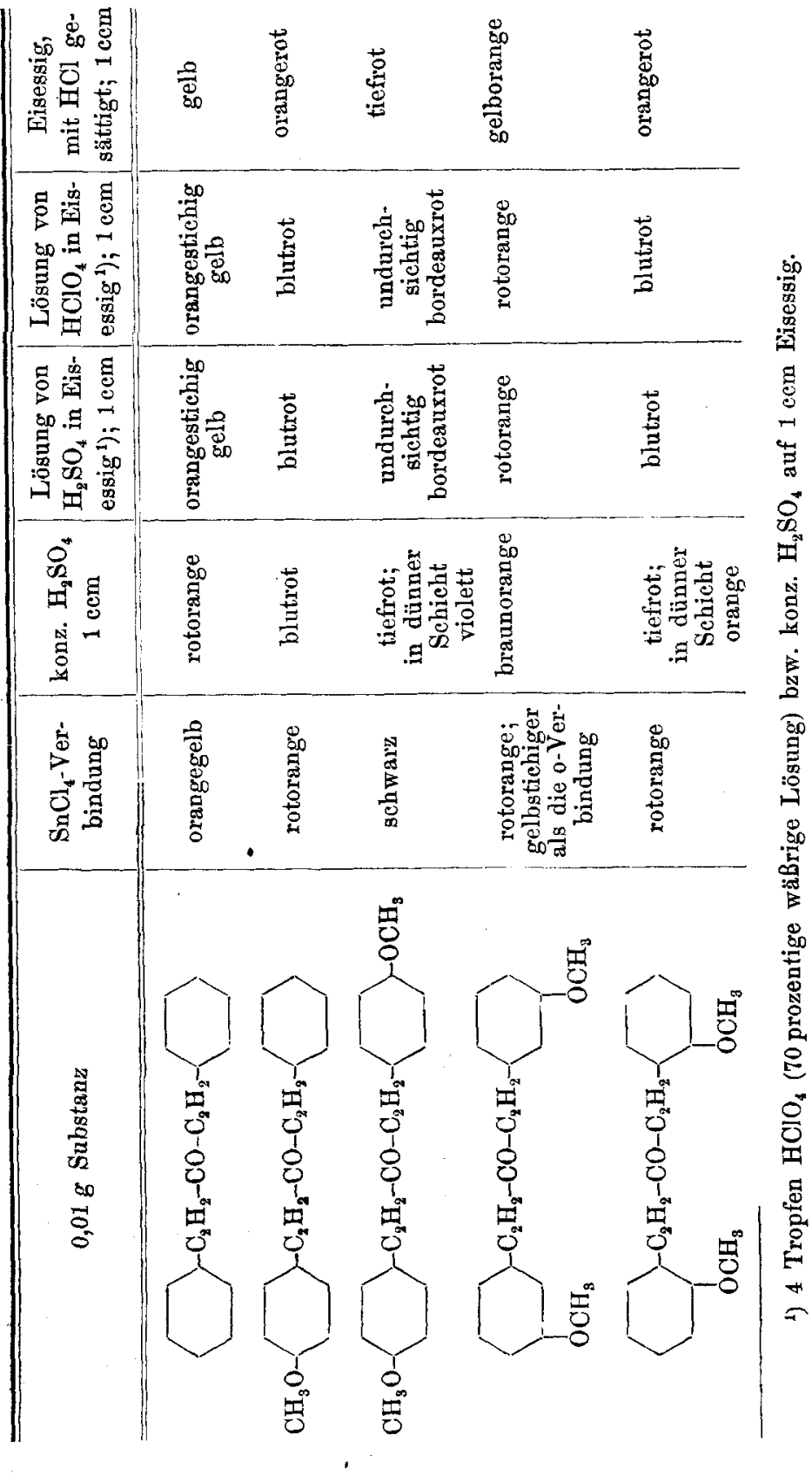


Die tiefsten Halochromiefarben finden wir jetzt bei der $\mathrm{p}$-Limethoxyverbindung, die wenigst tiefe beim $\mathrm{m}$-Isomeren; den Übergang zwischen beiden vermittelt die 0 -Verbindung.

Die Einschaltung einer zweiten Äthylenlücke zwischen Carbonyl und substituierten Benzolkern ändert den Charakter der Erscheinungen nicht weiter. So ist das Perchlorat der p-Methoxyverbindung

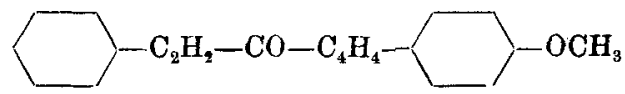

in Lösung rotstichig violett gefärbt, während die Perchloratlösungen der m-Methoxyverbindung

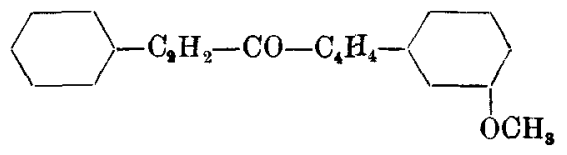

und des Grundkörpers

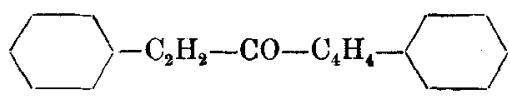
unter ganz den gleichen Bedingungen nur eine satt blutrote Farbe besitzen.

Die folgende kleine Tabelle, in der die Farben der Perchloratlösungen ${ }^{1}$ ) einer Reihe ungesättigter Ketone angegeben sind, zeigt uns sehr schön die starke bathochrome Wirkung, welche p-ständigen Methoxylen dann zukommt, wenn sie sich in Benzolkernen befinden, die durch Äthylenlücken vom Carbonyl getrennt sind.
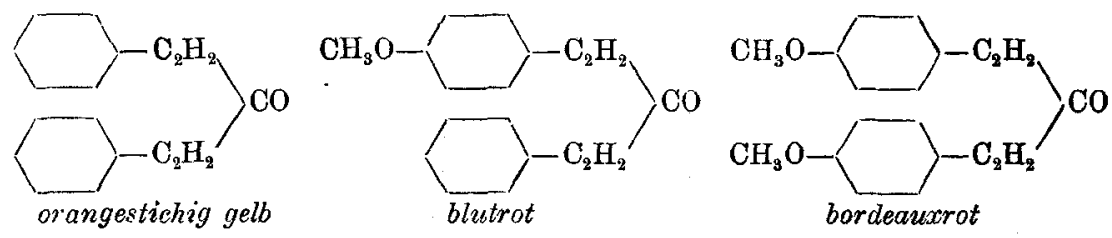

1) Die Farbenangaben beziehen sich auf Lösungen von je $0,01 \mathrm{~g}$ Substanz in $1 \mathrm{ecm}$ Eisessig, denen 4 Tropfen 70 prozentiger $\mathrm{HClO}_{4}$ zugesetzt wurden; gibt man za den Eisessiglösungen statt 4 Tropfen $\mathrm{HClO}_{4} 4$ Tropfen $\mathrm{H}_{2} \mathrm{SO}_{4}$ hinzu, so erhält man genau die gleichen Farben! 


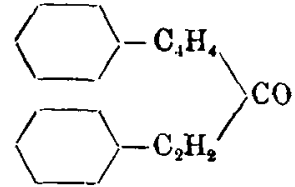

satt blutrot

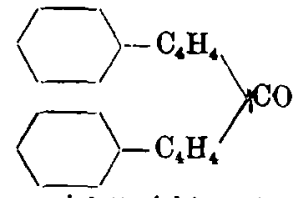

violettstichig rot

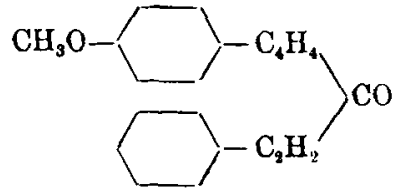

rotstichig violett
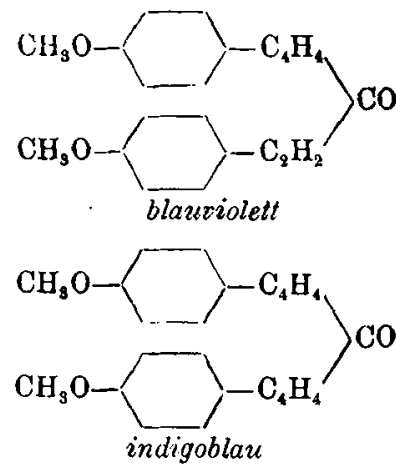

Sehr instruktiv ist in dieser Hinsicht auch eine Zusammenstellung von $\mathrm{SnCl}_{4}-V_{\text {erbindungen ungesättigter }}$ Ketone; wir erkennen eine weitgehende Analogie in der bathochromen Wirkung von Äthylenlücken und p-ständigen Methoxylen:

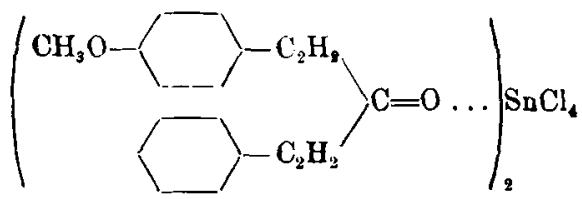

rotorange

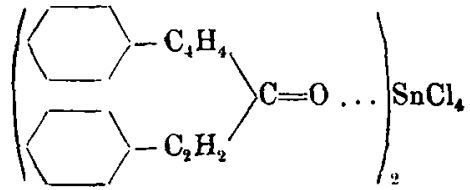

rotorange

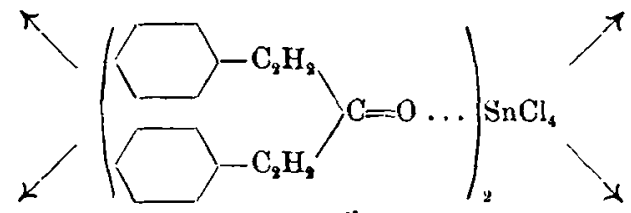

orangegelb

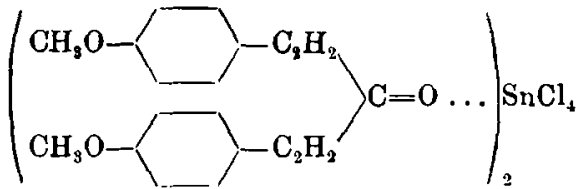

schwarz

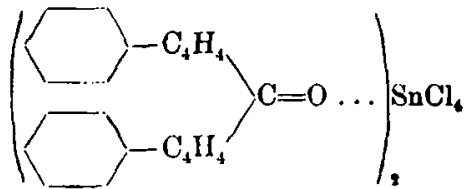

schwar $x$

Das wesentliche Ergebuis unserer Untersuchung über die Beeinflussung der Halochromieerscheinungen durch Methoxyle besteht nach alledem in der Feststellung des maßgebenden Einflusses, den die Art der Bindung 
des substituierten Benzolkerns ausübt. Ist der substituierte Benzolkern direkt an Carbonyl gebunden, so hat das Methoxyl dann eine besonders starke bathochrome Wirkung, wenn es sich in 0-Stellung, dann eine besonders schwache, wenn es sich in p-Stellung zum Carbonyl befindet; das m-ständige Methoxyl schließt sich in seiner Wirkung bald mehr der $0^{-}$, bald mehr der p-ständigen Gruppe an. Ist der substituierte Benzolkern durch eine oder mehrere Äthylenlücken vom Carbonyl getrennt, so verschiebt sich der bathochrome Effekt zugunsten des p-ständigen Methoxyls; die o-ständige Gruppe tritt in ihrer Wirkung hinter die p-ständige zurück; die m-ständige hat nun den geringsten Einfluß.

Die bathochrome Wirkung des Methoxyls nimmt also bei den Verbindungen R.CO. $\mathrm{C}_{6} \mathrm{H}_{4} \cdot \mathrm{OCH}_{3}$ in der Richtung $0 \rightarrow \mathrm{m} \rightarrow \mathrm{p}$, bei den Verbindungen R.CO. $(\mathrm{CH}=\mathrm{CH})_{n}$. $\mathrm{C}_{6} \mathrm{H}_{4} \cdot \mathrm{OCH}_{3}$ in der davon verschiedenen Richtung $\mathrm{p} \rightarrow 0$ $\rightarrow \mathrm{m}$ ab.

Es war von vornherein zu erwarten, daß die $\mathrm{OH}-$ Gruppen die Halochromieerscheinungen in der gleichen Weise beeinflussen wie die Methoxyle. In der Tat zeigen uns die folgenden Tabellen, daß wir bei den Oxyketonen, Oxyaldehyden und Oxysäuren auf dieselben Halochromieregeln stoßen, die wir von den Methoxyverbindungen her kennen. ${ }^{\mathbf{1}}$ )

Oxybensaldehyde

\begin{tabular}{c|c|c|c}
\hline & $\begin{array}{c}\mathrm{SnCl}_{4}- \\
\text { Verbindg. }\end{array}$ & $\begin{array}{c}\mathrm{H}_{2} \mathrm{SO}_{4^{-}} \\
\text {Lösung }\end{array}$ & $\begin{array}{c}\text { wäB. KOH } \\
\text { und } \\
\text { wäß. } \mathrm{NH}_{3}\end{array}$ \\
\hline 0 & gelb & orange & gelb \\
$\mathrm{m}$ & gelb & tiefgelb & gelb \\
farblos & hellgelb & farblos
\end{tabular}

Oxyacetophenone

\begin{tabular}{c|c|c} 
& $\begin{array}{c}\mathrm{H}_{2} \mathrm{SO}_{4^{-}} \\
\text {Lösung }\end{array}$ & $\begin{array}{c}\text { wäB. } \mathrm{KOH} \\
\text { und } \\
\text { wäB. } \mathrm{NH}_{3}\end{array}$ \\
\hline \hline 0 & tiefgelb & gelb \\
$\mathrm{m}$ & tiefgelb & $\begin{array}{c}\text { gelb } \\
\text { farblos }\end{array}$
\end{tabular}

1) Alle hier angefübrten Lösungsfarben beziehen sich auf streng vergleichbare Lösungen. Acetophenon, Benzophenon und Zimtsäure geben mit konz. $\mathrm{H}_{2} \mathrm{SO}_{4}$ fast farblose Lösungen. Xanthon gibt mit konz. $\mathrm{H}_{2} \mathrm{SO}_{4}$ eine blaßggelbe, Benzaldehyd eine grünstichig gelbe Lösung. 
Oxybenxophenone ${ }^{1}$ )

\begin{tabular}{c|c|c}
\hline \hline & $\begin{array}{c}\mathrm{H}_{2} \mathrm{SO}_{4}^{-} \\
\text {Verb. }\end{array}$ & $\begin{array}{c}\text { wäh. } \mathrm{NaOH} \\
\text { oder wäB. } \mathrm{NH}_{3}\end{array}$ \\
\hline m & $\begin{array}{c}\text { tiefgelb } \\
\text { tiefgelb }\end{array}$ & $\begin{array}{c}\text { tiefgelb } \\
\text { tiefgelb } \\
\text { (heller als bei o) } \\
\text { farblos }\end{array}$
\end{tabular}

Oxyxanthone ${ }^{2}$ )

\begin{tabular}{l|c|c}
\hline & $\begin{array}{c}\mathrm{H}_{2} \mathrm{SO}_{4}^{-} \\
\text {Lösung }\end{array}$ & $\begin{array}{c}\text { Na-Salz } \\
\text { Farbe }\end{array}$ \\
\hline 1-Oxy (o) & gelb & intensiv gelb \\
2-Oxy (m) & gelb & gelb \\
4-Oxy (m) & gelb & gelb \\
3-Oxy (p) & fast farblos & farblos
\end{tabular}

Oxynimtsäuren

\begin{tabular}{|c|c|c|}
\hline & $\mathrm{H}_{2} \mathrm{SO}_{4}$-Lösung & $\begin{array}{l}\text { wäBriges } \mathrm{KOH} \\
\text { und wäBr. } \mathrm{NH}_{3}\end{array}$ \\
\hline 0 & gelb & gelb \\
\hline $\mathrm{m}$ & blaßgelb & blaßgelb \\
\hline$p$ & orange & gelb \\
\hline
\end{tabular}

Von besonderem Interesse ist dabei die Tatsache, da $B$ sich die Oxyxanthone ganz den Oxybenzophenonen und Oxyacetophenonen anschließen, was nur dann verständlich ist, wenn man annimmt, dab sich die Addenden an den Carbonylsauerstoff und nicht etwa an den ätherartig gebundenen Brückensauerstoff anlagern.

In obigen Tabellen sind außer den Farben der $\mathrm{SnCl}_{4}$ und $\mathrm{H}_{2} \mathrm{SO}_{4}$-Verbindungen auch noch die Lösungsfarben der einzelnen Oxykörper in wäßrigem Alkali und wäßrigem Ammoniak angegeben. Aus der Gegenüberstellung von "Additionsfarben" und „Salzfarben" ergibt sich nun ohne weiteres die merkwürdige Tatsache, daß sich die beiden Farbenreihen weitgehend entsprechen, indem die Salz-

1) o-Verb.: Fast farblose Krystalle vom Schmelzp. 37-38 m-Verb. farblose Täfelchen vom Schmelzp. $38^{\circ} ; \mathrm{p}$-Verb. farblose Krystalle vom Schmelzp. $62^{\circ}$.

))

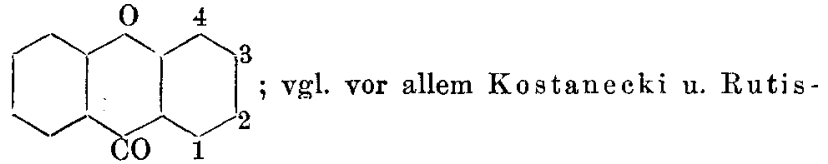

hauser, Ber. d. d. chem. Ges. 25, 1652 (1892). 
farben den gleichen Gesetzen gehorchen wie die Halochromieerscheinungen. Bei dem hentigen Stand unserer Kenntnisse läßt sich diese Parallelität wohl nur durch die Annahme erklären, daß in den Salzen das Metallatom koordinativ an den Carbonylsauerstoff gebunden ist, entsprechend der Formel:

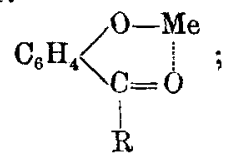

wir hätten es dann bei den Salzen mit intramolekularen Halochromieverbindungen zu tun.

Die hier erörterten Gesetzmäßigkeiten der Halochromieerscheinungen ungesättigter Ketone und verwandter Verbindungen erinnern in mancher Beziehung an bekannte Tatsachen aus der Chemie der Triphenylmethanfarbstoffe. Die Aminofuchsonimine haben nach Baeyer ${ }^{2}$ ) sämtlich eine wenig voneinander abweichende braune bis orange Farbe. Behandelt man sie mit Säuren, so entstehen durch Addition von Säuremolekülen „unter enormer Farbvertiefung" die sog. Farbsalze, die nun je nach der Zahl und Stellung der Aminogruppen charakteristische Farbunterschiede zeigen.

Genau das Gleiche haben wir aber bei den ungesättigten Methoxyketonen festgestellt; auch diese Verbindungen sind in ihrer gelblichen bis gelben Farbe nur wenig voneinander verschieden, geben aber, ähnlich wie die Fuchsonimine, mit Säuren tieffarbige, salzartige Additionsprodukte, deren Farbennuance je nach der Zahl und Stellung der Methoxyle charakteristisch wechselt.

Ein einfaches Beispiel möge das Gleichartige in der Farbsalzbildung und der Addition von Säuren an ungesättigte Nethoxyketone veranschaulichen:

1) Ber. d. d. chem. Ges. 37, 2878 (1904). 


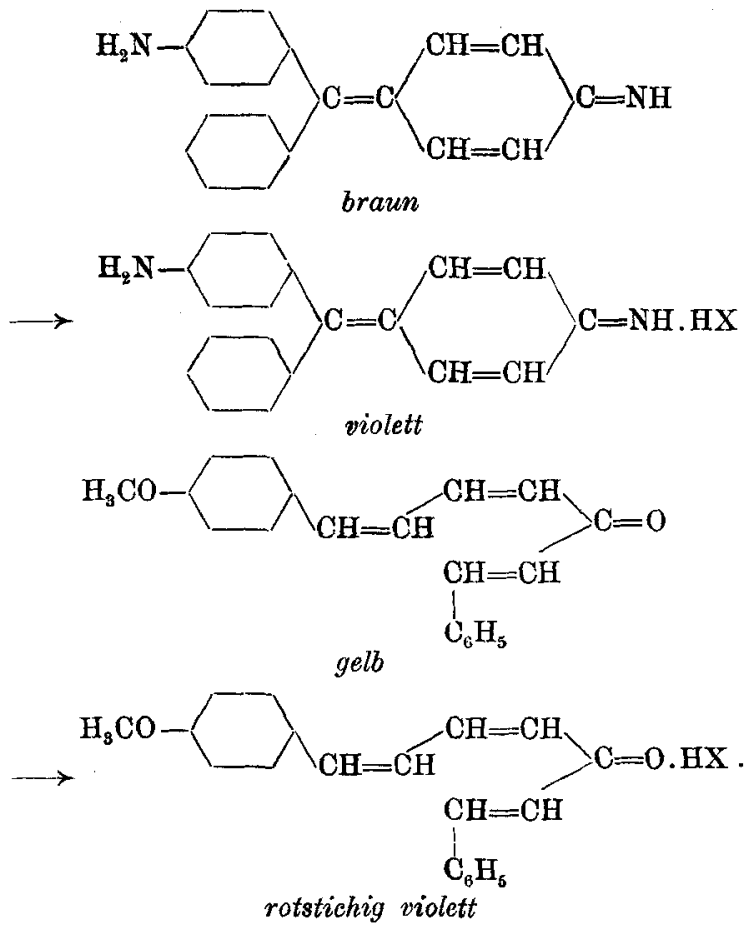

Dieser Vergleich zeigt uns sehr schön, daß wir in der Farbsalzbildung aus Fuchsoniminen eine ganz normale Halochromieerscheinung, und zwar eine solche von Ketiminen vor uns haben. $\left.{ }^{1}\right)$ Damit wird es auch verständlich, daß bei den Triphenylmethanfarbstoffen gerade die p-ständige Aminogruppe eine besonders starke bathochrome Wirkung ausübt. Bei diesen Farbstoffen (vgl. die obige Formel des Döbnerschen Violetts) ist nämlich der substituierte Benzolkern durch zwei Äthylenlücken von der Ketimingruppe getrennt. Von der Chemie der Halochromieverbindungen her wissen wir aber, dab der p-Substituent dann dem o- and m-Substituenten an bathochromer Wirkung überlegen ist, wenn zwischen Car-

1) Vgl. hierzn auch die bekannten Ausführungen von Baeyer u. Villiger, Ber. d. d. ehem. Ges. 35, 1189, 3013 (1902); 36, 2774 (1903); 37, 597, 2848, 3191 (1904); 38, 569, 1156 (1905). 
bonyl und substituierten Benzolkern äthylenlücken eingeschaltet sind.

In diesem Zusammenhang darf wohl auch darauf hingewiesen werden, dab nach Baejer ${ }^{1}$ ) Döbners Violett und das Kaliumsalz des p-Oxyfuchsons spektrochemisch fast identisch sind:
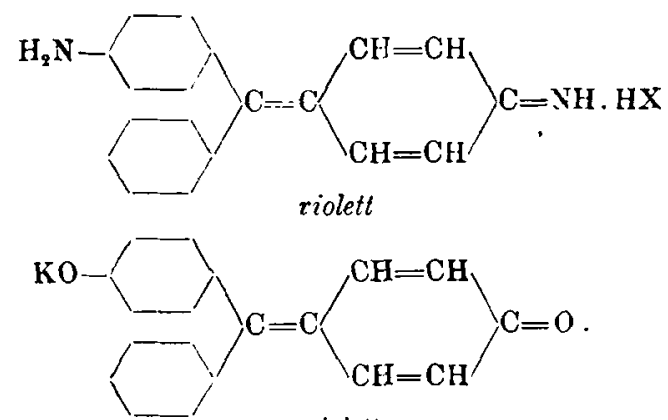

violelt

Da nach unserem Befund Alkalisalze und Halorhromieverbindungen der Oxyketone ganz allgemein identischen Farbgesetzen gehorchen (vgl. weiter oben), so deutet anch diese Tatsache auf den Charakter der Triphenylmethanfarbstofie als Halochromieverbindungen hin.

In einem ganz besonderen Zustande scheinen sich die freien Oxyfuchsone zu befinden. Fuchson und seine Oxyderivate Benzaurin und Aurin vereinigen sich als Ketone, wie die meisten übrigen Carbonylverbindungen, Jeicht mit Säuren. Folgende Salze der Fuchsonreihe konnten in gut krystallisierter Form isoliert werden:<smiles></smiles>

$$
\left(\begin{array}{l}
\mathrm{C}_{6} \mathrm{H}_{5} \\
\mathrm{C}_{6} \mathrm{H}_{5}>\mathrm{C}=\mathrm{C}_{6} \mathrm{H}_{4}=\mathrm{O} . \mathrm{H}
\end{array}\right)_{2} \mathrm{SnBr}_{6}
$$
rot nit grünem Glanz

$\left(\begin{array}{r}\mathrm{HO} . \mathrm{C}_{6} \mathrm{H}_{4} \\ \mathrm{C}_{8} \mathrm{H}_{6}\end{array}>\mathrm{C}=-\mathrm{C}_{6} \mathrm{HI}_{4}=\mathrm{J} . \mathrm{HI}\right)_{2} \mathrm{SnCl}_{6}$ orangefarben mit grïnem Glan:
$\left(\begin{array}{l}\mathrm{C}_{6} \mathrm{H}_{5} \\ \mathrm{C}_{6} \mathrm{H}_{5}\end{array}>\mathrm{C}=\mathrm{C}_{6} \mathrm{H}_{4}=0 . \mathrm{H}\right)_{2}^{\mathrm{SnCl}_{8}}$

rot mit grünem Glanx

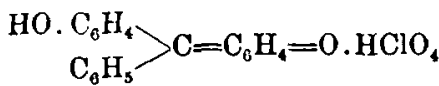
orangefarben mit grïnem Glanx $\left(\begin{array}{r}\mathrm{HO} . \mathrm{C}_{6} \mathrm{H}_{4} \\ \mathrm{C}_{6} \mathrm{H}_{5}\end{array}>\mathrm{C}=\mathrm{C}_{6} \mathrm{H}_{4}=\mathrm{O} . \mathrm{H}\right)_{2}^{\mathrm{SnBr}_{6}}$ rot mit griinem Glanz

1) Diese Anvalen 354, 152 (1907). 


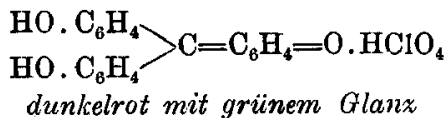

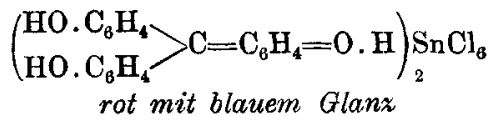

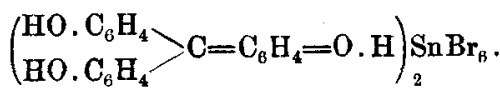

$$
\begin{aligned}
& \text { rot mit blauem Glanz }
\end{aligned}
$$

Man sollte nun erwarten, daß alle diese Verbindungen tieferfarbig als ihre Grundkörper sind. Das ist aber durchaus nicht der Fall. Zwar zeigen die Salze des Fuchsons gegenüber dem Fuchson selbst eine wenn auch geringe Farbvertiefung; in allen anderen Fällen aber sind die Salze weniger tieffarbig als ihre Grundkörper. ${ }^{1}$ ) Bei der.Addition von Säure an Benzaurin und Aurin tritt Farberhöhung und nicht Farbvertiefung ein. ${ }^{2}$ ) Die freien Oxyfuchsone müssen sich also in ihrer Konstitution wesentlich von den gewöhnlichen ungesättigten Oxyund Methoxyketonen unterscheiden. Darauf deutet auch schon ihre tiefe rote Farbe hin. Am einfachsten nimmt man an, daß die Fuchsone, bedingt durch intramolekulare Nebenvalenzabsättigung, chinhydronartig konstituiert sind; mit dieser Auffassung stehen alle bisher bekannten Eigenschaften der Oxyfuchsone in gutem Einklang.

\section{Experimenteller Teil.}

\section{a) Kohlenwasserstoffverbindungen der Chinone. ${ }^{9}$ )}

1. Verbindung von Monochlor-p-chinon mit Hexamethylbenzol,<smiles>CC(C)(C)OC1=CCC(=O)CC1</smiles>

Monochlorchinon wurde nach der Vorschrift von Levy und Schultz dargestellt. ${ }^{4}$ ) Gelbes, krystallinisches Pulver vom Schmelzp. $57^{\circ}$.

1) Zum Farbenvergleich müssen die Salze pulverisiert werden.

2) Vgl. hierzu vor allem K. A. Ho fmann, Ber, d. d. chem. Ges. 43, $184(1910)$, der schon das Perchlorat des Aurins beschrieben und auf die Farberhöhung hingewiesen hat.

3) Nach Versuchen von H. Mully.

4) Diese Annalen 210, 138 (1881). 
$0,2683 \mathrm{~g}$ gaben $0,2719 \mathrm{~g} \mathrm{AgCl}$.
$\mathrm{C}_{8} \mathrm{H}_{3} \mathrm{ClO}_{2}$ Ber. 24,89 .
Gef. 25,07 Proz. Cl.

Als eine Lösung von $0,14 \mathrm{~g}$ Monochlorchinon und $0,16 \mathrm{~g}$ Hexamethylbenzol (mol. Verh. 1:1) in wenig heißem Eisessig langsam erkaltete, schied sich ein Gemenge orangefarbener Nadeln und gelber Prismen aus; nun wurde die Hexamethylbenzol-Menge so lange vermehrt, bis (beim Molekularverhältnis 1:4) einheitliche große orangefarbene Nadeln auskrystallisierten. Schmelzpunkt nach dem Trocknen neben Natronkalk und Phosphorpentoxyd $99-103^{\circ}$. Bei längerer Aufbewahrung der Substanz tritt Zersetzung unter Aufhellung der Farbe ein.

$0,1671 \mathrm{~g}$ gaben $0,0802 \mathrm{~g} \mathrm{AgCl}$.

Ber. 11,64.

Gef. 11,87 Proz. Cl.

2. Verbindung von 2,5-Dichlor-p-chinon mit Durol.

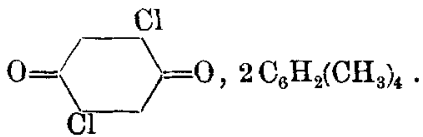

Darstellung des Dichlorchinons nach Ling. ${ }^{1}$ ) Gelbe Prismen vom Schmelzp. 158-161\%.

1 Mol. $(0,35 \mathrm{~g})$ Dichlorchinon und 1 Mol. $(0,27 \mathrm{~g})$ Durol wurden zusammen aus wenig heißem Eisessig krystallisiert. Fs schieden sich orangegelbe grobe Tafeln aus, vermengt mit gelben Prismen von Dichlorchinon. Erst anf Zusatz eines weiteren Moles $(0,27 \mathrm{~g})$ Durol gelang es, das Chinhydron einheitlich zu erhalten. Nach zweistündigem Trocknen neben Natronkalk und Phosphorpentoxyd im Vakuum schmolzen die Krystalle bei 82 bis $86^{\circ}$. Das Chinhydron ist nicht lange haltbar.

$0,3381 \mathrm{~g}$ gaben $0,2226 \mathrm{~g} \mathrm{AgCl}$.

Ber. 15,93.

Gef. 16,29 Proz. Cl.

1) Journ. Chem. Soc. 61, 558 (1892). 
3. Terbindung von 2,5-Dichlor-p-chinon mit Hexamethylbenzol.<smiles>CC(C)(C)OC1CCC(=O)CC1</smiles>

Man überläßt eine Lösung von $0,35 \mathrm{~g}$ Dichlorchinon und $0,49 \mathrm{~g}$ Hexamethylbenzol (mol. Verh. 2:3) in wenig heißem Eisessig der langsamen Krystallisation. Es scheiden sich hellrote Nadeln aus, welche neben Natronkalk und Phosphorpentoxyd im Vakuum getrocknet werden. Schmelzp. $132-136^{\circ}$. Der Körper ist einige Tage lang im Exsiccator haltbar.

$0,1858 \mathrm{~g}$ gaben $0,1549 \mathrm{~g} \mathrm{AgCl}$.

Ber. 20,91. Gef. 20,62 Proz. Cl.

4. Verbindung von Tetrachlor-p-chinon mit Hexamethylbenzol.<smiles>CCCOC(=O)C(Cl)Cl</smiles>

Aus der dunkelrotbraunen Lösung von $0,49 \mathrm{~g}$ Chloranil und $0,32 \mathrm{~g}$ Hexamethylbenzol (mol. Verh. 1:1) in heibem Eisessig krystallisieren beim langsamen Erkalten feine, lange Nadeln von violettbrauner Farbe mit rostfarbigem Obertächenglanz aus. Nach dem Trocknen in der üblichen Weise schmelzen die Krystalle bei 198 bis $202^{\circ}$. Das Chinhydron ist längere Zeit haltbar.

$0,1476 \mathrm{~g}$ gaben $0,2072 \mathrm{~g} \mathrm{AgCl}$.

Ber. $\mathbf{3 4 , 7 6 .}$

Gef. 34,73 Proz. Cl.

5. Verbindung von Tetrabrom-p-chinon mit Hexamethylbenzol.<smiles>CC(C)(C)OC1=C(Br)[C+]C(=O)C1Br</smiles>

Aus der dunkelrotbraunen Lösung von $0,50 \mathrm{~g}$ Bromanil und 0,32 $\mathrm{g}$ Hexamethylbenzol (mol. Verh. 1:1) in heißem Eisessig scheiden sich beim langsamen Erkalten 
dunkelviolettbraune, feine Nadeln mit rostfarbigem Oberfiächenglanz aus. Schmelzpunkt der getrockneten Krystalle $198-203^{\circ}$.

1. $0,1721 \mathrm{~g}$ gaben $0,2222 \mathrm{~g} \mathrm{AgBr}$.

2. $0,1469 \mathrm{~g}, 0,1893 \mathrm{~g} \mathrm{AgBr}$.

Ber. 54,57. Gef. 1 . 54,95 2. 54,84 Proz. Br.

6. Ferbiudung von Tetrachlor-o-chinon mit Benzol. ${ }^{1}$ )<smiles>CCC1C(=O)C(=O)C([GeH2])C1Cl</smiles>

Darstellung des Tetrachlor-0-chinons nach Jackson und Mac Laurin. ${ }^{2}$ ) Einzelheiten siehe in der Dissertation von H. Mully. Schmelzpunkt des reinen Produktes $129^{\circ}$.

$0,1513 \mathrm{~g}$ gaben $0,2414 \mathrm{~g} \mathrm{AgCl}$.

$0,3506 \mathrm{~g}, \quad 0,5602 \mathrm{~g} \mathrm{AgCl}$.

$\mathrm{C}_{6} \mathrm{Cl}_{4} \mathrm{O}$, Ber. 57,70. Gef- 57,32; 57,40 Proz. Cl.

Man löst Tetrachlor-o-chinon in wenig kaltem Benzol (die Substanz ist ungemein leicht löslich) und stellt die Lösung in ein schwaches Vakuum neben Paraffin. Nach kurzer Zeit scheiden sich tiefrote Krystalle von der Farbe des freien Tetrachlor-0-chiuons $a b$, welche auf gekühlten Tonplatten in einer Benzolatmosphäre kurze Zeit haltbar sind. Schmelzpunkt der Krystalle 37-42 ${ }^{\circ}$ an der Luft verwittern sie in wenigen Minuten.

1. $0,3363 \mathrm{~g}$ verloren im Vakuum $0,1645 \mathrm{~g}$ Benzol.

$2.0,3487 \mathrm{~g} \quad " \quad$ " $0,1677 \mathrm{~g} \quad$

Ber. 48,75. Gef. 48,91; 48,09 Proz. Benzol.

7. Verbindung von Tetrachlor-o-chinon mit Toluol.<smiles></smiles>

5) Siehe auch Cousin, Compt. rend. 129, 967 (1899).

2) Am. Chem. Journ. 39, 496 (1908). 
Aus der Lösung von Tetrachlor-0-chinon in reinem Toluol krystallisieren in einem schwach evakuierten Exsiccator neben Paraffin allmählich tiefrote, flache Nadeln aus. ${ }^{1)}$ Sie sind in einer Toluolatmosphäre längere Zeit haltbar, an der Luft verwittern sie jedoch in wenigen Minuten. In der Farbe unterscheidet sich die Toluolverbindung nicht von freiem Tetrachlor-0-chinon; ihr Schmelzpunkt liegt bei $45-50^{\circ}$.

Die Substanz wurde in schwachem Vakuum bei gewöhnlicher Temperatur zam Verwittern gebracht und dann bis zur Gewichtskonstanz im Trockenschrank auf $45^{\circ}$ erwärmt.

$0,2325 \mathrm{~g}$ verloren $0,0639 \mathrm{~g}$ Toluol.

Ber. 27,19. Gef. 27,48 Proz. Toluol.

8. Verbindung von Tetrachlor-o-chinon mit p-Xylol.

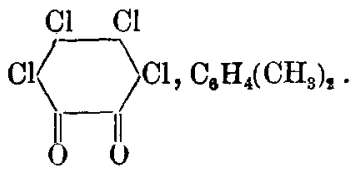

Die Verbindung krystallisiert aus einer Lösung von Tetrachlor-0-chinon in p-Xylol im Vakuum neben $\mathrm{Pa}$ raffin in tiefroten Prismen aus; sie werden etwa 3 Stunden lang auf Ton in einer Xylolatmosphäre getrocknet. In der Farbe unterscheidet sich dieses Chinhydron nicht von freiem Tetrachlor-o-chinon; es schmilzt unscharf bei $83^{\circ}$; an der Luft ist es nur einige Minuten lang haltbar. $0,0862 \mathrm{~g}$.

$0,2822 \mathrm{~g}$ gaben bei $45^{\circ}$ einen maximalen Gewichtsverlust von Ber. 30,15. Gef. 30,55 Proz. Xylol.

Das vollständig verwitterte Produkt schmolz bei $126-129^{\circ}$, zeigte also den Schmelzpunkt von Tetrachloro-chinon.

1) Jacks on und Mac Laurin, Am. Chem. Journ. 38, 168 (1 907). 
9. Verbindung von Tetrachlor-o-chinon mit Hexamethylbenzol.<smiles>CC(C)(C)[C@H]1[CH][C@@H](Cl)[C@H](Cl)C1=O</smiles>

Gießt man die kaltgesättigten Eisessiglösungen von $0,25 \mathrm{~g}$ Tetrachlor-0-chinon und 0,16 $\mathrm{g}$ Hexamethylbenzol zusammen, so erhält man eine braunschwarze Flüssigkeit, aus der sich allmählich grünschwarze, feine Nadeln ausscheiden. Die Krystalle schmelzen nach dem Trocknen auf Ton neben Natronkalk und Phosphorpentoxyd im Vakuum bei $140-143^{\circ}$; sie sind nur kurze Zeit beständig und gehen nach,und nach in ein weißes Pulver ïber. Auf folgendem Wege wurde gezeigt, daß in der Additionsverbindung unverändertes Hexamethylbenzol enthalten ist. Die Verbindung wurde in verdünntem wäßrigen Alkali aufgeschlämmt; dann wurde etwas Zinkstaub zugegeben und das Ganze schwach erwärmt. Sobald die Reduktion beendet, die chinoide Komponente also in Lösung gegangen war, wurde der Niederschlag abgesaugt, auf Ton getrocknet und mit Äther ausgezogen. Beim Verdunsten des $\ddot{A}$ thers hinterblieb in guter Ausbente eine weiße krystallinische Masse von Hexamethylbenzol, welche nach dem Umkrystallisieren aus Alkohol farblose glänzende Blättchen vom Schmelzp. 162-163 ${ }^{\circ}$ bildete (Schmelzpunkt des Rohprodukts $162^{\circ}$ ). Das so zurückgewonnene Hexamethylbenzol gab mit p-Chloranil und Eisessig die charakteristische braunrote Lösung.

1. $0,1631 \mathrm{~g}$ gaben $0,2308 \mathrm{~g} \mathrm{AgCl}$.

2. $0,2203 \mathrm{~g} " 0,3090 \mathrm{~g} \mathrm{AgCl}$.

Ber. 34,78. Gef. 1. 35,01 2. 34,70 Proz. Cl.

10. Verbindung von Phenanthrenchinon mit Hexamethylbenzol.

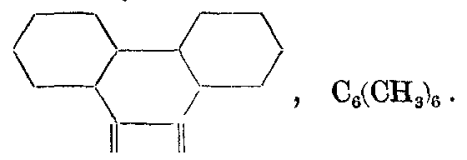


Aus der Lösung monomolekularer Mengen von Phenanthrenchinon und Hexamethylbenzol in heiBem Eisessig scheiden sich bald gat ausgebildete orangefarbene Krystallnadeln aus, welche wie üblich getrocknet werden.

Das Additionsprodukt ist kaum tieferfarbig als das freie Phenanthrenchinon; es schmilzt bei $160-163^{\circ}$; an der Luft hält es sich längere Zeit unverändert.

$0,3566 \mathrm{~g}$ verloren im Trockensehrank bei $100-110^{\circ} 0,1527 \mathrm{~g}$ an Gewicht; Phenanthrenchinon verflüchtigt sich bei dieser Temperatur nicht.

Ber. 43,80. Gef. 42,82 Proz. Hexamethylbenzol.

Schmelzpunkt des Rückstandes $204^{\circ}$; es bleibt also reines Phenanthrenchinon zurück.

b) Molekülverbindungen der Nitrokörper.

1. Perbindung des s-Trinitrobenzols mit Toluol. ${ }^{1}$ ) $\mathrm{C}_{6} \mathrm{H}_{3}\left(\mathrm{NO}_{2}\right)_{5}, \mathrm{C}_{6} \mathrm{H}_{5} . \mathrm{CH}_{3}$.

Man läßt die hellgrünstichig gelbe Lösung des Trinitrobenzols in siedendem Toluol langsam erkalten. Es krystallisieren fast farblose (schwach gelbstichige) lange Nadeln aus, welche anf Ton, neben Toluol, im Exsiccator getrocknet werden. - Der Körper verwittert an der Luft ungemein rasch; er ist nur in einer Toluolatmosphäre haltbar.

$0,6408 \mathrm{~g}$ (24 Stunden lang neben Toluol getrocknet) verloren im Vakuum über Paraffin 0,2083 g.

$0,4786 \mathrm{~g}$ (über Nacht neben Toluol getrocknet) gaben einen Gewiehtsverlust von $0,1437 \mathrm{~g}$.

Ber. 30,16. Gef. 32,50; 30,03 Proz. Toluol.

2. Verbindung des s-Trinitrobenzols mit p-Xylol.

$$
\mathrm{C}_{6} \mathrm{H}_{3}\left(\mathrm{NO}_{2}\right)_{3}, \mathrm{C}_{6} \mathrm{H}_{4}\left(\mathrm{CH}_{3}\right)_{2} \text {. }
$$

Beim Abkühlen der heißen Lösung des Trinitrobenzols in $\mathrm{p}$-Xylol krystallisieren hellgrünstichig gelbe

1) Die Verbindungen $1 \rightarrow 7$ dieses Abrchnitts wurden von Herm H. Mully, die übrigen von Frl. W. Jowleff hergestellt. 
Nadeln aus, welche auf Ton in einer Xylolatmosphäre getrocknet werden. Die Verbindung verwittert rasch an der Luft.

$0,8645 \mathrm{~g}$ gaben bei $45^{\circ}$ einen Gewichtsverlust von $0,3010 \mathrm{~g}$; $0,8681 \mathrm{~g}$ gaben bei $45^{\circ}$ einen Gewichtsverlust von $0,2881 \mathrm{~g}$.

Ber. 33,23. Gef. 34,82; 33,19 Proz. Xylol.

\section{Verbindung des s-Trinitrobenzols mit Durol. $\mathrm{C}_{6} \mathrm{H}_{3}\left(\mathrm{NO}_{2}\right)_{3}, \mathrm{C}_{6} \mathrm{H}_{2}\left(\mathrm{CH}_{3}\right)_{4}$.}

Man läßt eine Lösung von $0,21 \mathrm{~g}$ Trinitrobenzol und $0,13 \mathrm{~g}$ Durol in wenig heißem Eisessig langsam erkalten. Ausscheidung gut ausgebildeter, grünstichig gelber Blättchen, welche neben Phosphorpentoxyd und Natronkalk im Vakuum getrocknet werden. Schmelzp. 92-98 .

$0,2871 \mathrm{~g}$ gaben $31,3 \mathrm{ccm} \mathrm{N}\left(20,2^{\circ}, 729 \mathrm{~mm}\right)$.

Ber. 12,10 .

Gef. 12,18 Proz. N.

4. Ferbindung des s-Irinitrobenzols mit Hexamethylbenzol. $\mathrm{C}_{6} \mathrm{H}_{3}\left(\mathrm{NO}_{4}\right)_{3}, \mathrm{C}_{8}\left(\mathrm{CH}_{3}\right)_{6}$.

Aus einer Lösung von $0,21 \mathrm{~g}$ Trinitrobenzol und $0,16 \mathrm{~g}$ Hexamethylbenzol in wenig heißem Eisessig krystallisieren beim langsamen Erkalten gelbe Nadeln aus, welche häufig zu gekreuzten Büscheln vereinigt sind. Trocknen anf Ton neben Natronkalk und Phosphorpentoxyd im Vakuum. Schmelzp. 174-175\%.

$0,2065 \mathrm{~g} 21,2 \mathrm{cem} \mathrm{N}(720,5 \mathrm{~mm}, 21,5 \%$.

Ber. 11,20 .

Gef. 11,28 Proz. N.

5. Verbindung des s-Trinitrobenzols mit Stillien. ${ }_{2} \mathrm{C}_{6} \mathrm{H}_{3}\left(\mathrm{NO}_{z}\right)_{3}, \mathrm{C}_{6} \mathrm{H}_{3} . \mathrm{CH}=\mathrm{CH} . \mathrm{C}_{6} \mathrm{H}_{5}$.

Zur Darstellung dieses Additionsproduktes nimmt man zweckmäßig auf $1 \mathrm{Mol}$. Stilben $1 \frac{1}{2}$ Mol. Trinitrobenzol. Aus der rein gelben, heißen Eisessiglösung der Komponenten scheiden sich beim langsamen Erkalten 1-2 cm lange, goldgelbe Nadeln ab, die häufig Durchkreuzungszwillinge bilden. Sobald etwa $1 / 3$ der angewandten Substanz auskrystallisiert ist, saugt man rasch 
ab und bringt die Krystalle auf Ton neben Natronkalk und Phosphorpentoxyd ins Vakuum. Schmelzpunkt unscharf bei $107-110^{\circ}$.

$0,1149 \mathrm{~g} 14,55 \mathrm{cem} \mathrm{N}\left(709 \mathrm{~mm}, 18,5^{\circ}\right)$.

Ber. 13,84

Gef. 13,83 Proz. N.

6. Verbindung des s-Trinitrobenzols mit Hexamethyistilben. $\mathrm{C}_{8} \mathrm{H}_{3}\left(\mathrm{NO}_{2}\right)_{8},\left(\mathrm{CH}_{3}\right)_{3} \mathrm{C}_{6} \mathrm{H}_{2} \cdot \mathrm{CH}=\mathrm{CH} . \mathrm{C}_{6} \mathrm{H}_{2}\left(\mathrm{CH}_{8}\right)_{3}$.

Hexamethylstilben wurde nach Eilbs') ausgehend von Pseudocumol und Chloralhydrat dargestellt. Feine weiße Nadeln vom Schmelzp. 159-161 .

Wegen der Schwerlöslichkeit des Hexamethylstilbens in Eisessig muß man zur Gewinnung des Additionsproduktes einen großen Überschuß an Trinitrobenzol anwenden. Man läßt die heiße Lösung von $0,13 \mathrm{~g}$ Hexamethylstilben und $0,85 \mathrm{~g}$ Trinitrobenzol in wenig Eisessig (mol. Verh. der Komponenten 1:8) langsam erkalten. Aus der roten Fü̈ssigkeit scheiden sich zinnoberrote Prismen ab, welche wie üblich getrocknet werden. Schmelzp. $145-147^{\circ}$ unter Dunkelrotfärbung.

$0,2041 \mathrm{~g} 16,3 . \mathrm{ccm} N\left(726 \mathrm{~mm}, 17^{\circ}\right)$.

$$
\text { Ber. 8,80. Gef. } 8,98 \text { Proz. N. }
$$

7. Verbindung von s-I'rinitrobenzol mit $p, p^{\prime}$-Dimethorystillen. $2 \mathrm{C}_{6} \mathrm{H}_{3}\left(\mathrm{NO}_{2}\right)_{3}, \mathrm{H}_{3} \mathrm{CO} \cdot \mathrm{C}_{6} \mathrm{H}_{4} \cdot \mathrm{CH}=\mathrm{CH} . \mathrm{C}_{6} \mathrm{H}_{4} \cdot \mathrm{OCH}_{3}$.

Die Darstellung des $p, p^{\prime}-$ I)imethoxystilbens geschah nach der Vorschrift ron Elbs, ${ }^{2}$ ) ausgehend von Anisol und Chloralhydrat. Schmelzpunkt der farblosen Krystalle $212^{\circ}$.

Man läßt die tiefrote Tösung von 0,1己 g Dimethoxystilben und $0,85 \mathrm{~g}$ 'Trinitrobenzol in siedendem Fisessig (mol. Verh. der Komponenten 1:8) langsam erkalten. Zunüchst scheiden sich weiße Blättchen von Dimethoxystilben aus; diese sind nach 24 stündigem Stehen wieder verschwunden und in schöne rote Nadeln des Additions-

1) Journ. f. prakt. Chem. [2] 47, 51 (1893),

2) Journ. f. prakt. Chein. $[2\} 47$, 68 (1893). 
produktes übergegangen. Sie schmelzen, im Vakuum neben Natronkalk und Phosphorpentoxyd getrocknet, bei $145-155^{\circ}$ unter Zersetzung.

$0,2288 \mathrm{~g} 25,5 \mathrm{ccm} \mathrm{N}\left(729 \mathrm{~mm}, 16^{\circ}\right)$.

Ber. 12,60 .

Gef. 12,63 Proz. N.

8. Verbindung des o,p-Dinitrodesoxybenzoins mit Anilin.

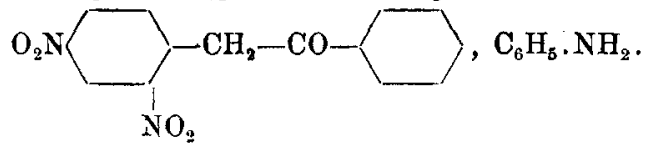

Darstellung des Dinitrodesoxybenzoins.

$o, p-D i n i t r o d e s o x y b e n z o i n$ wurde auf folgendem Wege erhalten: ${ }^{1}$ )

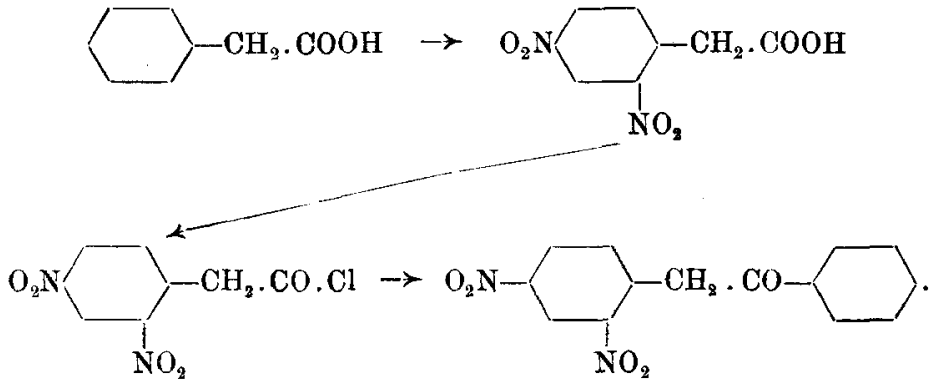

Die Nitrierung der Phenylessigsäure erfolgte nach der Vorschrift von Gabriel und Meyer ${ }^{2}$ ) mit rauchender Salpetersäure; Schmelzpunkt der Dinitrophenylessigsäure $180^{\circ}$. Durch Lösen der Dinitrosäure in heißem Thionylchlorid, Verdunsten des überschüssigen Lösungsmittels und Waschen des Rückstands mit $\ddot{\text { Ather wurde }}$ das Chlorid

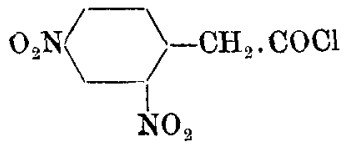

1) Diese von Frl. Jowleff in ihrer Dissertation (Zürich 1911) beschriebene Darstellungsweise ist inzwischen auch von $W$. Borsche, diese Annalen 390, 1 (1912), angegeben worden. Es sollen hier nur einige Daten zur Ergänzung der Borscheschen Angaben mitgeteilt werden.

2) Ber. d. d. chem. Ges. 14, 823 (1881). 
erhalten; bräunlichgelbe Blättchen vom Schmelzp. 64 bis $65^{\circ}$. Eine Chlorbestimmung gab folgendes Resultat:

$0,1225 \mathrm{~g}$ gaben $0,0685 \mathrm{AgCl}$.

$$
\begin{aligned}
& \text { Ber. für } \mathrm{C}_{8} \mathrm{H}_{5} \mathrm{O}_{5} \mathrm{~N}_{2} \mathrm{Cl} \quad \text { Gef. } \\
& \mathrm{Cl} \quad \mathbf{1 4 , 5 2} \quad 13,95
\end{aligned}
$$

Die Umwandlnng des Chlorids in Dinitrodesoxybenzoin geschah mit Benzol and Aluminiumchlorid. Das reine Keton bildet gelbliche, glänzende Nadeln vom Schmelzp. $135^{\circ}$ (nach Borsche 135-136 $)$, die mit alkoholischem Kali eine tiefviolette, mit alkoholischem Ammoniak eine violettrote Lösung geben. 0,01 g Substanz werden von $1 / 2 \mathrm{ccm}$ Anilin mit orangegelber, von $1 / 2 \mathrm{ccm}$ Dimethylanilin und geschmolzenem Diphenylamin mit orangeroter Farbe aufgenommen; geschmolzenes Acetanilid gibt eine blaß bräunlichgelbe Lösung.

Zur näheren Charakterisierung haben wir unseren Körper noch in das zugehörige Oxim verwandelt: Eine alkoholische Lösung von $1 \mathrm{Mol}$ Dinitrodesoxybenzoin wurde mit 3 Molen salzsaurem Hydroxylamin 12 Stunden lang im Einschmelzrohr auf $130-140^{\circ}$ erwärmt. Das Reaktionsprodukt wurde in Wasser gegossen und der gelbe Niederschlag aus Alkohol umkrystallisiert. Gelbliche Nadeln vom Schmelzp. 137-139 ${ }^{\circ}$, die mit alkoholischem Kali eine dunkelolivengrüne Lösung geben. Beim Erwärmen des Oxims mit alkoholischer Salzsäure bildet sich das Keton zurück.

$0,1168 \mathrm{~g}$ gaben $14,8 \mathrm{ccm}$ Stickgas bei $21^{\circ}$ und $722 \mathrm{~mm}$ Druck. $0,0955 \mathrm{~g} \quad, 12,0 \mathrm{ecm} \quad " 17^{\circ}, 724 \mathrm{~mm}$ " Ber. für $\mathrm{C}_{14} \mathrm{H}_{11} \mathrm{O}_{6} \mathrm{~N}_{3} \quad$ Gef.

$$
\text { N } 14,00 \quad 13,9814,09
$$

Anhangsweise sei noch erwähnt, daß sich das Dinitrophenylessigsäurechlorid mit Anilin in das Anilid

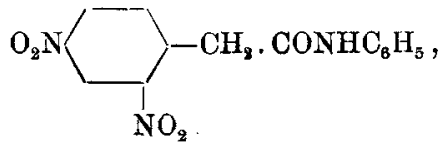

mit Phenylhydrazin in das Phenylhydrazid

Annalen der Chemie 412, Band. 


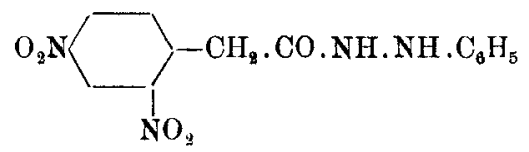

überführen läbt. Der erstere Körper bildet kleine gelbe Nadeln vom Schmelzp. $181-182^{\circ}$, die von alkoholischem Kali mit tiefgrünbrauner Farbe aufgenommen werden; der letztere besteht aus hellgelben, glänzenden Nadeln vom Schmelzp. $174-176^{\circ}$, die sich in alkoholischem Kali undurchsichtig violett lösen.

Anilid:

$0,1485 \mathrm{~g}$ gaben $19,0 \mathrm{cem}$ Stickgas bei $19^{\circ}$ und $721 \mathrm{~mm}$ Druck.

Phenylhydrazid:

$0,1147 \mathrm{~g}$ gaben $18,3 \mathrm{ccm}$ Stiekgas bei $20^{\circ}$ und $725 \mathrm{~mm}$ Druck.

$$
\begin{array}{ccc} 
& \text { Ber. } \mathrm{C}_{\mathbf{1 4}} \mathrm{H}_{\mathbf{2 2}} \mathrm{O}_{5} \mathrm{~N}_{4} & \text { Gef. } \\
\mathrm{N} & \mathbf{1 7 , 7 6} & 17,73
\end{array}
$$

Darstellung des Additionsproduktes.

Aus einer Lösung des Dinitrodesoxybenzoins in Anilin scheiden sich neben $\mathrm{P}_{2} \mathrm{O}_{5}$ allmählich goldgelbe Blättchen vom Schmelzp. etwa $91^{\circ}$ aus. An der Luft verwittert das Additionsprodukt nach einiger Zeit zu einem fast farblosen Pulver.

0,2481 g gaben 26,0 ecm Stickgas bei $21^{\circ}$ und $701 \mathrm{~mm}$ Druck.

$$
\mathrm{N} \begin{array}{cc}
\text { Ber. für } \mathrm{C}_{14} \mathrm{H}_{10} \mathrm{O}_{5} \mathrm{~N}_{2}, \mathrm{C}_{6} \mathrm{H}_{5} \mathrm{NH}_{2} & \text { Gef. } \\
11,08 & 11,22
\end{array}
$$

$0,0821 \mathrm{~g}$ gaben, nach dem Behandeln mit verd. $\mathrm{HCl}$ und Trocknen des Rückstands bei etwa $80^{\circ}, 0,0621 \mathrm{~g}$ Keton.

$$
\begin{array}{ccc}
\text { Ber. für } \mathrm{C}_{14} \mathrm{H}_{10} \mathrm{O}_{5} \mathrm{~N}_{2}, \mathrm{C}_{6} \mathrm{H}_{5} \mathrm{NH}_{2} & \text { Gef } \\
\text { Keton } & 75,46 & 75,64
\end{array}
$$

Aus den Liösungen des Dinitrodesoxybenzoins in o-Toluidin und Dimethylanilin krystallisiert beim Verdunsten bei gewöhnlicher Temperatur unverändertes Keton aus. 
9. Verbindung des o,p-Dinitro-p'-methyldesoxybenzoins mit Anilin.

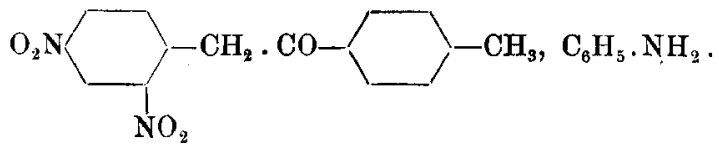

Darstellung des Dinitromethyldesoxybenzoins. Man schlämmt 4,5 g o,p-Dinitrophenylessigsäu rechlorid in trocknem Schwefelkohlenstoff auf, gibt $5 \mathrm{~g}$ Toluol und nach und nach $10 \mathrm{~g}$ Aluminiumchlorid hinzu und läßt das Ganze 24 Stunden stehen. ${ }^{1}$ ) Dann erwärmt man das Reaktionsgemisch 6-8 Stunden lang auf dem Wasserbad und gießt es in angesäuertes Wasser. Sobald sich nach Zusatz von Benzol bei schwachem Erwärmen zwei klare Schichten gebildet haben, hebt man die obere ab und stellt sie ins Vakuum. Den Benzolrückstand verreibt man zur Entfernung öliger Bestandteile mit etwas Äther; dann preßt man ihn auf .Ton ab und krystallisiert ihn aus Alkohol, der etwas $\mathrm{HCl}$ enthält, um. Die Ausbeute ist schlecht und sehr wechselnd.

Hellbräunlichgelbe Nadeln, die bei $135-136^{\circ}$ schmelzen ${ }^{2}$ ); sie sind in Benzol und Alkohol gut löslich, in Ligroin Jösen sie sich schwer.

$0,1380 \mathrm{~g}$ gaben $12,0 \mathrm{cem}$ Stickgas bei $22^{\circ}$ und $721 \mathrm{~mm}$ Druck.

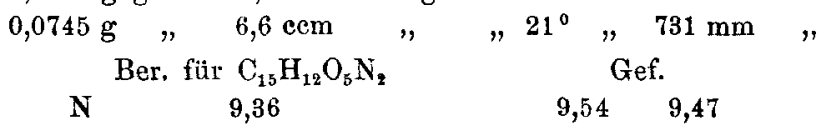

Bei einer Darstellung wurde das Dinitromethyldesoxybenzoin in Form hellgelber Blättchen bzw. flacher Nadeln vom Schmelzp. 95-96 erhalten; nach einigen Wochen betrug der Schmelzpunkt der Substanz 135 bis $136^{\circ}$, so daß Umlagerung in die normale Form eingetreten

1) Erwärmt man sofort, so tritt eine außerordentlich heftige Reaktion ein.

2) Eine Mischprobe des Dinitromethyldesoxybenzoins (F. = $\left.135-136^{\circ}\right)$ und des Dinitrodesoxybenzoins $\left(F .=135^{\circ}\right)$ schmilzt bei etwa $114^{\circ}$, zeigt also starke Depression. 
war. Alle Versuche, die Bildungsbedingungen der labilen Modifikation festzustelien, waren bisher vergeblich.

In seinen Farbenreaktionen entspricht das Dinitromethyldesoxybenzoin vollständig dem methylfreien Körper.

Darstellung des Additionsproduktes.

Aus einer konz. Lösung des Ketons in Amilin scheiden sich allmählich gelbe, blättchenförmige Nadeln ans, die bei $68^{\circ}$ schmelzen; sie wurden zur Analyse auf Ton an der Luft getrocknet.

$0,1128 \mathrm{~g}$ gaben bei vorsichtigem Erhitzen einen Gewichtsverlust von $0,0268 \mathrm{~g}$.

$$
\text { Ber.: 23,66. Gef.: 23,76 Proz. Anilin. }
$$

Aus der orangefarbenen Lösung des Ketons in 0-Toluidin krystallisiert beim Verdunsten unverändertes Keton aus.

10. Verbindung des o,p-Dinitro-p'-methoxydesoxybenzoins mit. Anilin.

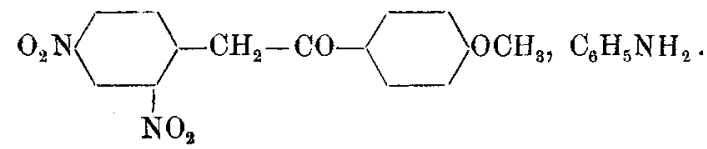

Darstellung des Ketons. Man schlämmt 0,p-Dinitrophenylessigsäurechlorid in trocknem Schwefelkohlenstoff auf und gibt $1 \frac{1}{2}-2 \mathrm{Mol}$. Anisol hinzu und so viel Aluminiumchlorid, wie das Gesamtgewicht von Säurechlorid und Anisol beträgt. Nach etwa 12 stündigem Stehen bei gewöhnlicher Temperatur erhitzt man das Reaktionsgemisch 6-8 Stunden lang anf dem Wasserbad und gießt es in Wasser. Man säuert an, fügt Benzol hinzu und erwärmt so lange, bis sich zwei klare Schichten gebildet haben. Die obere Schicht enthält das gesuchte Keton; durch Umkrystallisieren des Verdunstungsrückstandes ans Alkohol wird es in reiner Form gewonnen.

Durchsichtige, gelbliche Nadeln, die bei $101--103^{\circ}$ schmelzen; sie sind spielend löslich in Aceton, gut löslich in Benzol, Alkohol und $\ddot{A}$ ther; in Ligroin lösen sie sich nur wenig. 
Die Farbenreaktionen dieses Ketons entsprechen denen der methoxylfreien Verbindung.

$0,1022 \mathrm{~g}$ gaben $8,5 \mathrm{cem}$ Stiekgas bei $17^{\circ}$ und $717 \mathrm{~mm}$ Druek. $0,1006 \mathrm{~g} \quad 7,9 \mathrm{~cm} \quad, 20^{\circ}, 730 \mathrm{~mm}$ Druek.

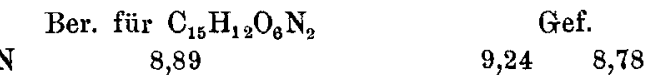

Darstellung des Additionsproduktes. Aus einer konz. orangefarbenen Lösung des Ketons in Anilin scheiden sich bei gewöhnlicher Temperatur allmählich gelbe, glänzende, blättchenförmige Nadeln $a b$; sie schmelzen unter vorhergehendem Sintern bei etwa $87^{\circ}$. An der Luft verwittern sie.

$0,1333 \mathrm{~g}$ gaben bei vorsichtigem Erhitzen einen Gewichtsverlust von $0,0301 \mathrm{~g}$.

Ber : 22,74. Gef.: 22,58 Proz. Anilin.

Mit o-Toluidin gibt das Keton kein festes Additionsprodukt.

\section{Verbindung des 2,4,6-Trinitrostilbens mit Benzol. $\mathrm{C}_{6} \mathrm{H}_{8}\left(\mathrm{NO}_{2}\right)_{9} . \mathrm{CH}=\mathrm{CH} . \mathrm{C}_{8} \mathrm{H}_{5}, \mathrm{C}_{8} \mathrm{H}_{6}$.}

Darstellung des Trinitrostilbens und des Benzoladditionsproduktes siehe Pfeiffer und Monath. ${ }^{1}$ )

$0,1740 \mathrm{~g}$ zeigten bei etwa $80^{\circ}$ einen Gewichtsverlust von $0,0344 \mathrm{~g}$ Ber.: 19,85 .

Gef: 19,77 Proz. Benzol.

12. Verbindung des 2,4,6-Trinitrostilbens mit Anilin.

$$
\mathrm{C}_{6} \mathrm{H}_{2}\left(\mathrm{NO}_{3}\right)_{8} \cdot \mathrm{CH}=\mathrm{CH} \cdot \mathrm{C}_{6} \mathrm{H}_{5}, \mathrm{C}_{6} \mathrm{H}_{5} \cdot \mathrm{NH}_{2} \text {. }
$$

Scheidet sich beim Erkalten der heißen Lösung des Trinitrostilbens in Anilin in schönen, orangeroten, blättchenförmigen Krystallen ab. Sie schmelzen bei 103 bis $105^{\circ}$ und verwittern an der Luft in einigen Tagen zu einem gelben Pulver von Trinitrostilben.

$0,1998 \mathrm{~g}$ gaben beim Behandeln mit wäBriger Salzsäure 0,1536 $\mathrm{g}$ Trinitrostilben.

Ber.: 77,21 .

Gef.: 76,88 Proz. Trinitrostilben.

1) Ber. d. d. chem. Ges. 39, 1306 (1906). 
13. Verbindung des 2,4,6-Trinitrostilbens mit Dimethylanilin. $\mathrm{C}_{6} \mathrm{H}_{2}\left(\mathrm{NO}_{2}\right)_{3}$. $\mathrm{CH}=\mathrm{CH} . \mathrm{C}_{6} \mathrm{H}_{5}, \mathrm{C}_{6} \mathrm{H}_{5} \mathrm{~N}\left(\mathrm{CH}_{3}\right)_{2}$.

Die Verbindung krystallisiert aus einer Lösung des Trinitrostilbens in Dimethylanilin in violettbraunen Blättchen. Sie schmelzen gegen $120^{\circ}$ und verwittern an der Luft allmählich.

$0,1706 \mathrm{~g}$ gaben beim Erhitzen auf etwa $100^{\circ}$ eineu Gewichtsverlust von $0,0478 \mathrm{~g}$.

Ber.: 27,75. Gef.: 28,02 Proz. Dimethylanilin.

\section{Terlindung des 2,4,6-Trinitrostilbens mit o-Toluidin.}

$$
\mathrm{C}_{8} \mathrm{H}_{2}\left(\mathrm{NO}_{2}\right)_{3} . \mathrm{CH}=\mathrm{CH} . \mathrm{C}_{6} \mathrm{H}_{5}, \mathrm{C}_{6} \mathrm{H}_{4}\left(\mathrm{CH}_{3}\right) \mathrm{NH}_{2} \text {. }
$$

Entsteht beim Erkalten der heißen Lösung des Trinitrostilbens in o-Toluidin. Rote, glänzende Blättchen, die auf Ton an der Luft getrocknet werden; sie schmelzen bei etwa $120^{\circ}$ zu einer roten Flüssigkeit; an der Laft verwittern sie allmählich zu einem gelben Pulver. $0,0313 \mathrm{~g}$.

$0,1230 \mathrm{~g}$ gaben beim Erhitzen einen Gewichtsverlust von Ber.: 25,36. Gef.: 25,45 Proz. o-Toluidin.

\section{c) Verbindungen der Ketone mit Zinnchlorid. ${ }^{1}$ )}

1. Di-benzal(-p-)methoxyacetophenon-zinntetrachlorid. $\mathrm{SnCl}_{4}, 2 \mathrm{C}_{6} \mathrm{H}_{5} . \mathrm{CH}=\mathrm{CH}, \mathrm{CO}, \mathrm{C}_{6} \mathrm{H}_{4} . \mathrm{OCH}_{8}, \mathrm{C}_{6} \mathrm{H}_{6}$.

Benzal-p-methoxyacetophenon wurde nach Stockhausen and Gattermann ${ }^{2}$ ) durch Kondensation von Zimtsäurechlorid mit Anisol erbalten; es bildet hellgraustichig gelbe Nadeln vom Schmelzp. 107. - Zur Darstellung des Additionsproduktes wurde zu einer Lösung des Methoxychalkons in absolutem Benzol eine Benzollösung von Zinntetrachlorid gegeben. Die Mengen der Komponenten betrugen bei Versuch I: $1 \mathrm{~g}$ Keton, $0,5 \mathrm{~g} \mathrm{SnCl}_{4}$ (mol. Verh. etwa 2,2:1), bei Versuch II: 0,6 g Keton, $0,5 \mathrm{~g} \mathrm{SnCl}_{4}$, bei Versuch III: $0,5 \mathrm{~g}$ Keton, $0,55 \mathrm{~g} \mathrm{SnCl}_{4}$. Die abgeschiedenen gelben, zum Teil etwas rötlich ge-

1) Nach Versuchen vou Ph. Fischer.

2) Ber. d. d. chem. Ges. 25, 3536 (1892). 
färbten Krystalldrusen wurden mit absolutem Benzol gewaschen und auf Ton neben $\mathrm{P}_{2} \mathrm{O}_{5}$ getrocknet. Der Körper gibt bei etwa $105^{\circ}$ eine dickflüssige Schmelze, sintert aber schon mehrere Grade vorher zusammen; bei höherer Temperatur tritt Gasentwicklung auf.

I. $0,1764 \mathrm{~g}$ gaben $0,1237 \mathrm{AgCl}$ und $0,0306 \mathrm{SnO}_{2}$.

II. $0,1703 \mathrm{~g}, 0,1183 \mathrm{AgCl} \# \quad 0,0292 \mathrm{SnO}_{2}$.

III. $0,1770 \mathrm{~g}, 0,1182 \mathrm{AgCl} \# 0,0317 \mathrm{SnO}_{2}$. Ber.

Gef.

$\begin{array}{lcccc} & & \text { I } & \text { II } & \text { III } \\ \text { Sn } & 14,60 & 13,67 & 13,51 & 14,11 \\ \text { Cl } & 17,42 & 17,34 & 17,17 & 16,51\end{array}$

2. Di-(-o-)anisalacetophenon-zinntetrachlorid. $\mathrm{SnCl}_{4}, 2 \mathrm{C}_{6} \mathrm{H}_{4}\left(\mathrm{OCH}_{3}\right) . \mathrm{CH}=\mathrm{CH} . \mathrm{CO} \cdot \mathrm{C}_{6} \mathrm{H}_{5}$.

Darstellung des Ketons. o-Anisalacetophenon wird am besten durch Methylieren des von Bablich und Kostanecki ${ }^{1}$ ) beschriebenen 0 -Oxybenzalacetophenons (gelbe Krystalle vom Schmelzp. $153^{\circ}$ ) erhalten. Man behandelt das Oxyketon bei $30-40^{\circ}$ abwechselnd mit $\mathrm{KOH}$ (etwa $4 \mathrm{~g}$ $\mathrm{KOH}$ in $50 \mathrm{ccm} \mathrm{H}_{2} \mathrm{O}$ ) und Dimethylsulfat, bis auf $\mathrm{Zn-}$ satz von $\mathrm{KOH}$ keine Rotfärbung mehr auftritt. Dann nimmt man das entstandene helle öl mit Äther auf, trocknet die ätherische Lösung mit Pottasche und destilliert den Äther ab. Es hinterbleibt ein fast farbloses Öl, das beim Reiben bald erstarrt. Zur Reinigung erwärmt man das Rohprodukt mit Ligroin, in welchem es schwer löslich ist, und versetzt die heiße Aufschlämmung mit so viel Äther, daß eine klare Lösung entsteht. Beim Erkalten scheiden sich prächtige, schwach gelbstichige Nadeln aus, deren Schmelzpunkt bei $64-65^{\circ}$ liegt. Der Körper ist leicht löslich in Äther, Benzol und Chloroform, gut löslich in Methyl- und Äthylalkohol.

$0,1583 \mathrm{~g}$ gaben $0,4668 \mathrm{CO}_{2}$ und $0,0829 \mathrm{H}_{2} \mathrm{O}$.

$\begin{array}{ccr} & \text { Ber. für } \mathrm{C}_{16} \mathrm{H}_{14} \mathrm{O}_{2} & \text { Gef. } \\ \mathrm{C} & 80,67 & 80,42 \\ \mathrm{H} & 5,88 & 5,86\end{array}$

1) Ber. d. d. chem. Ges. 29, 233 (1896). 
Bei der direkten Kondensation von Salicylaldehydmethyläther und Acetophenon (in alkoholischer Lösung mit $\mathrm{NaOH}$ ) wird ein Gemenge von 0-Methoxychalkon und o-Methoxybenzaldiacetophenon erhalten; durch fraktionierte Krystallisation aus Alkohol lassen sich die beiden Verbindungen voneinander trennen.

Das o-Methoxybenzaldiacetophenon, $\mathrm{C}_{6} \mathrm{H}_{4}\left(\mathrm{OCH}_{3}\right) \mathrm{CH}\left(\mathrm{CH}_{2}\right.$. CO. $\left.\mathrm{C}_{8} \mathrm{H}_{5}\right\rangle_{2}$, bildet weiße Nädelchen vom Schmelzp. 113 bis $114^{\circ}$, welche sich sehr leicht in Benzol und Chloroform, gut in Äther, Methyl- and Äthylalkohol lösen. Es gleicht in Zusammensetzung und Eigenschaften dem 0-Oxybenzaldiacetophenon von Cornelson und Kostanecki. ${ }^{1}$ )

$0,2092 \mathrm{~g}$ gaben $0,6121 \mathrm{CO}_{2}$ und $0,1127 \mathrm{H}_{2} \mathrm{O}$.

$\begin{array}{ccr} & \text { Ber. für } \mathrm{C}_{24} \mathrm{H}_{22} \mathrm{O}_{3} & \text { Gef. } \\ \text { C } & 80,44 & 79,80 \\ \mathrm{H} & 6,14 & 6,03\end{array}$

Darstellung des Additionsproduktes. Man gibt zu einer Lösung von $0,4 \mathrm{~g}$ des Ketons in möglichst wenig absolutem Benzol etwa $1 \mathrm{~g}$ wasserfreies Zinntetrachlorid. Beim Stehen der orangefarbenen Flüssigkeit im verschlossenen Gefäß scheidet sich allmählich ein rotes, krystallinisches Pulver ab, welches mit Benzol gewaschen und auf Ton neben $\mathrm{P}_{2} \mathrm{O}_{5}$ getrocknet wird.

Beim Erhitzen färbt sich der Körper bräunlich; er schmilzt gegen $135-136^{\circ}$ zu einer roten Flüssigkeit. Beim Liegen an der Juft wird er bald harzig: kaltes Wasser zersetzt unter Zinnsäureabscheidung.

I. $0,2902 \mathrm{~g}$ gaben $0,2310 \mathrm{AgCl}$ und $0,0591 \mathrm{SnO}_{2}$.

II. $0,2439 \mathrm{~g}$ gaben $0,1911 \mathrm{AgCl}$ und $0,0504 \mathrm{SnO}_{2}$.

Ber.

$\begin{array}{llll}\text { Sn } & 16,15 & 16,05 & 16,29 \\ \text { Cl } & 19,27 & 19,68 & 19,37\end{array}$

3. 7i-(m-)anisalacetophenon-zinntetrachlorid. $\mathrm{SnCl}_{4}, 2 \mathrm{C}_{6} \mathrm{H}_{4}\left(\mathrm{OCH}_{3}\right) . \mathrm{CH}=\mathrm{CH} . \mathrm{CO} \cdot \mathrm{C}_{6} \mathrm{H}_{5}$.

Darstellung des Ketons. $\mathrm{m}$-Anisalacetophenon läßt sich sowohl durch Methylieren des m-Oxybenzalacetophenons,

1) Ber. d. d. chem. Ges. 29, 240 (1896). 
wie auch durch direkte Kondensation von m-Methoxybenzaldehyd mit Acetophenon erhalten. Die erstere Methode ist zur Darstellnng größerer Substanzmengen vorzuziehen.

Fine warme Lösung von $8 \mathrm{~g}$ m-Oxybenzalacetophenon ${ }^{1)}$ und $5 \mathrm{~g} \mathrm{KOH}$ in $50 \mathrm{ccm}$ Wasser (Temperatur $40-50^{\circ}$ ) wird so oft mit kleinen Mengen Dimethylsulfat geschüttelt, bis die über dem abgeschiedenen Öl befindliche Flüssigkeit sauer reagiert. Dann wird eine Lösung von $2 \mathrm{~g}$ $\mathrm{KOH}$ in wenig Wasser zugesetzt und das Ganze wiederum mit Dimethylsulfat durchgeschüttelt. Man wiederholt den abwechselnden Zusatz von Alkali und Dimethylsulfat so lange, bis die durch die Einwirkung des Dimethylsulfats entfärbte Flüssigkeit durch Alkali nicht mehr gelb gefärbt wird, verdünnt mit Wasser, zerstört das überschüssige Dimethylsulfat durch Erhitzen auf $60-70^{\circ}$ und extrahiert das gebildete Methylderivat mit Äther.

Beim Verdunsten der mit Pottasche getrockneten ätherischen Schicht hinterbleibt ein dickes öl, das beim Reiben nach und nach zu Krystallen von blättchenartigem Habitus erstarrt. Man preßt sie auf T'on ab, wäscht sie mit etwas Methylalkohol und krystallisiert sie aus heißem Methylalkohol um. Es scheiden sich schön gelbstichige Blättchen vom Schmelzp. $64^{\circ}$ aus, die sehr leicht löslich in Chloroform, Benzol und Ather, gut Jöslich in Methylund Äthylalkohol sind.

Zur Darstellung des $m$-Anisalacetophenons durch direkte Kondensation versetzt man eine Lösung von $10 \mathrm{~g}$ m-Methoxybenzaldehyd und $12 \mathrm{~g}$ Acetophenon in $100 \mathrm{~g}$ Alkohol mit $10 \mathrm{~g} 10$ prozentiger wäbriger Natronlauge, nimmt das abgeschiedene Öl nach 24 Stunden mit Äther auf und trocknet die ätherische Schicht mit Pottasche. Nach dem Abdampfen des äthers hinterbleibt ein öl, welches nach einigen Tagen krystallinisch erstarrt; das Rohprodukt wird aus Methylalkohol umkrystallisiert.

1, Bablieh und Kostanecki, Ber: d. d. chem. Ges. 29, 23 a (1896). 
o- und m-Anisalacetophenon haben fast den gleichen Schmelzpunkt, sind aber Jeicht von einander zu unterscheiden. Die 0 -Verbindung bildet feine, konzentrisch gruppierte Nadeln und löst sich in konz. Schwefelsäure mit rotgelber Farbe; die m-Verbindung krystallisiert in schiefen Tafeln oder Blättchen, die sich in konz. Schwefelsäure hellgelb lösen. Eine Mischprobe der beiden Ketone schmilzt bei $45^{\circ}$, zeigt also erhebliche Depression.

$0,2065 \mathrm{~g}$ gaben $0,6070 \mathrm{CO}_{2}$ und $0,1075 \mathrm{H}_{2} \mathrm{O}$.

$\begin{array}{ccr} & \text { Ber. für } \mathrm{C}_{16} \mathrm{H}_{14} \mathrm{O}_{2} & \text { Gef. } \\ \mathrm{C} & 80,67 & 80,21 \\ \mathrm{H} & 5,88 & 5,83\end{array}$

Darstellung des Additionsproduktes. Man löst $0,4 \mathrm{~g}$ m-Anisalacetophenon in äuBerst wenig Benzol und gibt $0,4 \mathrm{~g}$ wasserfreies Zinntetrachlorid hinzu. Allmählich scheiden sich dann die gelben Krystalldrusen des gesuchten Additionsproduktes ab; sollten sich selbst nach stundenlangem Stehen keine Krystalle bilden, so sät man zweckmäßig einige Krystallsplitter einer bei einem früheren Versuch erhaltenen Substanzprobe ein. Die Krystalle werden von der Mutterlauge befreit und sofort im Reaktionsgefä 6 mit absolutem Benzol gewaschen.

Der Körper bildet gelbe, kompakte Krystalle, die sich beim Erhitzen rot färben und dann zwischen 100 bis $110^{\circ} \mathrm{zu}$ einer roten Flüssigkeit schmelzen. In seiner Farbe entspricht er weitgehend der $\mathrm{SnCl}_{4}$-Verbindung des Benzalacetophenons. Er löst sich mit hellgelber Farbe in absolutem Alkohol; seine Lösung in siedendem Benzol ist tiefgelb gefärbt. Wasser zersetzt unter Zinnsäureabscheidung.

I. $0,1815 \mathrm{~g}$ gaben $0,1438 \mathrm{AgCl}$ und $0,0380 \mathrm{SnO}_{2}$.

II. $0,2423 \mathrm{~g} \quad 0,1900 \mathrm{AgCl}, 0,0499 \mathrm{SnO}_{2}$. Ber.

Gef.

\begin{tabular}{cccc} 
& Ber. & \multicolumn{2}{c}{ Gef. } \\
& & I & II \\
Sn & 16,15 & $16, \% 0$ & 16,23 \\
Cl & 19,27 & 19,60 & 19,40
\end{tabular}




\section{Di-(p-)anisalacetophenon-zinntetrachlorid,} $\mathrm{SaCl}_{4}, 2 \mathrm{C}_{6} \mathrm{H}_{4}\left(\mathrm{OCH}_{8}\right) . \mathrm{CH}=\mathrm{CH} . \mathrm{CO} . \mathrm{C}_{6} \mathrm{H}_{5}$.

p-Anisalacetophenon wurde in hellgelben Nadeln vom Schmelzp. 77-78 erhalten. $^{1}$ ) - Zur Darstellung des Additionsproduktes läßt man die Komponenten in möglichst wenig Benzol aufeinander einwirken. Man gibt zu einer fast gesättigten Lösung von $0,5 \mathrm{~g}$ Keton in absolutem Benzol $1-1,5 \mathrm{~g}$ wasserfreies Zinntetrachlorid. Es entsteht sofort eine tieforangefarbene Flüssigkeit, aus der sich — bei Abschluß von Luftfeuchtigkeit das Additionsprodukt allmählich in reichlicher Menge abscheidet; eventuell müssen Krystalle, die von einer früheren Darstellung herrühren, eingesät werden. Der Körper wird im Reaktionsgefä $B$ schnell mit absolutem Benzol gewaschen und auf Ton neben $\mathrm{P}_{2} \mathrm{O}_{5}$ getrocknet.

Er bildet ein krystallinisches, orangerotes Pulver, welches außerordentlich zersetzlich ist und sich selbst im Exsiccator oberflächlich gelb färbt. An der Luft geht er schnell in ein orangerotes, klebriges Harz über; beim Erhitzen wird er zunächst weich und schmilzt dann bei etwa $105-110^{\circ} \mathrm{zu}$ einer tiefroten, fast undurchsichtigen Flüssigkeit. Alkohol und Eisessig verwandeln den Körper in eine gelbe Masse und lösen ihn dann klar auf; Wasser gibt bei gewöhnlicher Temperatur ein fast weißes Pulver; kocht man mit Wasser, so scheiden sich Zinnsäureflocken ab.

I. $0,1905 \mathrm{~g}$ gaben $0,1485 \mathrm{AgCl}$ und $0,0381 \mathrm{SnO}_{2}$.

II. $0,2110 \mathrm{~g} \quad, \quad 0,1629 \mathrm{AgCl} \quad, 0,0423 \mathrm{SnO}_{4}$. Ber.

$\begin{array}{cccc} & & \text { I } & \text { II } \\ \text { Sn } & 16,15 & 15,76 & 15,80 \\ \text { Cl } & 19,27 & 19,19 & 19,01\end{array}$

5. Di-(p-)anisalbenzalacelon-zinntetrachlorid, $\mathrm{SuCl}_{4}, 2 \mathrm{C}_{6} \mathrm{H}_{5} \cdot \mathrm{CH}=\mathrm{CH} . \mathrm{CO} . \mathrm{CH}=\mathrm{CH} . \mathrm{C}_{6} \mathrm{H}_{4} \cdot \mathrm{OCH}_{3}$.

Die Darstellung des p-Anisalbenzalacetons erfolgte nach Baeyer und Villiger ${ }^{2}$ ); gelbe Nadeln vom Schmelz-

1) Darstellung siehe Pond und Schoffstall; Amer. Soc. 22, 666 (1900).

2) Ber. d. d. chem. Ges. 3̋̄, 3022 (1902). 
punkt $96,5^{\circ}$. - Wird eine Lösung von $0,9 \mathrm{~g}$ des Ketons in absolutem Benzol mit einer Benzollösung von $0,3 \mathrm{~g}$ Zinntetrachlorid versetzt, so scheidet sich das Additions. produkt als harzige, allmählich krystallinisch werdende Masse ab. Man wäscht sie mit Benzol und trocknet sie im Vakuumexsiccator neben $\mathrm{P}_{2} \mathrm{O}_{5}$.

Der Körper bildet ein rotes, krystallinisches Pulver, welches einige Zeit lang an der Luft beständig ist. Er besitzt keinen scharfen Schmelzpunkt; bei etwa $158^{\circ}$ beginnt er zusammenzusintern, bei $172^{\circ}$ ist er zu einer tiefroten Flüssigkeit geschmolzen. In absolutem Alkohol löst er sich mit gelber, in Eisessig mit schön oranger Farbe. Wasser gibt bei gewöhnlicher Temperatur ein gelbes Pulver, kocht man mit Wasser, so tritt völlige Zersetzung ein.

$0,1650 \mathrm{~g}$ gaben $0,1200 \mathrm{AgCl}$ und $0,0305 \mathrm{SnO}_{2}$. Ber. Gef.

$\begin{array}{lll}\mathrm{Sn} & 15,08 & 14,56 \\ \mathrm{Cl} & 18,00 & 17,99\end{array}$

6. Di-di(-o-)anisalaceton-zinntetrachlorid, $\mathrm{SnCl}_{4}, 2 \mathrm{CO}\left(\mathrm{CH}=\mathrm{CH} . \mathrm{C}_{6} \mathrm{H}_{4} \mathrm{OCH}_{3}\right)_{2}, \mathrm{C}_{6} \mathrm{H}_{6}$.

Die Darstellung des Di-o-anisalacetons erfolgte nach der Vorschrift von Baeyer und Villiger ${ }^{1}$ ) durch Kondensation von Aceton mit Salicylaldehydmethyläther. Leuchtend gelbe Blättchen vom Schmelzp. 123-124. ${ }^{\circ}$ Man gibt za einer Lösung von $1 \mathrm{~g}$ Keton in absolutem Benzol eine Benzollösung von $0,3 \mathrm{~g}$ Zinntetrachlorid (mol. Verh. der Komponenten etwa 3:1). Es bildet sich eine dunkelrote Flüssigkeit, aus der sich bald orangerote Kryställchen absetzen; nach etwa 12 Stunden giebt man die Mutterlauge $a b$, wäscht den Rückstand mit Benzol und trocknet ihn auf Ton neben $\mathrm{P}_{2} \mathrm{O}_{5}$.

Die Farbe des Körpers ist rotstichiger als die des m-Isomeren. Er schmilzt bei $180^{\circ}$ zu einer blutroten, fast undurchsichtigen Flüssigkeit. Alkohol löst mit hell-

1) Ber. d. d. chem. Ges. 35,3022 (1902). 
gelber Farbe; Eisessig gibt in der Kälte eine gelborange, in der Wärme eine schön orangerote Lösung; kühlt man die heiße Lisessiglösung ab, so schlägt die Farbe wieder nach Gelborange um. Di-0-anisalaceton selbst löst sich in Eisessig nur mit grünstichig gelber Farbe; beim Erwärmen ändert sich die Farbe nicht. Die Eisessiglösung der $\mathrm{SnCl}_{4}$-Verbindung des m-Iianisalacetons ist hellgelb gefärbt. Wasser verwandelt das Additionsprodukt in wenigen Minuten in eine gelbe Masse; kocht man mit Wasser, so scheiden sich Zinnsäureflocken ab.

I. $0,1917 \mathrm{~g}$ gaben $0,1168 \mathrm{AgCl}$ und $0,0293 \mathrm{SnO}_{\mathbf{2}}$.

II. $0,1356 \mathrm{~g}, 0,0818 \mathrm{AgCl}, 0,0216 \mathrm{SnO}_{2}$. Ber.

Gef.

\begin{tabular}{lrrr} 
& Ber. & \multicolumn{2}{c}{ Gef. } \\
Sn & 12,84 & I & II \\
Cl & 15,32 & 12,05 & 12,55 \\
& & 15,07 & 14,92
\end{tabular}

\section{Di-di(-m-)anisalaceton-zinntetrachlorid, $\mathrm{SnCl}_{4}, 2 \mathrm{CO}\left(\mathrm{CH}=\mathrm{CH} . \mathrm{C}_{6} \mathrm{H}_{4} \cdot \mathrm{OCH}_{3}\right)_{2}$.}

Di-m-anisalaceton wurde nach B aey er und Villige $r^{1}$ ) erhalten, indem zunächst Aceton mit m-Methoxybenzaldehyd zum m-Methoxybenzalaceton und dann letzteres mit einem zweiten Molekül des Aldehyds zum disubstituierten Aceton kondensiert wurde. Hellgelbe, strahlenförmig angeordnete Prismen vom Schmelzp. 55-56 ${ }^{\circ}$. Man gibt zu einer Lösung von $0,4 \mathrm{~g}$ Keton in absolutem Benzol eine Benzollösung von 0,4 g Zinntetrachlorid (mol. Verh. der Komponenten etwa 1:1). Es entsteht eine orangerote Lösung, aus der sich bald das Additionsprodukt in krystallinischer Form abscheidet; es wird schnell mit Benzol gewaschen und auf Ton neben $\mathrm{P}_{2} \mathrm{O}_{5}$ getrocknet.

Der Körper bildet ein krystallinisches, schön orangefarbenes Pulver; er ist tieferfarbig als das analog zusammengesetzte Additionsprodukt des Dibenzalacetons, aber weniger tief gefärbt als die $\mathrm{SnCl}_{4}$-Verbindung des Di-0-anisalacetons. In kaltem Alkohol löst er sich mit

1) Ber. d. d. chem. Ges. 35, 3023 (1902). 
hellgelber, in heißem Benzol mit tiefgelber Farbe: durch heißes Wasser wird er unter Zinnsäureabscheidung zersetzt. Beim Erwärmen im Schmelzpunktsröhrchen färbt sich der Körper schon unterhalb $100^{\circ}$ tiefrot, gegen $170^{\circ}$ gibt er eine tiefrote, fast undurchsichtige Schmelze.

Die Analyse einer 2 Stunden lang neben $\mathrm{P}_{y} \mathrm{O}_{5}$ getrockneten Substanzprobe stimmt am besten auf die Formel: $\mathrm{SnCl}_{4}, 2$ Keton, $\mathrm{C}_{6} \mathrm{H}_{6}$.

$0,2016 \mathrm{~g}$ gaben $0,1221 \mathrm{AgCl}$ und $0,0320 \mathrm{SnO}_{4}$.

Ber. Gef.

$\begin{array}{lll}\mathrm{Sn} & 12,84 & 12,51 \\ \mathrm{Cl} & 15,32 & 14,98\end{array}$

Wird die Substanz 2 Tage lang im Vakuum neben $\mathrm{P}_{2} \mathrm{O}_{5}$ getrocknet, so besitzt sie die normale Zusammensetzung: $\mathrm{SnCl}_{4}$ 2 Keton.

$0,1808 \mathrm{~g}$ gaben $0,1190 \mathrm{AgCl}$ und $0,0322 \mathrm{SnO}_{2}$.

Ber.

Gef.

$\begin{array}{lll}\text { Sn } & 14,02 & 14,04 \\ \text { C1 } & 16,72 & 16,28\end{array}$

8. Di-di(-p-)anisalaceton-zinntetrachlorid, $\mathrm{SnCl}_{4}, 2 \mathrm{CO}\left(\mathrm{CH}=\mathrm{CH} . \mathrm{C}_{6} \mathrm{H}_{4} \mathrm{OCH}_{3}\right)_{2}$.

Di-p-anisalaceton, dargestellt nach Baeyer und Villige ${ }^{1}$ ), bildete hellgelbe Blättchen rom Schmelzpunkt $129^{\circ}$. - Zur Darstellung des Additionsproduktes gibt man zu einer Lösung von Dianisalaceton in absolutem Benzol eine Benzollösung von Zinntetrachlorid; molekulares Verhältnis der Komponenten am besten 3:1. Es entsteht ein krystallinischer, schwarzer Niederschlag, der abfiltriert und auf Ton über $\mathrm{P}_{2} \mathrm{O}_{5}$ getrocknet wird.

Mit Wasser geht der Körper in eine schmutziggelbe Masse über, mit Aceton entsteht eine orangefarbene Lösung. Alkohol gibt ein rötliches Pulver, das sich allmählich klar auflöst. Schüttelt man den Körper mit Benzol, so färbt sich die Flüssigkeit gelb; beim Kochen bildet sich eine orangefarbene Lösung unter Abscheidung einer harzigen Masse.

1) a. a. $O$. 
I. $0,1491 \mathrm{~g}$ gaben $0,1029 \mathrm{AgCl}$ und $0,0260 \mathrm{SnO}_{2}$.

II. $0,1538 \mathrm{~g} \quad 0,1052 \mathrm{AgCl}, 0,0270 \mathrm{SnO}_{2}$.

Ber.

Gef.

\begin{tabular}{cccc} 
& Ber. & \multicolumn{2}{c}{ Gef. } \\
Sn & 14,02 & I & II \\
Cl & $\mathbf{1 6 , 7 3}$ & 13,74 & 13,83 \\
& & 17,07 & 16,91
\end{tabular}

9. Di-dipiperonalaceton-zinntetrachlorid. $\mathrm{SnCl}_{4}, 2 \mathrm{CO}$. $\left.\mathrm{CH}=\mathrm{CH} . \mathrm{C}_{6} \mathrm{H}_{3} \mathrm{O}_{2} \mathrm{CH}_{2}\right)_{2}$.

Darstellung des Dipiperonalacetons nach F. Haber ${ }^{\mathbf{1}}$ ); gelbe Nadeln vom Schmelzp. $185^{\circ}$. - Man löst 0,5 g Dipiperonalaceton in heißem, absolutem Benzol (der Körper ist relativ schwer löslich), läßt etwas erkaiten und fügt $0,5 \mathrm{~g}$ Zinntetrachlorid hinzu. Es entsteht sofort ein schwarzer Niederschlag. Nach etwa 1 Stunde giebt man die Mutterlauge sorgfältig ab, bringt den Rückstand auf ein Filter, wäscht ihn gut mit absolutem Benzol und trocknet ihn zwischen zwei Tonplatten neben $\mathrm{P}_{2} \mathrm{O}_{5}$.

Der Körper wird an der Luft schnell braun bis orange; mit Wasser geht er in eine gelbe Masse über. Eisessig ändert die Farbe des Körpers nicht; die Eisessiglösung ist orangegelb gefärbt. Alkohol und Pyridin geben gelbe Puiver und gelbe Lösungen.

I. $0,2357 \mathrm{~g}$ gaben $0,1460 \mathrm{AgCl}$ und $0,0393 \mathrm{SnO}_{2}$.

II. $0,1292 \mathrm{~g} \quad, \quad 0,0787 \mathrm{AgCl}, 0,0214 \mathrm{SnO}_{2}$. Ber.

Gef.

$\begin{array}{cccc} & & \text { I } & \text { II } \\ \text { Sn } & 13,15 & 13,14 & 13,05 \\ \text { Cl } & 15,69 & 15,34 & 15,06\end{array}$

10. Di-benzalcinnamylidenaceton-zinntetrachlorid, $\mathrm{SnCl}_{4}, 2 \mathrm{C}_{6} \mathrm{H}_{5} . \mathrm{CH}=\mathrm{CH} . \mathrm{CO} . \mathrm{CH}=\mathrm{CH} . \mathrm{CH}=\mathrm{CH} \cdot \mathrm{C}_{6} \mathrm{H}_{5}$.

Benzalcinnamylidenaceton, dargestellt nach $\mathrm{Schol} \mathrm{tz}^{2}$ ), bildete hellgelbe Blättchen vom Schmelzp. 106 ${ }^{\circ}$ - Man löst das Keton in absolutem Benzol und gibt auf 3 bis 4 Mol. desselben $1 \mathrm{Mol}$. Zinntetrachlorid, gelöst in abso-

I) Ber. d. d. chem. Ges. 24, 617 (1891).

2) Ber. d. d. chem. Ges. 29, 614 (1896). 
Iutem Benzol, hinza. Es scheidet sich zunächst ein dunkelfarbenes ÖI an den Wänden des Gefäßes ab, welches nach einigen Stunden krystallinisch erstarrt. Man wäscht das Reaktionsprodukt mit Benzol und trocknet es auf Ton neben $\mathrm{P}_{2} \mathrm{O}_{5}$.

Kupferrote, glänzende, kleine Blättchen, die bei etwa $171^{\circ}$ zu einer dunklen Flüssigkeit schmelzen; an der Luft lassen sie sich einige Minuten lang unverändert anfbewahren. Sie sind mit orangestichig gelber Farbe leicht löslich in Eisessig; in Benzol lösen sie sich mit gelber Farbe. Wasser verwandelt den Körper in eine etwas klebrige, gelbe Masse; beim Kochen mit Wasser tritt völlige Zersetzung ein. Gibt man zum Additionsprodukt wenig absoluten Alkohol, so bilden sich rein gelbe, glänzende Blättchen, die im Vakuumexsiccator (auch an der Luft) allmählich wieder eine kupferrote Farbe annehmen. Ähnlich wie gegen Äthylalkohol verhält sich der Körper gegen Methylalkohol, Äthylacetat und Aceton. Wahrscheinlich entstehen in all diesen Fällen ternäre Molekülverbindungen, die allerdings mit freiem Benzalcinnamylidenaceton verunreinigt sind.

$$
\begin{array}{crc}
0,0940 \mathrm{~g} \text { gaben } & 0,0184 \mathrm{SnO}_{2} . & \\
0,1570 \mathrm{~g} \# \quad 0,1148 \mathrm{AgCl}^{*} & \\
& \text { Ber. } & \text { Gef. } \\
\mathrm{Sn}_{\mathrm{Cl}} & 15,23 & 15,43 \\
\mathrm{Cl} & 18,18 & 18,08
\end{array}
$$

d) Perchlorate und Halogenostanneate der Ketone. ${ }^{1}$ )

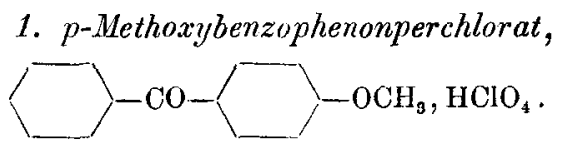

p-Nethoxybenzophenon läßt sich bequem nach der Vorschrift von Gattermann, Erhardt und $\mathrm{Naisch}{ }^{2}$ )

1) Verbindungen 1-14 und Verbindung 24 sind von H. Mully, die übrigen (15-23) von P. Monti dargestellt worden.

2) Ber. d. d. chem. Ges. 2s, 1204 (1890). 
darstellen. - Harte, farblose Krystalle vom Schmelzpunkt $60-62^{\circ}$.

Man trägt in geschmolzenes p-Methoxybenzophenon (1 Mol.) 70 prozentige Überchlorsäure ein (etwa 3 Mol.). Aus der dunklen Flüssigkeit scheiden sich nach 4 bis 5 tägigem Stehen neben Natronkalk und Phosphorpentoxyd im Vakuum große, schmutzig gelbbraune Krystalle aus, welche auf vorgetrockneten Tonplatten abgepreBt und im Vakuum neben Natronkalk und Phosphorpentoxyd getrocknet werden. Das so dargestellte Perchlorat ist so zerflieblich, daß es nicht weiter gereinigt werden kann.

$0,5068 \mathrm{~g}$ gaben $0,2406 \mathrm{AgCl}^{1}$ )

Ber. 11,35; Gef. 11,75 Proz. Cl.

2. Benzalacetophenonperchlorat,

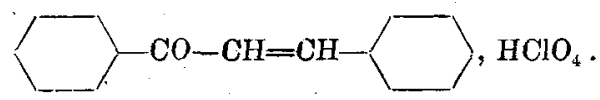

Eine kaltgesättigte Lösung von etwa $1 \mathrm{~g}$ Benzalacetophenon in Eisessig wurde mit einem Überschuß von 70 prozentiger Überchlorsäure versetzt. Beim Stehen im Vakuum neben Natronkalk und Phosphorpentoxyd schieden sich bald reingelbe feine Kryställchen aus, die auf vorgetrockneten Tonplatten im Vakuum neben Natronkalk und Phosphorpentoxyd getrocknet wurden.

Die Krystalle halten sich nur 5-6 Tage unverändert; sie färben sich bei $92-96^{\circ}$ dunkel unter Zersetzung.

$0,2918 \mathrm{~g}$ (getrocknet wie oben angegeben, bis der tägliche Gewichtsverlust nur noch klein war) gaben $0,1386 \mathrm{AgCl}$. Ber. 11,49;

Gef. 11,75 Proz. Cl.

1) Die Analysen der Perehlorate wurden allgemein so durchgefährt, daB die Substanzen im Einsohmelzrohr mit rauchender Salpetersäure und Silbernitrat bei $280-300^{\circ}$ zersetzt wurden; dann wurde das gebildete $\mathrm{AgCl}$ abfiltriert und gewogen.

Annalen der Chenio 412. Band. 


\section{Benzal-p-methoxyacetophenonperchlorat,}

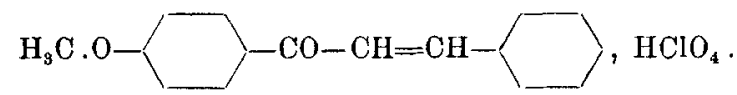

Das Keton wurde aus Zimtsäurechlorid und Anisol dargestellt. ${ }^{1}$ ) Farblose Krystallnadeln vom Schmelzpunkt $106-107^{\circ}$.

Man setzt zu einer Lösung von 4,5 $\mathrm{g}$ des Ketons in möglichst wenig Eisessig $8 \mathrm{~g} 70$ prozentige Überchlor säure. Aus der gelben Flüssigkeit scheiden sich im Vakuum neben Natronkalk und Phosphorpentoxyd allmählich orangegelbe Krystalle aus, welche wie üblich getrocknet werden. Schmelzp. 63-78 .

$$
\begin{gathered}
0,1597 \mathrm{~g} \text { gaben } 0,0681 \text { AgCl. } \\
\text { Ber. 10,47; }
\end{gathered}
$$

\section{4. p-Methoxybenzalacetophenonperchlorat,}

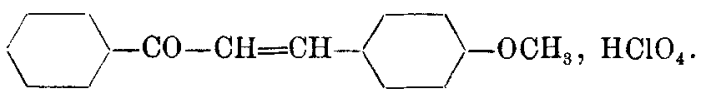

Darstellung des Ketons aus Anisaldehyd und Acetophenon. $^{2}$ ) Feine hellgelbe Nadeln rom Schmelzp. 77 bis $78^{\circ}$.

Man versetzt eine kalt gesättigte Lösung von $2 \mathrm{~g}$ Keton in Eisessig mit $3,6 \mathrm{~g} 70$ prozentiger Überchlorsäure. Nach wenigen Minuten erstarrt das Ganze zu einem Brei feiner orangeroter Nadeln. Absaugen und Trocknen wie üblich. - Die orangeroten Krystalle zeigen einen intensiv blauen Oberflächenschimmer; Schmelzpunkt $103-107^{\circ}$. Bei längerem Aufbewahren Zersetzung unter Änderung der Farbe nach Violett.

$0,2788 \mathrm{~g}$ gaben $0,1163 \mathrm{AgCl}$.

$$
\text { Ber. 10,47; Gef. 10,32 Proz. Cl. }
$$

1) Stockhausen und Gattermann, Ber. d. d. chem. Ges. 25, 3536 (1892).

2) Baejer und Villiger, Ber. d. d ehem. Ges. 30, 3022 (1902). 


\section{5. $p$-Methoxydibenzalacetonperchlorat, $\left\lceil-\mathrm{CH}=\mathrm{CH}-\mathrm{CO}-\mathrm{CH}=\mathrm{CH}-\square-\mathrm{OCH}_{3}, \mathrm{HClO}_{4}\right.$.}

Darstellung des Ketons aus Benzalaceton und Anisaldehyd. ${ }^{1}$ ) Hellgelbe, warzenförmig gruppierte Nadeln vom Schmelzp. $96^{\circ}$.

Man fügt za einer kaltgesättigten Lösung von $1 \mathrm{~g}$ Keton in Eisessig $1,6 \mathrm{~g} 70$ prozentige Überchlorsäure Aus der blutroten Lösung scheiden sich im Vakuum neben Natronkalk und Phosphorpentoxyd violette Nadeln mit stark blauer Oberflächenfarbe aus. Schmelzpunkt der wie üblich getrockneten Krystalle $123-125^{\circ}$.

$0,3453 \mathrm{~g}$ gaben $0,1382 \mathrm{AgCl}$.

Ber. 9,73; Gef. 9,90 Proz. Cl.

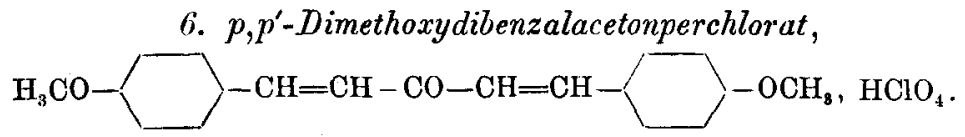

Darstellung des Ketons aus Aceton und Anisaldehyd. $\left.{ }^{1}\right)$ Blaßgelbe Blättchen vom Schmelzp. 128-1310.

Man fügt zu einer Lösung von $1 \mathrm{~g}$ Keton in Eisessig $1,5 \mathrm{~g}$ 70prozentige Überchlorsäure und läßt die fluorescierende, karminrote Flüssigkeit im Vakuum stehen. Die abgeschiedenen Krystalle werden mit etwas kaltem Eisessig gewaschen und auf Ton, wie üblich, getrocknet. - Die frisch hergestellten Krystalle haben eine violettschwarze Grundfarbe und grünen Oberflächenglanz; sie sind nur kurze Zeit haltbar; bei $160-162^{\circ}$ im Kapillarröhrchen Zersetzung. Durch Erwärmen des Perchlorats mit Wasser, Ausäthern der Flüssigkeit, Verdunsten des Äthers und Umkrystallisieren des Rückstands kann man das Dianisalaceton leicht in guter Ausbeute zurückgewinnen.

a) Krystalle nicht mit Eisessig gewaschen; 0,1653 g gaben $0,0646 \mathrm{AgCl}$.

b) Krystalle mitEisessig gewaschen; 0,1994 g gaben 0,0725 AgCl. Ber. 8,99;

Gef. a) 9,67

b) 9,00 Proz. Cl.

1) Baeyer und Villiger, Ber. d. d. chem. Ges. 35, 3022 (1902). 


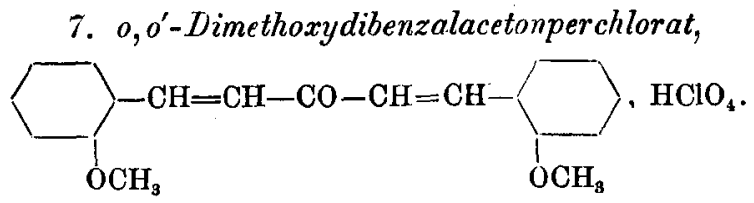

Darstellung des Ketons aus Aceton und Salicylaldehydmethyläther. $\left.{ }^{1}\right)$ Krystalle vom Schmelzp. $124^{\circ}$.

Eine Lösung von $1 \mathrm{~g}$ Keton in wenig Eisessig wird mit $1,5 \mathrm{~g} 70$ prozentiger Überchlorsäure versetzt. Aus der blutroten Flüssigkeit scheiden sich bald Krystalle ab, die abgesaugt, mit wenig Eisessig gewaschen und im Vakuum getrocknet werden. Violettes Krystallmehl mit intensiv käfergrüner Oberflächenfarbe, vergleichbar den Fuchsinkrystallen. Durch Zersetzen des Perchlorats mit Wasser wird unverändertes Keton erhalten.

$0,2284 \mathrm{~g}$ gaben $0,0837 \mathrm{AgCl}$.
Ber. 8,99;
Gef. 9,07 Proz. Cl.

\section{Cinnamylidenbenzalacetonperchlorat,}

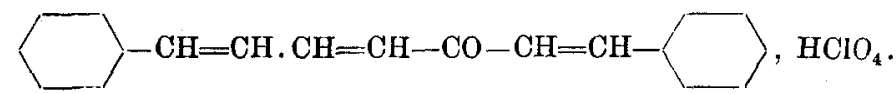

Das Keton wurde abweichend von der üblichen Darstellungsweise durch Kondensation von Benzalaceton mit Zimtaldehyd erhalten. In eine Lösung von $10 \mathrm{~g}$ Benzalaceton ${ }^{2}$ ) und $12 \mathrm{~g}$ Zimtaldehyd in $40 \mathrm{ccm}$ Alkohol wurden $5 \mathrm{~g} 10$ prozentige Natronlauge eingetragen. Die Flüssigkeit färbte sich sofort dunkel; nach wenigen Minuten hatte sich ein braunes Öl abgeschieden, welches allmählich krystallinisch erstarrte. Umkrystallisieren des Rohprodukts aus Methylalkohol; reingelbes Krystallpulver vom Schmelzp. 107,5-108,50; Ausbente gut.

Zur Darstellung des Perchlorats gibt man zu einer Lösung von $1 \mathrm{Mol}$. Keton in wenig Eisessig $3 \mathrm{Mol}$. 70 prozentige Überchlorsäure. Aus der blutroten Flüssigkeit scheiden sich im Vakuum bordeauxfarbene, glänzende,

1) Baeyer u. Villiger, Ber, d. d. chem. Ges. 35, 3022 (1902).

2) Darstellung s. Vorländer, diese Annalen 294, 275 (1897). 
warzenförmig gruppierte Nadeln aus; sie werden abgesangt und wie üblich getrocknet. Im trockenen $\mathrm{Zu}$ stande besitzen sie einen schwachen grünen Oberflächenglanz; sie schmelzen unter Zersetzung bei $156-163^{\circ}$.

$0,3485 \mathrm{~g}$ gaben $0,1361 \mathrm{AgCl}$.

Ber. 9,85; Gef. 9,66 Proz. Cl.

9. p-Methoxycinnamylidenbenzalacetonperchlorat, $\mathrm{CH}_{3} \mathrm{O}-\longrightarrow \mathrm{CH}=\mathrm{CH}-\mathrm{CH}=\mathrm{CH}-\mathrm{CO}-\mathrm{CH}=\mathrm{CH}-\square, \mathrm{HClO}_{4}$.

Zur Darstellung des p-Methoxycinnamylidenbenzalacetons wurde der von Thiele und Giese ${ }^{1}$ ) beschriebene p-Methoxyzimtaldehyd mit Benzalaceton kondensiert. Über die Gewinnung des p-Methoxyzimtaldehyds siehe die Angaben in der Dissertation von H. Mully..$^{2}$ )

Molekulare Mengen von $p$-Methoxyzimtaldehyd ${ }^{3}$ ) und Benzalaceton wurden in der 5-10fachen Menge Alkohol gelöst; dann wurde die Lösung mit 10 prozentiger Natronlauge versetzt (auf je $1 \mathrm{~g}$ Aldehyd 1/2 g Natronlauge). Die Flüssigkeit färbte sich sofort dunkel und schon nach 5-10 Minuten setzte sich ein braunes Öl ab, welches nach etwa 2 Stunden zu einem Krystallkuchen erstarrte. Rohausbeute 40-50 Proz. des angewandten Aldehyds. Umkrystallisieren aus Methylalkohol unter Zusatz von Tierkohle. - Das reine Keton bildet ein feinkrystallinisches, reingelbes Pulver vom Schmelzpunkt $115-116^{\circ}$, welches in fast allen gebräuchlichen Lösungsmitteln leicht löslich ist; schwer löslich in Ligroin.

Methoxylbestimmung nach Zeisel unter Zusatz von Phenol.4) $0,2835 \mathrm{~g}$ gaben $0,2230 \mathrm{AgJ}$.

Methoxyl 10,69

Ber. für $\mathrm{C}_{20} \mathrm{H}_{18} \mathrm{O}_{2} \quad$ Gef.

10,39

Darstellung des Perchlorats. Aus der intensiv blauvioletten Lösung von $2 \mathrm{~g}$ Keton und $3 \mathrm{~g} 70$ prozentiger

1) Ber. d. d. chem. Ges, 36, 842 (1903).

2) Zürich 1915 .

3) Die Versuche wurden mit je $1-4 \mathrm{~g}$ Aldehyd ausgeführt.

$\left.{ }^{4}\right)$ Weishut, Monatsh. 33, 1165 (1912). 
Überchlorsäure in wenig Eisessig krystallisieren nach kurzer Zeit stahlblaue Nadeln mit sehr schwachem, grünem Oberflächenglanz aus, welche im Vakuum in der ublichen Weise getrocknet werden. Schmelzp. $133-147^{\circ}$ unter Zersetzung.

$0,2281 \mathrm{~g}$ gaben $0,0839 \mathrm{AgCl}$.

$0,2217 \mathrm{~g}, \quad 0,0812$ AgCl.

Ber. $9.09 ; \quad$ Gef. 9,$10 ; 9,06$ Proz. Cl.

10. m-Methoxycinnamylidenbenzalacetonperchlorat,

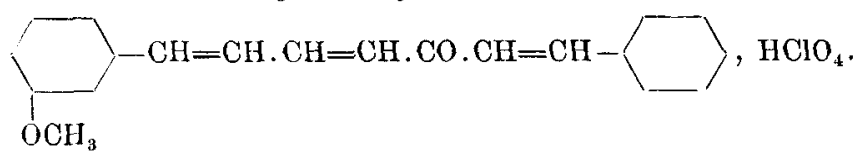

Zur Darstellung des m-Methoxycinnamylidenbenzalacetons methyliert man m-Oxybenzaldehyd mit Dimethylsulfat zum m-Methoxybenzaldehydund kondensiert letzteren mit Acetaldehyd zum m-Methoxyzimtaldehyd; den m-Methoxyzimtaldehyd vereinigt man mit Benzalaceton zu dem gesuchten Keton.

Die Methylierung des m-Oxybenzajdehyds geschieht wie üblich.

Darstellung des m-Methoxyzimtaldehyds. Zur Lösung von $40 \mathrm{~g} \mathrm{~m}$-Methoxybenzaldehyd in $300 \mathrm{ccm}$ Alkohol werden $1500 \mathrm{ccm}$ dest. Wasser, $40 \mathrm{~g}$ Acetaldehyd und 25 g 10 prozentige Natronlauge gegeben. Dann wird das Reaktionsgemisch in einer gut verschlossenen Flasche 7 Tage lang auf der Schüttelmaschine geschüttelt und schließlich 24 Stunden lang auf $30-35^{\circ}$ erwärmt. Nach Ablauf dieser Zeit säuert man die Flüssigkeit mit Essigsäure schwach an, sättigt mit Kochsalz und nimmt den Aldehyd mit $\ddot{A}$ ther auf. Beim Verdunsten des Äthers nach dem Trocknen mit wasserfreiem Natriumsulfat hinterbleibt ein dunkelgelbes, dickflïssiges Öl, das mehrmals sorgfältig im Vakuum fraktioniert wird. Die Hauptmenge des gesuchten Aldehyds ist bei $11 \mathrm{~mm}$ Druck in der mittleren Fraktion von $160-180^{\circ}$ enthalten. Man erhält schlieblich ein schwach gelbes öl, das in 
einer Kältemischung durch Reiben der Gefäßwände mit einem Glasstab zum Erstarren gebracht werden kann.

Das krystallinisch erstarrte öl wird auf gut rorgekühlten Tonplatten abgepreßt and im Exsiccator im Eisschrank aufbewahrt. Zur Reinigung löst man das gelblich weiße, schon bei Zimmertemperatur schmelzende Pulver in dem halben Volumen Alkohol und kühlt die Lösung in einer Kältemischung ab. Sollte auf diese Weise keine Krystallisation erfolgen, so impft man mit einer Spur unreiner Substanz. Der Schmelzpunkt des Aldehyds liegt nach einmaliger Krystallisation bei $37^{\circ}$ (Erweichungspunkt $25^{\circ}$ ). Rohausbeute 10-12 Proz. des Ausgangsmaterials.

Zur Feststellung seiner Formel wurde der Aldehyd in sein Phenylhydrazon verwandelt. $0,5 \mathrm{~g}$ des Aldehyds wurden in wenig Alkohol gelöst; dann wurde die berechnete Menge Phenylhydrazin hinzugefügt und das Reaktionsgemisch 10 Minuten lang auf dem Wasserbad erwärmt. Beim Erkalten krystallisierten gelbe Warzen ans, welche durch Umkrystallisieren aus 70 prozentigem Alkohol gereinigt wurden. Rohausbeute $0,55 \mathrm{~g}$. Schmelzpunkt des reinen Phenylhydrazons $105-106^{\circ}$.

$0,1660 \mathrm{~g}$ Phenylhydrazon gaben $16,8 \mathrm{ecm}$ Stickgas bei $20^{\circ}$ und $729 \mathrm{~mm}$ Druek.

$\begin{array}{ccc} & \text { Ber. für } \mathrm{C}_{16} \mathrm{H}_{10} \mathrm{ON}_{2} & \text { Gef. } \\ \mathrm{N} & 11,11 & 11,31\end{array}$

Darstellung des m-Methoxycinnamylidenbenzalacetons. Man fügt zu einer Lösung von $4 \mathrm{~g}$ m-Methoxyzimtaldehyd und $3,7 \mathrm{~g}$ Benzalaceton in 8-10 $\mathrm{g}$ Alkohol $4 \mathrm{~g} 10$ prozentige wäßrige Natronlauge und läßßt das Ganze verschlossen stehen. Es scheidet sich dann allmählich ein dunkles Öl ab, welches beim Abkühlen in Eis krystallinisch erstarrt. Zur Reinigung krystallisiert man das Rohprodukt zuerst aus Methylalkohol, dann aus Tetrachlorkohlenstoff und zuletzt wieder aus Methylalkohol um. Das reine Keton bildet schöne', gelbe Nadeln vom Schmelzp. 99-101 ${ }^{\circ}$; es ist sehr leicht löslich in Eis- 
essig, Benzol, Chloroform, Tetrachlorkohlenstoff, Aceton und Essigester, leicht löslich in Äther und heißem Äthyl- und Methylalkohol, fast unlöslich in Ligroin.

I. 4,726 mg gaben $14,38 \quad \mathrm{CO}_{2}$ und $2,64 \quad \mathrm{H}_{2} \mathrm{O}$.

II. $4,530 \mathrm{mg} \quad \# \quad 13,795 \quad \mathrm{CO}_{2} \quad, \quad 2,48 \quad \mathrm{H}_{2} \mathrm{O}$.

III. $4,265 \mathrm{mg} \quad " \quad 13,00 \quad \mathrm{CO}_{2} \quad, \quad 2,395 \mathrm{H}_{2} \mathrm{O}$.

\begin{tabular}{ccrrr} 
& Ber. für & \multicolumn{3}{c}{ Gef. } \\
& $\mathrm{C}_{20} \mathrm{H}_{18} \mathrm{O}_{2}$ & $\mathrm{I}$ & II & III \\
$\mathrm{C}$ & 82,72 & 82,99 & 82,05 & $\mathbf{8 3 , 1 3}$ \\
$\mathrm{H}$ & 6,26 & 6,25 & 6,13 & 6,28
\end{tabular}

Darstellung des Perchlorats. Man gibt $\mathrm{zu}$ einer Lösung von $0,5 \mathrm{~g}$ Keton in wenig Eisessig $0,8 \mathrm{~g} 70$ prozentige Überchlorsäure und stellt die tief blutrote Flüssigkeit ins Vakuum neben Natronkalk und Phosphorpentoxyd. Nach 1-2 Stunden ist die Flüssigkeit mit violettschwarzen feinen Krystallen erfüllt, welche mit ganz wenig Eisessig gewaschen und in gewohnter Weise getrocknet werden. Im trocknen Zustand zeigen die Krystalle grünen Oberflächenglanz; sie schmelzen unter Zersetzung bei $155-157^{\circ}$.

$0,1992 \mathrm{~g}$ gaben $0,0747 \mathrm{AgCl}$.

Bex. 9,45; Gef. 9,28 Proz. Cl.

11. $p, p^{\prime}$-Dimethoxycinnamylidenbenzalacetonperchlorat, $\mathrm{H}_{3} \mathrm{CO} \longrightarrow-\mathrm{CH}=\mathrm{CH} . \mathrm{CH}=\mathrm{CH} . \mathrm{CO} . \mathrm{CH}=\mathrm{CH} \longrightarrow-\mathrm{OCH}_{3}, \mathrm{HClO}_{4}$.

Darstellung des Ketons. Man versetzt eine Lösung von $1,85 \mathrm{~g}$ p-Methoxyzimtaldehyd und $2,14 \mathrm{~g}$ Anisalaceton $^{1}$ ) in $20 \mathrm{ccm}$ Alkohol mit $1 \mathrm{~g} 10$ prozentiger wäßriger Natronlauge. Nach 2stündigem Schütteln scheiden sich gelbe Krystalle aus, welche auf Ton im Vakuum getrocknet werden. Durch vorsichtiges Verdünnen der Mutterlauge mit Wasser kann man noch eine zweite Krystallisation erhalten. Rohausbeute etwa 3 g. Aus Alkohol umkrystallisiert bildet das Keton schöne, hellgelbe, warzenförmig angeordnete Krystalle

1) Baeyer u. Villiger, Ber. d. d. chem. Ges. 35, 1192 (1902). 
oder goldgelbe, speerförmige Gebilde; beide Formen schmelzen bei $146-148^{\circ}$. Das Keton ist sehr leicht löslich in Eisessig, Benzol, Chloroform und Tetrachlorkohlenstoff, leicht löslich in heißem Methyl- und Äthylalkohol, kaum löslich in Ligroin.

$4,765 \mathrm{mg}$ gaben $2,78 \mathrm{H}_{2} \mathrm{O}$ und $13,73 \mathrm{CO}_{2}$.

$\begin{array}{ccc} & \text { Ber. für } \mathrm{C}_{21} \mathrm{H}_{20} \mathrm{O}_{3} & \text { Gef. } \\ \mathrm{C} & \mathbf{7 8 , 7 6} & \mathbf{7 8 , 5 8} \\ \mathrm{H} & 6,30 & 6,53\end{array}$

Darstellung des Perchlorats. Versetzt man eine konz. Eisessiglösung des Ketons (1 Mol.) mit 70 prozentiger Überchlorsäure (3 Mol.), so färbt sie sich tief blauviolett. Im Vakuum neben Natronkalk und Phosphorpentoxyd scheiden sich aus der Flüssigkeit dunkel blauviolette Nadeln aus, welche in trockenem Zustand fast schwarz erscheinen und einen grünen Oberflächenglanz besitzen. Das Perchlorat hält sich im Vakuum nur 1-2 Tage; an der Luft zieht es Feuchtigkeit an und wird missfarbig. Eine Analyse wurde nicht ausgeführt.

12. Methylendioxycinnamylidenbenzalacetonperchlorat,<smiles>O=CC=CC=CC1CCC([C+][O-])CC1</smiles>

Darstellung des Ketons. Man kondensiert nach Ladenburg und $S c h o l z^{1}$ ) Piperonal mit Acetaldehyd zu Piperonylacrolein und vereinigt dann das Kondensationsprodukt mit Benzalaceton zu dem gesuchten Keton Unser Piperonylacrolein zeigte, entsprechend der Angabe von Winzenheimer ${ }^{2}$ ), den Schmelzp. 83,5-84 ${ }^{\circ}$.

Man fügt zu einer Lösung von 1 Tl. Piperonylacrolein und der berechneten Menge Benzalaceton in dem 10 fachen Volumen Alkohol $1 / 2$ Tl. 10prozentiger

1) Ber. d. d. chem. Ges. 27, 2958 (1894).

2) Nach Ladenburg und Scholz ist der Sehmelzp. $70^{\circ}$, nach Winzenheimer [Ber. d. d. chem. Ges. 41, 2378 (1908)] liegt er bei $84,5-85,5^{\circ}$. 
Natronlauge. Nach kurzer Zeit setzt sich ein dunkles Öl ab, welches nach 48 Stunden teils krystallinisch, teils harzig erstarrt. Zur Reinigung der Substanz krystallisiert man das Rohprodukt zuerst aus Tetrachlorkohlenstoff und dann aus einem Benzol-Ligroin-Gemisch um. Das reine Keton bildet hellgelbe Nadeln vom Schmelzp. 109 bis $110^{\circ}$; es ist in den gebräuchlichen Lösungsmitteln leicht löslich, nur in Ligroin löst es sich schwer. Die Ausbeute beträgt 38-40 Proz. an angewandtem Piperonylacrolein.

$0,2058 \mathrm{~g}$ gaben $0,5939 \mathrm{CO}_{2}$ und $0,0909 \mathrm{H}_{2} \mathrm{O}$.

$\begin{array}{ccc} & \text { Ber. für } \mathrm{C}_{20} \mathrm{H}_{10} \mathrm{O}_{3} & \text { Gef. } \\ \mathrm{C} & 78,94 & \mathbf{7 8 , 7 0} \\ \mathrm{H} & 5,30 & 4,94\end{array}$

Darstellung des Perchlorats. Aus der dunkelvioletten Lösung von Keton und 70prozentiger Überchlorsäure (Mol.-Verh. 1:3) in Eisessig scheiden sich beim Stehen im Vakuum mikroskopisch feine Krystallnadeln aus. Nach dem Trocknen im Vaknumexsiccator bildet der Körper ein schwarzviolettes Krystallmehl mit käfergräner Oberflächenfarbe. An der Luft unbeständig. Das frisch hergestellte Präparat schmilat bei $138-151^{\circ}$.

$0,2058 \mathrm{~g}$ gaben $0,0773 \mathrm{AgCl}$.

Ber. 8,77;

Gef. 9,29 Proz. Cl.

\section{Dicinnamylidenacetonperchlorat,}

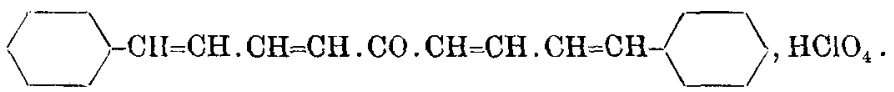

Die Darstellung des Ketons erfolgte nach Diel und Kinhorn. ${ }^{1}$ ) Goldgelbe Krystalle vom Schmelzp. $142^{0}$.

Versetzt man die kalt gesättigte gelbe Lösung des Ketons (1 Mol) in Fisessig mit einem Überschub von 70 prozentiger Überchlorsäure (etwa 3 Molen), so färbt sich die Flüssigkeit sofort dunkel rotviolett. Beim Stehen im Vakuum krystallisieren blauviolette Nadeln aus, welche mit ganz wenig Eisessig gewaschen und wie

1) Ber. d. d. chem. Ges. 1s, 2324 (1885). 
üblich getrocknet werden. Die frisch hergestellten Krystalle haben einen intensiv blauen Oberflächenglanz; ihre Farbe geht aber bald in ein stumpfes Violettschwarz über. Bei $130-148^{\circ}$ tritt Zersetzung ein. Erwärmt man das Perchlorat mit. Wasser, so zerfällt es in seine Komponenten; durch Ausäthern des Reaktionsgemisches läßt sich unverändertes Keton gewinnen.

I. $0,2325 \mathrm{~g}$ gaben $0,0848 \mathrm{AgCl}$.

II. $0,3008 \mathrm{~g} \# 0,1095 \mathrm{AgCl}$.

Ber. 9,17; Gef. I. 9,06, II. 9,01 Proz. Cl.

\section{4. $p, p^{\prime}$-Dimethoxydicinnamylidenacetonperchlorat,}<smiles>COC1CCC(C=CC=CC=CC=CC=CC=O)CC1</smiles>

Darstellung des Ketons. Man kondensiert p-Methoxyzimtaldehyd mit Aceton $z a$ p-Methoxycinnamylidenaceton und setzt dieses Keton mit einem zweiten Nolekül p-Methoxyzimtaldehyd um.

Eine Mischung von $4,9 \mathrm{~g}$ p-Methoxyzimtaldehyd, $8 \mathrm{~g}$ Aceton, $100 \mathrm{ccm}$ Alkohol, $360 \mathrm{ccm}$ Wasser und $4 \mathrm{~g} 10$ prozentiger Natronlauge wird 3 Tage lang in einer gut verschlossenen Flasche geschüttelt. Nach erfolgter Kondensation ist die Flüssigkeit mit feinen gelben Nadeln und erstarrten Öltröpfchen erfüllt, welche abgesaugt und auf Ton abgepreßt werden. Rohausbeute 4,7 g. Durch 2-3malige Krystallisation des Rohprodukts aus Alkohol unter Zusatz von Tierkohle erhält man das $p$-Methoxycinnamylidenaceton in hellgelben Blättchen vom Schmelzpunkt $107-108,5^{\circ}$.

4,331 mir gaben $12,22 \mathrm{CO}_{2}$ and $2,57 \mathrm{H}_{2} \mathrm{O}$.

$\begin{array}{ccr} & \text { Ber. für } \mathrm{C}_{13} \mathrm{H}_{14} \mathrm{O}_{2} & \text { Gef. } \\ \mathrm{C} & 77,18 & 76,95 \\ \mathrm{H} & 6,98 & 6,64\end{array}$

Zur Lösung von $4 \mathrm{~g}$ rohem p-Methoxycinnamylidenaceton und $2,5 \mathrm{~g}$ p-Methoxyzimtaldehyd in $85 \mathrm{ccm}$ Alkohol werden $120 \mathrm{ccm}$ Wasser und $12 \mathrm{~g} 10$ prozentige Natronlange gegeben; dann wird das Ganze in einer gut ver- 
schlossenen Flasche 2 Tage lang geschüttelt. I)ie gebildeten orangegelben Krystallflocken werden abgesaugt und auf Ton getrocknet. Rohausbente $5,1 \mathrm{~g}$. Zur Reinigung wird das Rohprodukt mehrmals aus absolutem Alkohol unter Zusatz von Tierkohle oder abwechselnd aus Alkohol und Eisessig umkrystallisiert. Das $p, p^{\prime}-D i$ methoxydicinnamylidenaceton bildet hellgraugelbe, glänzende Blättchen ohne scharfen Schmelzpunkt; sie geben bei $167-168^{\circ}$ eine trübe Schmelze, die sich erst bei 177 bis $180^{\circ}$ unter Dunkelfärbung klärt. Sehr leicht löslich in Benzol, Chloroform und Tetrachlorkohlenstoff, schwer löslich in Äther; Äthylalkohol und Holzgeist lösen in der Wärme leicht, in der Kälte schwerer.

$4,429 \mathrm{mg}$ gaben $12,99 \mathrm{CO}_{2}$ und $2,54 \mathrm{H}_{2} \mathrm{O}$.

$\begin{array}{ccr} & \text { Ber. für } \mathrm{C}_{29} \mathrm{H}_{22} \mathrm{O}_{3} & \text { Gef. } \\ \mathrm{C} & 6,41 & 6,42 \\ \mathrm{H} & \mathbf{7 9 , 7 4} & 79,81\end{array}$

Darstellung des Perchlorats. Man fügt zu der kalt gesättigten Eisessiglösung von 1 Mol. Keton 3 Mol. 70 prozentiger Überchlorsäure. Die Lösung färbt sich sofort intensiv indigoblau; beim Stehen im Vakuum neben Phosphorpentoxyd und Natronkalk scheiden sich bald indigoblaue Nadeln aus. Die trockenen Krystalle zeigen grünen Oberflächenglanz und schmelzen sehr unscharf unter Zersetzung bei etwa $150^{\circ}$. An der Luft ziehen sie Wasser an und zersetzen sich schnell. Auch in Vakuum neben $\mathrm{P}_{2} \mathrm{O}_{5}$ sind sie nur wenige Tage haltbar. Das Perchlorat wurde nicht analysiert.

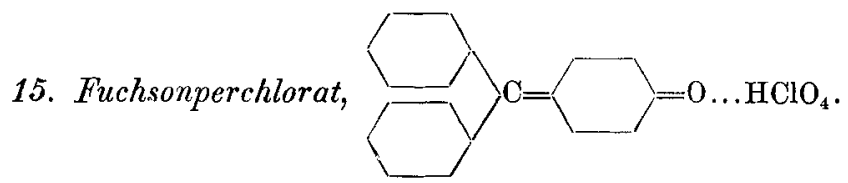

Zur Darstellung des Fuchsons wurde Benzilsäure mit Anisol zu p-Methoxytriphenylessigsäure kondensiert und diese durch Einwirkung von konz. Schwefelsäure in p-Methoxytriphenylcarbinol übergeführt. Das Carbinol 
ließ sich mit Chlorwasserstoff in p-Methoxytriphenylchlormethan verwandeln, welches seinerseits durch Erhitzen auf $200^{\circ}$ Fuchson lieferte. $\left.{ }^{1}\right)$ Gelbbraune Krystalle vom Schmelzp. $167^{\circ}$.

Darstellung des Perchlorats. Man fügt zu einer Lösung von $1 \mathrm{~g}$ Fuchson in $10 \mathrm{ccm}$ Eisessig $1,7 \mathrm{~g} 70$ prozentiger Überchlorsäure und stellt die Flüssigkeit ins Vakuum neben Natronkalk. Ausbente an Perchlorat etwa $1 \mathrm{~g}$; Trocknen auf Ton neben Natronkalk.

Schöne lange, prismatische rote Nadeln mit blauem Oberflächenglanz. Das Pulver des Perchlorats ist orangegelb, im Gegensatz zu dem des Benzaurinperchlorats, welches rotorange ist. Der Schmelzpunkt liegt bei etwa $215-216^{\circ}$. In Alkohol leicht löslich mit hellgelber Farbe; auf Zusatz von Wasser entsteht eine gelbstichige Fällung, die sich in wäßriger $\mathrm{KOH}$ klar löst. Von Wasser wird das Perchlorat bei gewöhnlicher Temperatur nur langsam angegriffen, siedendes Wasser zerstört schnell.

I. $0,2018 \mathrm{~g}$ gaben $0,0846 \mathrm{AgCl}$.

II. $0,1395 \mathrm{~g} \quad, \quad 0,0584 \mathrm{AgCl}$.

Ber. 9,90 ; Gef. I. 10,37, If. 10,36 Proz. Cl.

16. Fuchson-,
chlorostanneat,

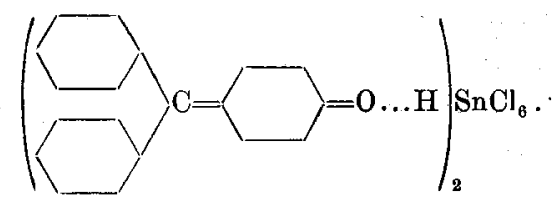

Man gibt zu einer Lösung von $0,5 \mathrm{~g}$ Fuchson in $10 \mathrm{ccm}$ Eisessig eine Lösung von $0,5 \mathrm{~g}$ wasserfreiem Zinntetrachlorid in mit $\mathrm{HCl}$ gesättigtem Eisessig und überläßt das Gemisch in einem geschlossenen Gefäß der freiwilligen Krystallisation. Trocknen der Krystalle auf Ton neben Natronkalk. Ausbeute etwa $1 \mathrm{~g}$.

Schöne rote, durchsichtige Nadeln mit grünem Oberflächenglanz, deren Pulver gelbstichiger orange ist als das

1) Bistrzycki und Herbst, Ber. d. d. chem. Ges. 36, 2335 (1903); vgl. auch Dissertation von Rostoworowski, Freiburg (Schweiz) 1911. 
Pulver des entsprechenden Benzaurinkörpers. In Alkohol löslich mit hellgelber Farbe; versetzt man die alkoholische Lösung mit Wasser, so entsteht ein hellgelber Niederschlag, der sich auf Zusatz von etwas Kalilange klar auflöst. Kochendes Wasser gibt Zinnsäureabscheidung; mit kaltem $W$ asser bildet sich ein gelbes Pulver. Schmelzp. 210-211 .

I. $0,1732 \mathrm{~g}$ gaben $0,0314 \mathrm{SnO}_{2}$ und $0,1743 \mathrm{AgCl}$.

II. $0,2630 \mathrm{~g} \cdot, \quad 0,0492 \mathrm{SnO}_{2} \quad, \quad 0,2658 \mathrm{AgCl}$.

Ber.

Gef.

$\begin{array}{lccc} & & \text { I } & \text { II } \\ \mathrm{Sn} & 14,00 & 14,29 & 14,74 \\ \mathrm{Cl} & 25,06 & 24,89 & 25,00\end{array}$

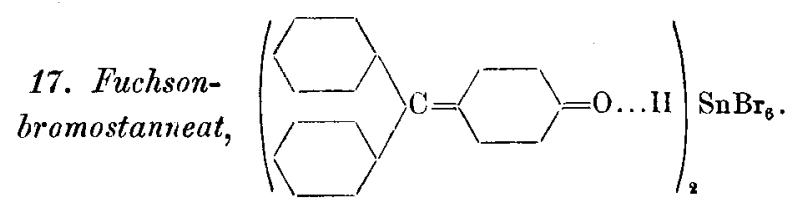

Man gibt zu einer Lösung von $0,5 \mathrm{~g}$ Fuchson in $10 \mathrm{ccm}$ Eisessig eine Lösung von $0,9 \mathrm{~g}$ wasserfreiem Zinntetrabromid in mit Bromwasserstoff gesättigtem Eisessig und überläßt das Reaktionsgemisch der freiwilligen Krystallisation. Ausbeute an Doppelsalz etwa $0,75 \mathrm{~g}$; Trocknen auf Ton neben Natronkalk.

Schöne, rote, durchsichtige, prismatische Krystalle mit prachtvoll grïnem Oberflächenglanz, welche bei 204 bis $205^{0}$ schmelzen. In pulverisiertem Zustand gelbstichiger als Benzaurinbromostanneat. In absolutem Alkohol löslich mit hellgelber Farbe; auf Zusatz von Wasser entsteht eine gelbliche Fällung, die sich in $\mathrm{KOH}$ klar löst. Kochendes Wasser zersetzt vollständig.

I. $0,1494 \mathrm{~g}$ gaben $0,0200 \mathrm{SnO}_{2}$ und $0,1507 \mathrm{AgBr}$.

II. $0,3282 \mathrm{~g} \quad, \quad 0,0435 \mathrm{SnO}_{2}, 0,3286 \mathrm{AgBr}$.

Ber.

Gef.

$\begin{array}{cccc} & & \text { I } & \text { II } \\ \text { Sn } & 10,65 & 10,55 & 10,45 \\ \text { Br } & 42,97 & 42,92 & 42,61\end{array}$


18. Benzaurinperchlorat,

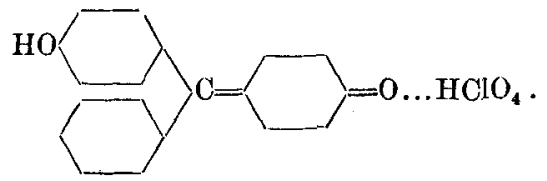

Benzaurin wurde durch Kondensation von Benzotrichlorid mit Phenol erhalten; Reinigung des Rohprodukts mit Hilfe von Natriumbisulfit. Rotes Pnlver. ${ }^{1}$ )

Zur Darstellung des Perchlorats fügt man zu einer Lösung von $1 \mathrm{~g}$ Benzaurin in $15 \mathrm{ccm}$ Eisessig 1,6 $\mathrm{g} 70$ prozentige Überchlorsäure und läßt das Ganze im Vakuum neben Natronkalk stehen. Das auskrystallisierte Perchlorat wird auf Ton neben Natronkalk getrocknet. Ausbeute etwa $0,85 \mathrm{~g}$.

Orangefarbene Nädelchen mit schönem, grünem Oberflächenglanz; im pulverisierten Zustand rotorange, also tieferfarbig als pulverisiertes Fuchsonperchlorat. Weniger rotstichig (im pulverisierten Zustand) als Benzaurin selbst. Mit oranger Farbe löslich in absolutem Alkohol und in Eisessig; der Schmelzpunkt liegt bei 246-_247 .

I. $0,1040 \mathrm{~g}$ gaben $0,0415 \mathrm{AgCl}{ }^{2}$ )

II. $0,2147 \mathrm{~g}, " 0,0850 \mathrm{AgCl}^{2}$ )

Ber. 9,48 ; Gef. I. 9,87, II. 9,82 Proz. Cl.

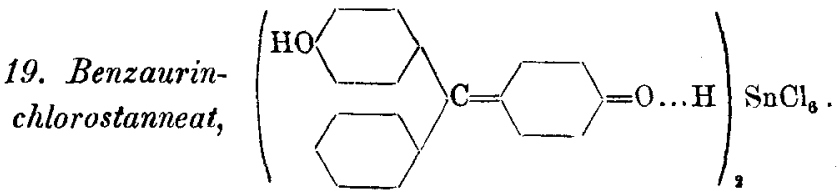

Man gibt zu einer Lösung von $1 \mathrm{~g}$ Benzaurin in $15 \mathrm{ccm}$ Eisessig eine Lösung von $0,95 \mathrm{~g} \mathrm{SnCl}_{4}$ in mit Chlorwasserstoff gesättigtem Eisessig. Das Doppelsalz krystallisiert fast sofort aus; Trocknen auf Ton neben Natronkalk; Ausbeute etwa $0,7 \mathrm{~g}$.

Kleine orangefarbene Kryställchen mit grünem Oberflächenschimmer, welche bei $268-269^{\circ}$ unter Zersetzung schmelzen. Gut löslich mit oranger Farbe in Alkohol,

1) Döbner, diese Annalen 217, 227 (1883).

$\left.{ }^{2}\right)$ Schmelzen mit Soda im Platintiegel. 
viel schwerer löslich in Eisessig. Siedendes Wasser zersetzt schnell; kaltes Wasser läbt die Substanz einige Zeit lang unverändert.

I. $0,1846 \mathrm{~g}$ gaben $0,0306 \mathrm{SnO}_{2}$ und $0,1753 \mathrm{AgCl}$.

II. $0,1844 \mathrm{~g} \quad, \quad 0,0314 \quad \mathrm{SnO}_{\sharp} \quad, \quad 0,1758 \mathrm{AgCl}$.

III. $0,1938 \mathrm{~g} \quad " \quad 0,0334 \mathrm{SnO}_{2}$. $0,1732 \mathrm{~g} \quad 0,1682 \mathrm{AgCl}$.

Ber.

Gef.

$\begin{array}{ccccc} & & \text { I } & \text { II } & \text { III } \\ \text { Sn } & 13,49 & 13,06 & \mathbf{1 3 , 4 2} & 13,58 \\ \text { Cl } & 24,15 & 23,50 & 23,58 & 24,01\end{array}$

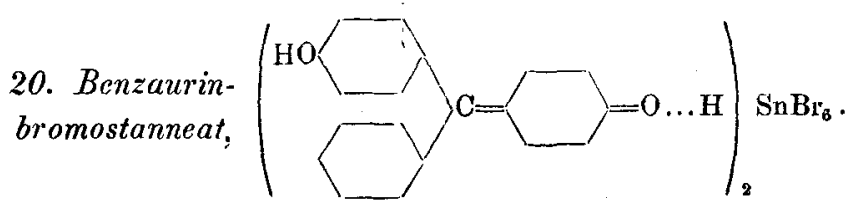

Man fügt zu einer Lösung von $1 \mathrm{~g}$. Benzaurin in $15 \mathrm{ccm}$ Eisessig eine Lösung von $1,5 \mathrm{~g}$ Zinntetrabromid in mit Bromwasserstoff gesättigtem Eisessig. Beim Stehen allmählich Abscheidung des Doppelsalzes; Trocknen neben Natronkalk. Ausbeute etwa $0,8 \mathrm{~g}$.

Schöne, kompakte, durchsichtige, rote Krystalle mit grünem Oberflächenglanz, welche bei $256-257^{\circ}$ unter Zersetzung schmelzen. In Alkohol und Eisessig mit oranger Farbe löslich; siedendes Wasser zersetzt schnell.

Bei der Salzbildung des Benzaurins findet Farberhöhung statt. Während pulverisiertes Benzaurin rotorange gefärbt ist, geben Benzanrinchlorstanneat und Benzaurinbromostanneat beim Verreiben gelborange Palver.

I. $0,2061 \mathrm{~g}$ gaben $\left.0,0270 \mathrm{SnO}_{2} \cdot{ }^{1}\right)$

$$
0,1459 \mathrm{~g} " \quad 0,0186 \mathrm{SnO}_{2} \text { und } 0,1428 \mathrm{AgBr} .{ }^{2} \text { ) }
$$

II. $\left.0,1968 \mathrm{~g} \quad, \quad 0,0264 \mathrm{SnO}_{2} \cdot{ }^{1}\right)$ $0,2314 \mathrm{~g} \quad, \quad 0,2242 \mathrm{AgBr}$.

1) Zers. mit $\mathrm{HNO}_{3}$ im Bombenrohr.

2) Zers. mit Wasser unter Zusatz von $\mathrm{NH}_{4} \mathrm{NO}_{3}$ auf dem Wasserbad. 
Ber.

\begin{tabular}{cccc} 
& \multicolumn{2}{c}{ I } & If \\
$\mathrm{Sn}$ & 10,36 & $10,33 \quad 10,05$ & $\mathbf{1 0 , 5 7}$ \\
$\mathrm{Br}$ & 41,78 & 41,65 & $\mathbf{4 1 , 2 3}$
\end{tabular}

21. Aurinperchlorat,

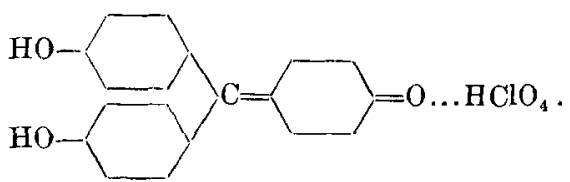

Käufliches Aurin wurde folgendermaßen gereinigt: In die alkoholische Lösung des Rohprodukts wurde Ammoniak eingeleitet. Der dunkelrote Niederschlag wurde abfiltriert, mit Wasser und Eisessig aufgekocht und aus wäßrigem Eisessig umkrystallisiert. Dunkelrote Blättchen mit grünem Oberflächenglanz.

Aurinperchlorat ist schon von K. A. Hofmann ${ }^{1}$ ) beschrieben worden. Wir erhielten das Salz in roten Krystallen mit grünem Oberflächenglanz. Das Pulver des Aurinperchlorats ist etwas gelbstichiger als das Pulver des Benzaurinperchlorats.

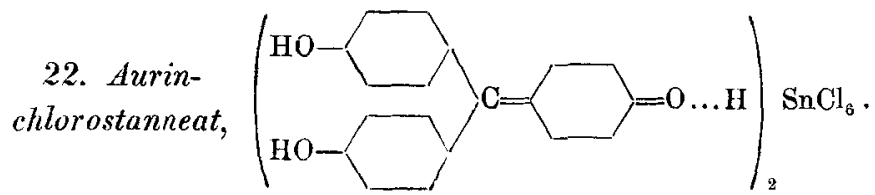

Man gibt $\mathrm{zu}$ einer Lösung von $1 \mathrm{~g}$ Aurin in $20 \mathrm{ccm}$ Eisessig eine Lösung von $0,9 \mathrm{~g}$ wasserfreiem Zinntetrachlorid in mit $\mathrm{HCl}$ gesättigtem Eisessig und überläBt das Reaktionsgemisch der freiwilligen Krystallisation. Das Doppelsalz scheidet sich allmählich in gut krystallisierter Form aus; Trocknen wie üblich.

Kleine rote Krystalle mit blauem Oberflächenglanz, die keinen Schmelzpunkt besitzen. In pulverisiertem Zustand ist das Doppelsalz gelbstichig orange, während das Aurin selbst beim Verreiben ein rotes Pulver gibt; wir haben es also hier bei der Salzbildung mit einer

1) Ber. d. d. ehem. Ges. 43, 184 (1910). 
Farberhöhung zu tun. Gegen kaltes Wasser sind die Krystalle ziemlich stabil, heiBes Wasser zersetzt schnell.

I. $0,1471 \mathrm{~g}$ gaben $0,0236 \mathrm{SnO}_{2}$ und $0,1343 \mathrm{AgCl}$.

$0,1209 \mathrm{~g} \quad, \quad 0,0192 \mathrm{SnO}_{2}$.

II. $0,1685 \mathrm{~g} \quad, \quad 0,0274 \mathrm{SnO}_{2} \quad, \quad 0,1561 \mathrm{AgCl}$.

Ber.

Gef.

\begin{tabular}{|c|c|c|c|}
\hline & & \multicolumn{2}{|r|}{ II } \\
\hline $\mathrm{Sn}$ & 13,02 & $12,64 \quad 12,52$ & 12,82 \\
\hline $\mathrm{Cl}$ & 23,30 & 22,59 & 22,92 \\
\hline
\end{tabular}

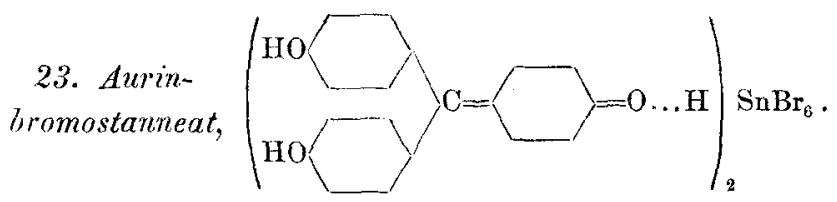

Man fügt zu einer Lösung von $1 \mathrm{~g}$ Aurin in $20 \mathrm{ccm}$ Eisessig eine Lösung von $1,5 \mathrm{~g} \mathrm{SnBr}_{4}$ in mit Bromwasserstoff gesättigtem Eisessig. Das Doppelsalz scheidet sich allmählich in kleinen roten Krystallen mit blauem Oberflächenglanz aus. Trocknen wie üblich.

Uas Doppelsalz besitzt keinen Schmelzpunkt; im pulverisierten Zustand besitzt es dieselbe Farbennuance (gelbstichig orange) wie gepulvertes Aurinchlorostanneat.

I. $0,1519 \mathrm{~g}$ gaben $0,0190 \mathrm{SnO}_{2}$ und $0,1459 \mathrm{AgBr}$.

$$
0,1386 \mathrm{~g}, \quad 0,0175 \mathrm{SnO}_{2} \text {. }
$$

II. $0,1818 \mathrm{~g} \quad, \quad 0,0225 \mathrm{SnO}_{2} \quad, \quad 0,1704 \mathrm{AgBr}$.

III. $0,2382 \mathrm{~g} ", \quad 0,0294 \mathrm{SnO}_{2} \quad, 0,2206 \mathrm{AgBr}$.

Ber.

Gef.

\begin{tabular}{|c|c|c|c|c|}
\hline & & I & II & III \\
\hline $\mathrm{sp}$ & 10,08 & $9,86 \quad 9,95$ & 9,75 & 9,73 \\
\hline $\mathrm{Br}$ & 40,65 & 40,88 & 39,89 & 39,41 \\
\hline
\end{tabular}

I. $\mathrm{Sn}: \mathrm{Br}=1: 6,14 ; \quad$ II. $\mathrm{Sn}: \mathrm{Br}=1: 6,09 ; \quad$ III. $\mathrm{Sn}: \mathrm{Br}=1: 6,02$.

24. $p$-Mithoxytriphenylmetlylperchlorat,

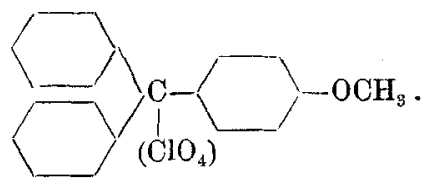

p-Methoxytriphenylcarbinol ist Zwischenphase bei der Darstellung des Fuchsons (siehe oben). 
Man fügt zu einer Eisessiglösung von $2 \mathrm{~g}$ p-Methoxytriphenylcarbinol $1,5 \mathrm{~g} 70$ prozentige Überchlorsäure und stellt das Reaktionsgemisch über Natronkalk ins Vakuum. Im Verlauf von einigen Stunden haben sich feine, orangefarbene Krystalle abgeschieden, welche mit wenig Fisessig gewaschen und wie üblich getrocknet werden.

$0,2455 \mathrm{~g}$ gaben $0,0973 \mathrm{AgCl}$.

Ber. 9,52; Gef. 9,80 Proz. Cl.

Ein festes Zinntetrachloriddoppelsalz des p-Methoxytriphenylmethylchlorids herzustellen, ist nicht gelungen.

Zürich, Chemisches Universitätslaboratorium, im Februar 1916. ${ }^{\mathbf{}}$ )

1) Fast sämtliche Mikroanalysen dieser Arbeit sind von Herrn Dr. H. Lieb in Graz ausgeführt worden, dem auch an dieser Stelle unser bester Dank ausgesprochen sei.

(Gesehlossen den 6. November 1916.) 